WELLISON JOSÉ DE SANTANA GOMES

\title{
Estudo do Efeito de Incertezas na Otimização Estrutural
}

Dissertação apresentada à Escola de Engenharia de São Carlos como parte dos requisitos para obtenção do título de Mestre em Engenharia de Estruturas.

Área de concentração: Engenharia de Estruturas

Orientador: Prof. Dr. André Teófilo Beck

São Carlos

2010 
AUTORIZO A REPRODUÇÃO E DIVULGAÇÃO TOTAL OU PARCIAL DESTE TRABALHO, POR QUALQUER MEIO CONVENCIONAL OU ELETRÔNICO, PARA FINS DE ESTUDO E PESQUISA, DESDE QUE CITADA A FONTE.

Ficha catalográfica preparada pela Seção de Tratamento da Informação do Serviço de Biblioteca - EESC/USP

Dissertação (Mestrado-Programa de Pós-Graduação e Área de Concentração em Engenharia de Estruturas) -- Escola de Engenharia de São Carlos da Universidade de São Paulo, 2010 .

1. Estruturas - confiabilidade. 2. Estruturas otimização. 3. Algoritmos híbridos. I. Título. I. Título. 


\section{FOLHA DE JULGAMENTO}

Candidato(a): Engenheiro WELLISON JOSÉ DE SANTANA GOMES.

Dissertação defendida e julgada em 25/02/2010 perante a Comissão Julgadora:
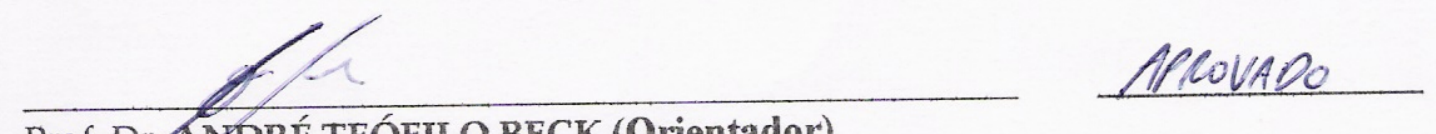

Prof. Dr.ANDRÉ TEÓFILO BECK (Orientador)

(Escola de Engenharia de São Carlos/USP)

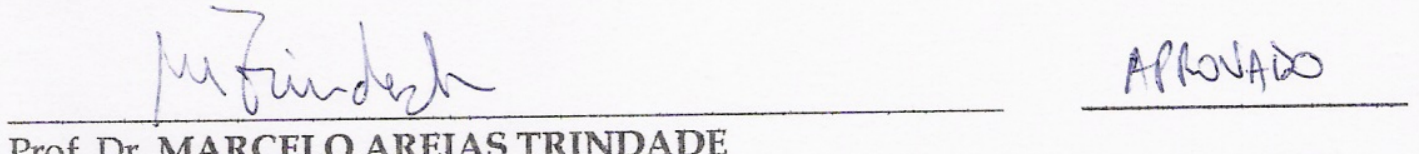

(Escolo de Engenharia de São Carlos/USP)

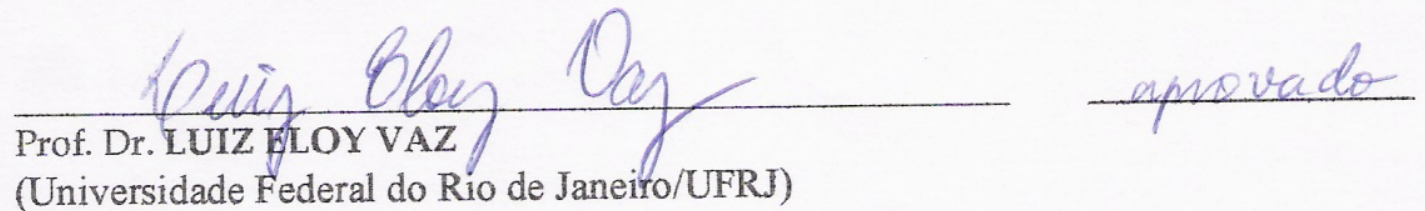

(Universidade Federal do Rio de Janeiro/UFRJ)
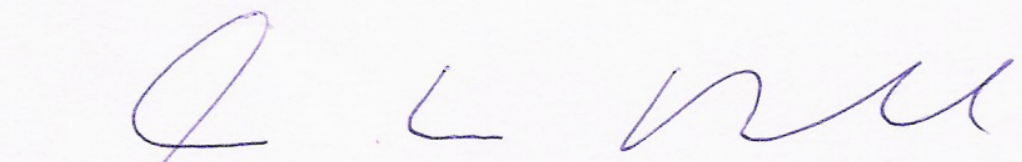

Prof. Associado MARCIO ANTONIO RAMALHO Coordenador do Programa de Pós-Graduação em Engenharia Civil (Engenharia de Estruturas)

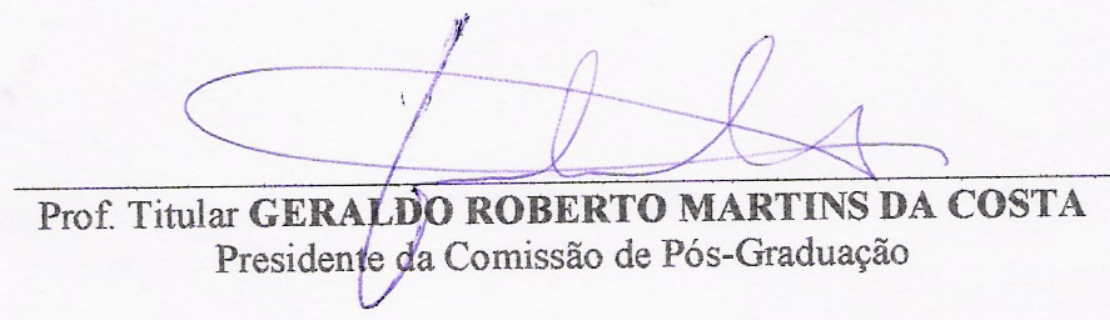



Dedico este trabalho à minha família, em especial aos meus pais e ao meu irmão. 



\section{Agradecimentos}

À minha família, em especial aos meus pais e irmão, por toda a força e por tudo que sempre me ensinaram, mesmo em tempos de distância física.

À minha namorada Joyce Trindade, cuja paciência e ajuda nem tenho como agradecer, e por estar sempre ao meu lado. E à sua família e todos os bons momentos que compartilhamos.

Ao professor André Beck, orientador do presente trabalho, pelas discussões semanais (muitas vezes quase diárias), pela paciência, dedicação e atenção, indispensáveis ao desenvolvimento deste e à minha adaptação a uma nova realidade (morar em outro estado, longe da família).

Aos amigos e demais colegas da turma do mestrado, em especial ao Dênis Delázari e Francisco Quim.

A todos os professores do Departamento de Engenharia de Estruturas da Escola de Engenharia de São Carlos - USP, que contribuíram para minha formação, e aos funcionários por estarem sempre disponíveis e dispostos a ajudar.

Ao CNPq, pelo auxílio financeiro nos primeiros meses do mestrado, e à FAPESP pelo auxílio nos outros 18 meses. 



\section{RESUMO}

GOMES, W. J. S. Estudo do efeito de incertezas na otimização estrutural. 2010. 96 p. Dissertação (Mestrado) - Escola de Engenharia de São Carlos, Universidade de São Paulo, São Paulo, 2010.

Este trabalho apresenta um estudo do efeito de incertezas na otimização estrutural. Tal efeito pode ser quantificado em termos de probabilidades de falha bem como do risco, ou custo esperado de falha. O estudo se baseia na comparação dos resultados obtidos através de três distintas formulações do problema de otimização estrutural: otimização determinística, otimização baseada em confiabilidade e otimização de risco estrutural. Para efeitos de comparação, informações sobre risco de falha estrutural (produto da probabilidade de falha pelo custo de falha) são incorporadas nas três formulações. A otimização determinística (DDO - Deterministic Design Optimization) permite encontrar uma configuração estrutural que é ótima em termos mecânicos, mas não considera explicitamente a incerteza dos parâmetros e seus efeitos na segurança estrutural. Em conseqüência, a segurança da estrutura ótima pode ser comprometida, em comparação à segurança da estrutura original. A otimização baseada em confiabilidade (RBDO - Reliability-Based Design Optimization) garante que a estrutura ótima mantenha um nível mínimo (e mensurável) de segurança. Entretanto, os resultados são dependentes da probabilidade de falha usada como restrição na análise. A otimização de risco estrutural (RBRO - Reliability-Based Risk Optimization) aumenta o escopo do problema, buscando um balanço entre economia e segurança, objetivos estes que de uma forma geral competem entre si. Isto é possível através da quantificação de custos associados à construção, operação e manutenção da estrutura, bem como das conseqüências monetárias de falha. A experiência mostra que problemas de otimização estrutural possuem muitos mínimos locais. Com o intuito de encontrar o mínimo global em todos os problemas de otimização estudados, são utilizados neste trabalho dois métodos de otimização heurísticos: Algoritmos Genéticos e Método do Enxame de Partículas. Tendo a eficiência como objetivo, dois métodos com fundamentação matemática também são estudados: os métodos de Powell e de Polak-Ribiere. Finalmente, buscando uma relação de compromisso entre confiabilidade (capacidade de encontrar o mínimo global em todos os problemas) e eficiência, quatro algoritmos híbridos são construídos, combinando os quatro métodos citados anteriormente. Efeitos de incertezas na otimização estrutural são estudados através da comparação de soluções obtidas via diferentes formulações do problema de otimização. São apresentados alguns estudos de caso, enfatizando as diferenças entre os 
projetos ótimos obtidos por cada formulação. O estudo mostra que, em geral, a estrutura ótima só é encontrada pela formulação mais abrangente: a otimização de risco ou RBRO. O estudo mostra que, para que a formulação DDO encontre a mesma configuração ótima da formulação RBRO, é necessário especificar um coeficiente de segurança ótimo para cada modo de falha. De maneira semelhante, o estudo mostra que quando os custos associados a diferentes modos de falha são distintos, a formulação RBDO somente resulta na estrutura ótima quando uma probabilidade de falha ótima é especificada como restrição para cada modo falha da estrutura.

Palavras-chave: Estruturas - confiabilidade. Estruturas - Otimização. Algoritmos Híbridos. 


\section{ABSTRACT}

GOMES, W. J. S. On the effects of uncertainty on optimum structural design. 2010. 96 p. Dissertation (M. Sc.) - Escola de Engenharia de São Carlos, Universidade de São Paulo, São Paulo, 2010.

In this study the effects of uncertainty on optimum structural design are investigated, by comparing three distinct formulations of a structural optimization problem. Such effects can be quantified in terms of failure probabilities and risk, or expected costs of failure. Deterministic Design Optimization (DDO) allows one the find the shape or configuration of a structure that is optimum in terms of mechanics, but the formulation do not consider explicitly parameter uncertainty and its effects on structural safety. As a consequence, safety of the optimum structure can be compromised, in comparison to safety of the original structure. Reliability-based Design Optimization (RBDO) has emerged as an alternative to properly model the safety-under-uncertainty part of the problem. With RBDO, one can ensure that a minimum (and measurable) level of safety is achieved by the optimum structure. However, results are dependent on the failure probability used as constraint in the analysis. Risk optimization increases the scope of the problem, by addressing the compromising goals of economy and safety, and allowing one to find a proper point of balance between these goals. This is accomplished by quantifying the costs associated to construction, operation and maintenance of the structure, as well as the monetary consequences of failure. Experience shows that structural optimization problems can have multiple local minima. With the objective of finding the global minimum in all studied problems, two heuristic optimization methods are used in this study: Genetic Algorithms and Particle Swarm Optimization. Aiming at efficiency, two methods with mathematical foundations are also considered: the methods of Powel and Polak-Ribiere. Finally, looking for a compromise between reliability (capacity to find the global minimum) and efficiency, four hybrid algorithms are constructed, combining the four methods just cited. The study investigates the effects of uncertainty on optimum structural design by comparing solutions obtained via the different formulations of the optimization problem. The paper presents some case studies, highlighting the differences in the optimum designs obtained with each formulation. The study leads to a better understanding of the limitations of each formulation in the solution of structural optimization problems. The investigation shows that, in general, the optimum structure can only be found by the most comprehensive formulation: risk optimization or RBRO. The study shows that DDO only leads to the optimum structure if an optimum safety coefficient is used as 
constraint for each individual failure mode. In a similar way, the investigation shows that when the costs associated to distinct failure modes are different, the RBDO formulation only leads to the optimum structural design if an optimum failure probability is specified as constraint for each failure mode of the structure.

Keywords: Structures - Reliability. Structures - Optimization. Hybrid Algorithms. 


\section{Lista de Figuras}

Figura 1 - Pórtico hiperestático plano

Figura 2 - Resultado da otimização topológica de uma viga engastada (FONTE: Amstutz \& Andrä (2005)).

Figura 3 - Fluxograma do Método do Lagrangiano Aumentado.

Figura 4 - Fluxograma do Algortimo PSO básico

Figura 5 - Fluxograma do algoritmo genético SCE. 45

Figura 6 - Passos de contração e reflexão do NSM. 46

Figura 7 - Fluxograma do Método de Powell Modificado. 49

Figura 8 - Fluxograma do Método de Polak-Ribiere.

Figura 9 - Fluxograma do método de busca unidirecional para o método de Polak-Ribiere...53

Figura 10 - Fluxograma do método de busca unidirecional para o método de Powell. ...........54

Figura 11 - Hipercubo mais o ponto central para o caso 3D ...............................................56

Figura 12 - Escopo das formulações de otimização estrutural. ...............................................63

Figura 13 - Sistema estrutural composto por três barras em paralelo.....................................67

Figura 14 - Definição de $\eta$ (FONTE: Hendawi \& Frangopol (1994)). .....................................68

Figura 15 - Comparação de custos ótimos - Problema (1A). ................................................. 72

Figura 16 - Comparação de custos ótimos - Problema (1B).................................................. 73

Figura 17 - Comparação de custos ótimos - Problema (1C).................................................... 74

Figura 18 - Sistema estrutural composto por três barras em série...........................................74

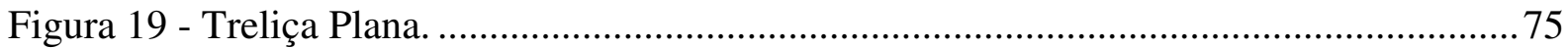

Figura 20 - Comparação de custos ótimos para o problema da treliça plana. .......................... 77

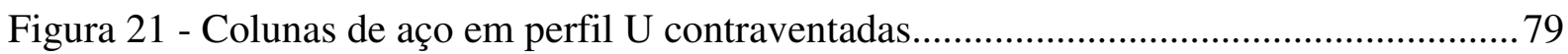

Figura 22 - Comparação entre custos ótimos para o problema da coluna formada por perfis U contraventados.

Figura 23 - Custos esperados totais obtidos pelas formulações RBDO e RBRO_esc, com relação ao custo de referência (RBRO).

Figura 24 - Custos de manufatura obtidos pelas formulações RBDO e RBRO_esc, com relação ao custo de referência (RBRO).

Figura 25 - Média da função objetivo (em relação ao PSS_POWELL) ....................................85

Figura 26 - Máximo da função objetivo (em relação ao PSS_POWELL). .............................. 86

Figura 27 - Média de chamadas à função objetivo (em relação ao PSS_POWELL) ............... 86 


\section{Lista de Tabelas}

Tabela 1 - Algumas distribuições de probabilidade contínuas.

Tabela 2 - Distribuições de probabilidade comumente utilizadas na descrição de variáveis

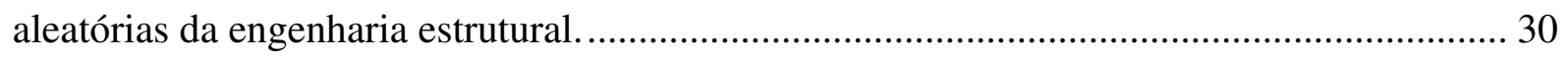

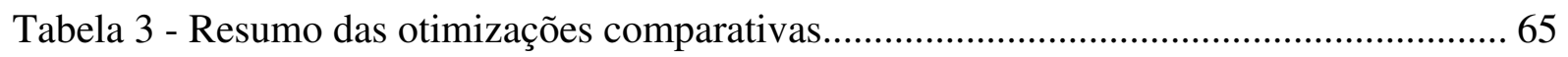

Tabela 4 - Resumo dos dados das VAs do problema de três barras em paralelo...................... 68

Tabela 5 - Variações do problema de três barras em paralelo. ................................................. 71

Tabela 6 - Resultados para o problema (1A), áreas em $\mathrm{cm}^{2}$.................................................. 71

Tabela 7 - Resumo dos dados das VAs do problema da treliça plana. ................................... 76

Tabela 8 - Resumo dos dados das VAs do problema da coluna de aço................................. 79

Tabela 9 - Quantidade de contraventamentos versus altura da estrutura............................... 82 


\section{Lista de Siglas}

AG-SCE Algoritmo genético - Evolução de complexos conjugados (Shuffled Complex Evolution)

AG_POWELL Método híbrido constituído pelo AG-SCE e método de Powell

AG_PR Método híbrido constituído pelo AG-SCE e método de Polak-Ribiere

CET Custo esperado total

CM Custo de manufatura

DDO Otimização estrutural determinística (Deterministic Design Optimization)

DSC Algoritmo de Davis, Swann e Campey

FDA Função de distribuição acumulada de probabilidades

FDP Função densidade de probabilidade

FMP Função massa de probabilidade

FORM Método de confiabilidade de primeira ordem (First Order Reliability Method)

MPP Ponto mais provável de falha (Most Probable Point)

PR Método de Polak-Ribiere

PSO Otimização por enxame de partículas (Particle Swarm Optimization)

PSS Método Particle Swarm - Simplex

PSS_POWELL Método híbrido constituído pelo PSS e método de Powell

PSS_PR Método híbrido constituído pelo PSS e método de Polak-Ribiere

RBDO Otimização baseada em confiabilidade (Reliability-Based Design Optimization)

RSF Fator de carregamento (Resistance Sharing Factor)

StRAnD Programa para cálculos de confiabilidade estrutural (Structural Reliability

Analysis and Design)

VA Variável aleatória 


\section{Lista de Símbolos}

$\begin{array}{ll}\text { c.v. } & \text { Coeficiente de variação } \\ \text { d } & \text { Direção de busca } \\ E & \text { Módulo de elasticidade do material } \\ f_{y} & \text { Resistência do material } \\ g(\mathbf{X}, \mathbf{z}) & \text { Equação de estado limite } \\ P_{f} & \text { Probabilidade de falha } \\ \mathbf{X} & \text { Vetor de variáveis aleatórias } \\ \mathbf{z} & \text { Vetor de variáveis de projeto (de otimização) } \\ \beta & \text { Índice de confiabilidade } \\ \lambda & \text { Coeficiente de segurança } \\ \mu_{X} & \text { Valor médio da variável aleatória } X \\ \sigma_{X} & \text { Desvio-padrão da variável aleatória } X\end{array}$




\section{SUMÁRIO}

1. INTRODUÇÃ

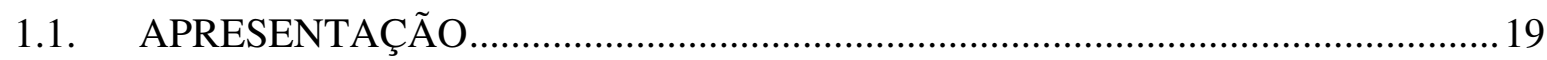

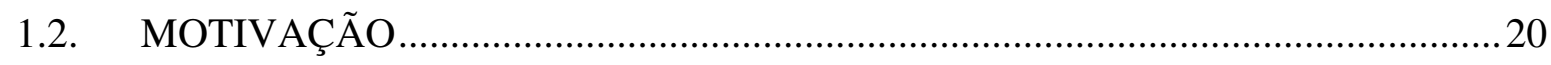

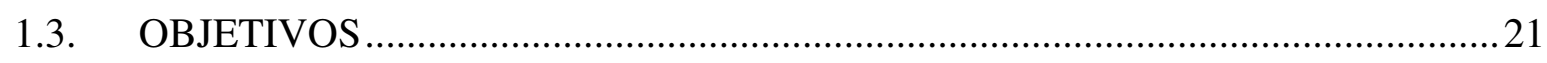

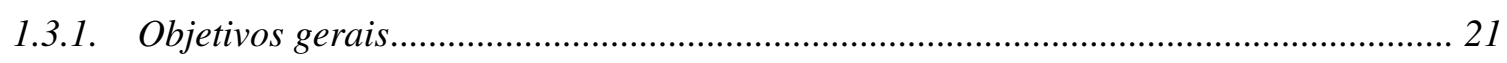

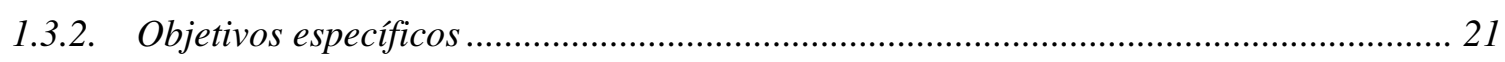

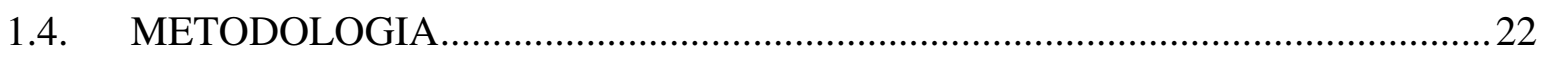

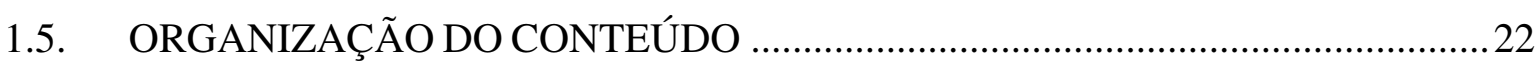

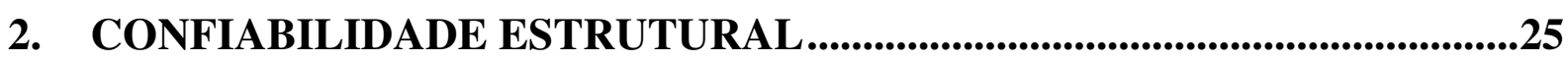

2.1. ESTADOS LIMITES E COEFICIENTES DE SEGURANÇA ................................25

2.2. VARIÁVEIS ALEATÓRIAS.............................................................................26

2.2.1. Valor esperado, variância e momentos de uma VA........................................................ 28

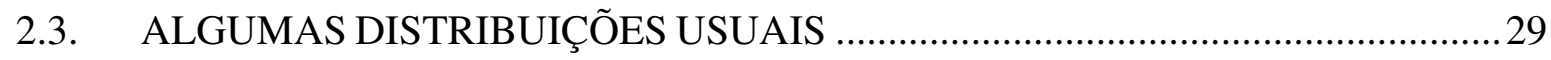

2.4. INCERTEZA NA ENGENHARIA ESTRUTURAL_.................................................30

2.5. FORMULAÇÃO DO PROBLEMA DE CONFIABILIDADE ESTRUTURAL

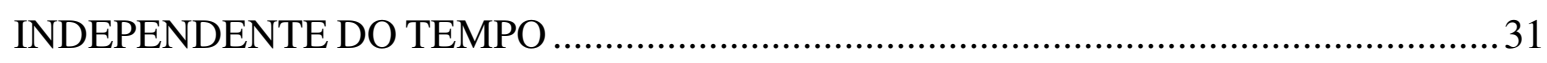

2.6. MÉTODO DE CONFIABILIDADE DE PRIMEIRA ORDEM (FORM) .................32

2.6.1. Algoritmo de Hassofer, Lind, Rackwitz e Fiessler ....................................................... 34

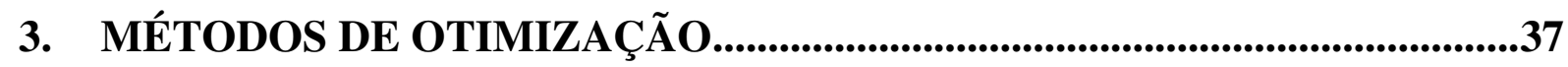

3.1. FORMULAÇÃO DO PROBLEMA DE OTIMIZAÇÃO ..........................................38

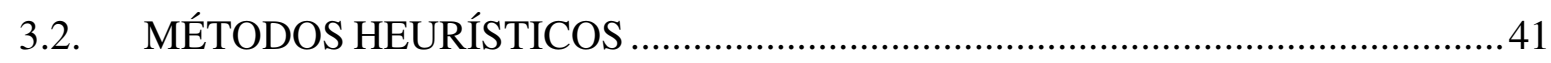

3.2.1. $P S O$

3.2.2. Algoritmo Genético SCE ………………………………………………………… 43

3.3. MÉTODOS COM FUNDAMENTAÇÃO MATEMÁTICA....................................45

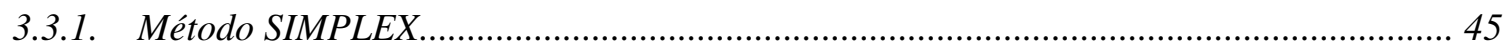

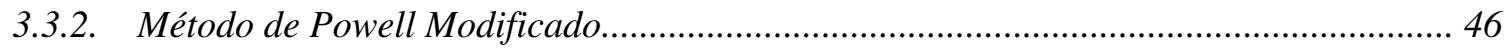

3.3.3. Método de Polak-Ribiere.................................................................................... 49

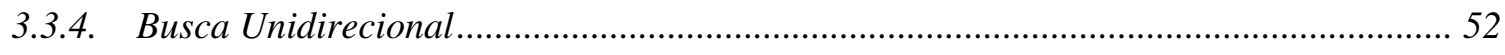

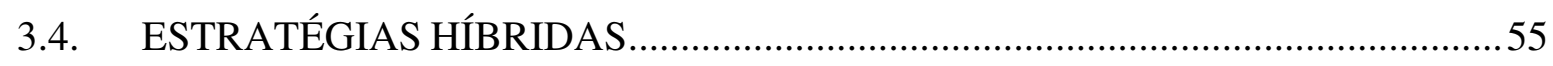

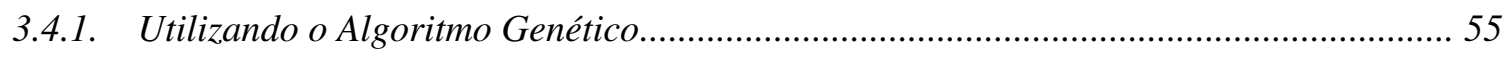

3.4.2. Utilizando o algoritmo PSO (PSS) ................................................................ 55 
4. FORMULAÇÕES DE OTIMIZAÇÃO ESTRUTURAL ...................................59

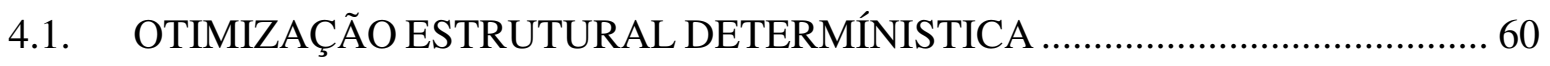

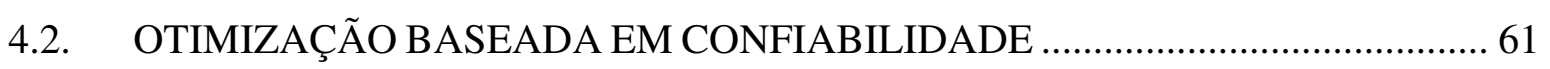

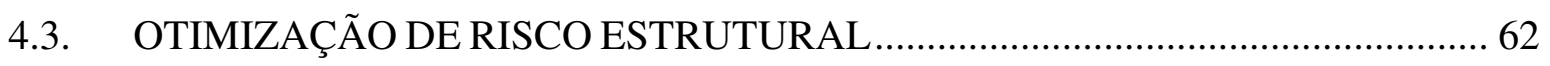

4.4. SOBRE AS TRÊS FORMULAÇÕES APRESENTADAS …………………….......... 62

4.5. ANÁLISES COMPARATIVAS DE OTIMIZAÇÃO................................................. 64

5. EXEMPLOS NUMÉRICOS .......................................................................67

5.1. SISTEMA ESTRUTURAL: TRÊS BARRAS EM PARALELO..................................... 67

5.2. SISTEMA ESTRUTURAL: TRÊS BARRAS EM SÉRIE....................................... 74

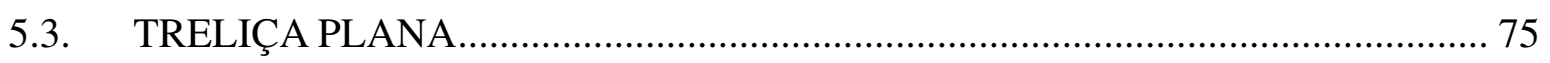

5.4. COLUNA DE AÇO EM PERFIS U CONTRAVENTADOS …………………....... 78

6. DESEMPENHO DOS MÉTODOS DE OTIMIZAÇÃO.....................................85

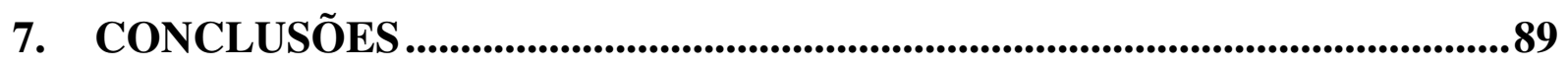

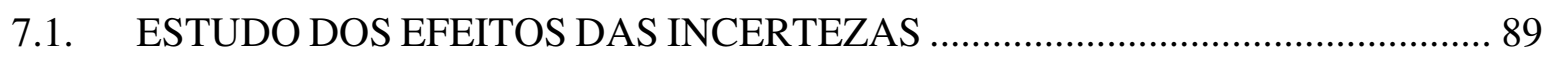

7.2. ANÁlISE DE DESEMPENHO E CONFIABILIDADE DOS MÉTODOS DE

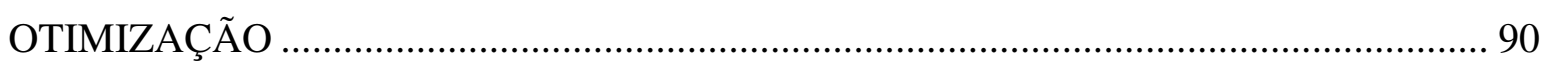

7.3. SUGESTÕES PARA TRABALHOS FUTUROS .................................................. 91

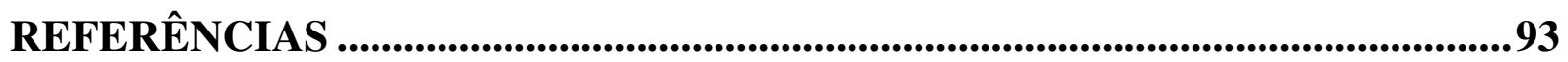




\section{INTRODUÇÃO}

\subsection{APRESENTAÇÃO}

Em um ambiente competitivo, sistemas estruturais devem ser projetados levando em conta não apenas a sua funcionalidade, mas os custos esperados de construção e de operação e sua capacidade de geração de lucros. Custos e lucros são diretamente afetados pelo risco que a estrutura oferece a usuários, empregados, ao público em geral e ao meio ambiente.

Risco (ou custo esperado de falha) pode ser entendido como o produto de um custo de falha pela probabilidade de que esta falha aconteça. A probabilidade de falha de uma estrutura está diretamente relacionada com os coeficientes de segurança adotados no projeto, bem como com os níveis de controle e manutenção praticados na operação da estrutura.

No projeto de estruturas, os objetivos economia e segurança competem entre si. Em geral, mais segurança envolve maiores custos e mais economia significa menos segurança. Projetar sistemas estruturais envolve encontrar um balanço entre estes objetivos. Na prática comum de engenharia, este balanço é feito de forma subjetiva. Com o uso de normas de projeto, este balanço passa a ser feito pelo comitê de norma, que define os coeficientes de segurança a serem adotados, sem endereçar explicitamente a questão. Os coeficientes de segurança são aplicados na tentativa de fazer com que as estruturas alcancem um índice de confiabilidade alvo, ou seja, que a probabilidade de falha seja menor do que um valor préestabelecido.

$\mathrm{Na}$ busca por um projeto de engenharia ótimo, várias formulações podem ser utilizadas, dentre estas formulações estão as três adotadas no presente trabalho: a otimização determinística, a otimização baseada em confiabilidade e a otimização de risco baseada em confiabilidade.

A otimização estrutural determinística (DDO - Deterministic Design Optimization) aborda o problema da busca por um projeto ótimo do ponto de vista econômico, visando redução no uso de materiais, mas não verifica diretamente o aspecto de segurança, ou seja, a estrutura é otimizada sem que sejam calculadas probabilidades de falha. A otimização baseada em confiabilidade (RBDO - Reliability-Based Design Optimization), também conhecida como RBO (Reliability-Based Optimization (FRANGOPOL, 1985)) permite endereçar a questão da segurança ao impor restrições em termos de probabilidades de falha admissíveis, 
mas não leva em conta os custos esperados de falha. As formulações de DDO e RBDO podem ser utilizadas para obter eficiência do ponto de vista estrutural (mecânico), o que certamente tem benefícios econômicos, mas não endereçam diretamente o compromisso entre economia e segurança. Ao incluir os custos esperados de falha no balanço econômico, a otimização de risco estrutural (RBRO - Reliability Based Risk Optimization (BECK \& VERZENHASSI, 2008a; BECK \& VERSANHASSI, 2008b)) permite encontrar o ponto ótimo no balanço entre economia e segurança. Esta formulação (RBRO) é complementar às formulações DDO e RBDO, no sentido de que o projeto mais econômico é também o mais eficiente do ponto de vista mecânico e do ponto de vista da segurança.

\subsection{MOTIVAÇÃO}

A motivação deste trabalho parte do exemplo mostrado na Figura 1, um pórtico plano hiperestático treliçado formado por 6 barras e sujeito a duas cargas de mesma intensidade (uma horizontal e outra vertical) em uma de suas extremidades superiores. A otimização determinística desta estrutura, a depender da formulação, pode levar à retirada de uma das barras, sem levar em conta o fato que a existência dessas barras implica na existência de caminhos alternativos de falha estrutural.

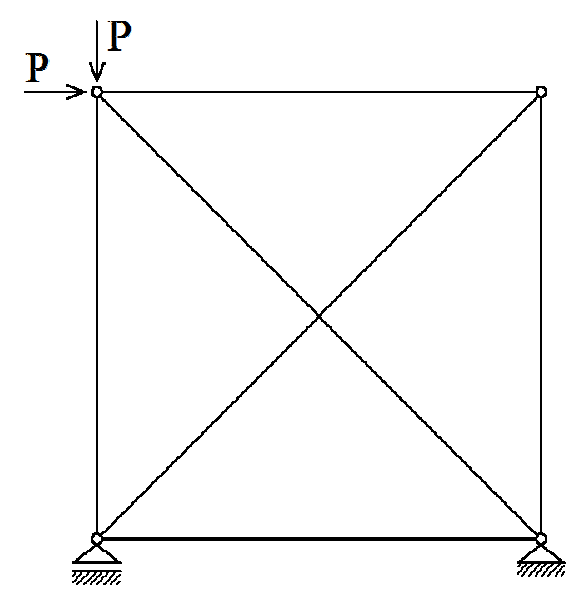

Figura 1 - Pórtico hiperestático plano.

Outro exemplo motivador é mostrado na Figura 2, que apresenta um dos resultados obtidos por Amstutz \& Andrä (2005) para a otimização topológica de uma viga engastada submetida a um carregamento concentrado na extremidade livre. Fica claro que esta otimização terá mais modos de falha e mais pontos materiais (todos?) projetados contra o limite, de forma que a retirada de um pequeno pedaço da estrutura leva à falha da mesma. 


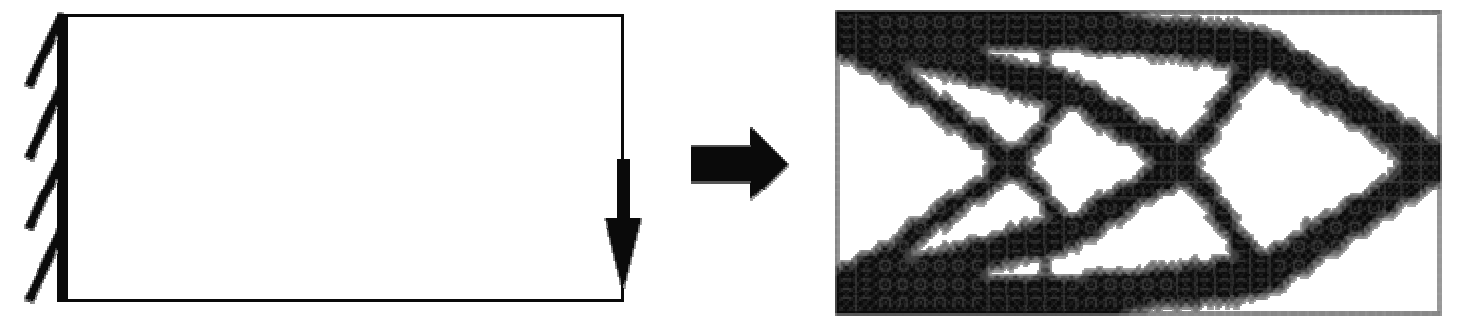

Figura 2 - Resultado da otimização topológica de uma viga engastada (FONTE: Amstutz \& Andrä (2005)).

Os dois casos apresentados representam situações nas quais podem existir diferenças muito grandes entre as estruturas ótimas encontradas quando se leva em conta (ou não) explicitamente a segurança estrutural. Estas diferenças conduzem à definição dos objetivos do presente trabalho.

\subsection{OBJETIVOS}

\subsubsection{Objetivos gerais}

Estudar e compreender efeitos de incertezas na otimização estrutural. Isto pode ser feito comparando as formulações de otimização estrutural DDO (Deterministic Design Optimization), que não leva em conta explicitamente as incertezas, RBDO (Reliability-Based Design Optimization), que leva em conta a probabilidade de falha do sistema estrutural, e RBRO (Reliability Based Risk Optimization), que leva em conta as probabilidades de falha da estrutura e seus respectivos custos. Em particular, busca-se entender e demonstrar como cada formulação limita o escopo do problema, restringindo o espaço de soluções e levando a diferentes projetos ótimos.

Convém ressaltar que não se pretende realizar comparações de mérito entre as formulações (por exemplo, afirmar que uma formulação é melhor do que outra).

\subsubsection{Objetivos específicos}

Implementar algoritmos de programação não-linear em um módulo computacional a ser acoplado ao programa de confiabilidade estrutural StRAnD (Structural Risk Analysis and 
Design, responsável por cálculos de confiabilidade estrutural (BECK, 2007)), de maneira a resolver problemas de otimização estrutural desenvolvidos nas três formulações apresentadas.

Aplicar o programa computacional a diversos problemas, comparar e estudar os resultados obtidos para cada formulação, bem como a eficiência de cada método de otimização na busca pela solução ótima global.

\subsection{METODOLOGIA}

Inicialmente foi feita uma revisão abordando os tópicos deste trabalho: confiabilidade estrutural, programação não-linear e algoritmos heurísticos de otimização. A revisão prosseguiu de forma mais específica, levando ao estudo de trabalhos desenvolvidos nas áreas de otimização determinística, algoritmos híbridos de otimização e otimização baseada em riscos, por exemplo.

Foram implementados então algoritmos de otimização, constituídos por algoritmos com fundamentação matemática, algoritmos heurísticos e algoritmos híbridos. A implementação foi feita em linguagem FORTRAN 90, utilizando técnicas de orientação a objetos para permitir fácil modificação e/ou inclusão de métodos de otimização, dentre outras facilidades.

Por último os métodos foram aplicados a vários problemas, comparando-se as diferentes formulações de otimização e o desempenho dos métodos de otimização utilizados.

\subsection{ORGANIZAÇÃO DO CONTEÚDO}

No capítulo 2 são apresentados, de maneira bastante concisa, os conceitos de Confiabilidade Estrutural utilizados neste trabalho, abordando um pouco da teoria relacionada e apontando referências que podem ser consultadas para maiores detalhes.

No capítulo 3 define-se o problema geral de otimização e procura-se mostrar os métodos de otimização e as estratégias híbridas desenvolvidas, com enfoque na implementação computacional destes.

A seguir, são expostas no capítulo 4 as formulações de otimização estrutural a serem realizadas para compreender os efeitos de incertezas na otimização estrutural. 
O capítulo 5 traz os exemplos numéricos, seus resultados e discussões a respeito dos mesmos. Procura-se comparar as formulações de otimização à medida em que vão sendo apresentados os resultados.

No sexto capítulo é feita uma análise do desempenho dos métodos de otimização implementados, procurando determinar qual dentre estes é o mais eficiente e confiável para os problemas de interesse deste trabalho.

Finalmente, no capítulo 7, são apresentadas as conclusões a respeito tanto das incertezas e seus efeitos na otimização estrutural, quanto do desempenho e confiabilidade dos métodos de otimização estudados. 


\section{CONFIABILIDADE ESTRUTURAL}

Sistemas estruturais e os elementos que o compõem, devem ser economicamente viáveis, cumprir de maneira satisfatória determinada função estrutural e manter um nível adequado de segurança durante o período denominado vida útil. $\mathrm{Na}$ tentativa de atingir esses objetivos, projetos estruturais devem atender a alguns requisitos básicos, equacionados na forma de estados limites.

\subsection{ESTADOS LIMITES E COEFICIENTES DE SEGURANÇA}

Os estados limites podem ser divididos em duas categorias principais: os estados limites de serviço, que correspondem aos requisitos funcionais e condições normais de uso, e os estados limites últimos, que correspondem aos requisitos de segurança e que estão relacionados ao esgotamento da capacidade portante ou de deformação da estrutura. Este esgotamento implica colapso ou dano grave e permanente para a mesma.

Cada modo de falha pode ser formulado por meio de uma equação de estado limite $g(\mathbf{X}, \mathbf{z})$, Equação (1), onde o vetor $\mathbf{z}$ contém as $N$ variáveis de projeto e o vetor $\mathbf{X}$ contém $M$ variáveis aleatórias.

$$
g(\mathbf{X}, \mathbf{z})=g\left(X_{1}, X_{2}, \ldots, X_{M}, z_{1}, z_{2,}, z_{N}\right)=0
$$

Valores negativos da equação de estado limite implicam falha estrutural, enquanto que valores positivos implicam não falha. Isso leva à definição dos chamados domínios de falha $\left(D_{f}\right)$ e do domínio de sobrevivência $\left(D_{s}\right)$, conforme as Equações (2) e (3).

$$
\begin{aligned}
& D_{f}=\{\mathbf{x} \mid g(\mathbf{X}, \mathbf{z}) \leq 0\} \\
& D_{s}=\{\mathbf{x} \mid g(\mathbf{X}, \mathbf{z})>0\}
\end{aligned}
$$

Durante muitos anos, o projeto de sistemas estruturais foi realizado utilizando-se o chamado método das tensões admissíveis, onde um único coeficiente de segurança era utilizado para criar uma margem de segurança entre resistência e solicitação. A razão entre a 
tensão resistente e a tensão solicitante foi denominada fator de segurança (SORENSEN, 2004), ou coeficiente de segurança.

Apesar da adoção de uma margem de segurança, existe a probabilidade de que o sistema estrutural atinja um ou mais estados limites. Essa probabilidade é ocasionada pela existência de parâmetros que são variáveis aleatórias por natureza e de outros que não podem ser definidos deterministicamente devido a fontes diversas de incerteza.

Em outras palavras, pode-se dizer que as incertezas levam à existência de probabilidades de falha da estrutura com relação aos diversos modos de falha. A teoria da confiabilidade estrutural permite a determinação destas probabilidades de falha, e, conseqüentemente, dos coeficientes de segurança a serem utilizados para projetar estruturas com probabilidades de falha aceitáveis.

Adotando a resistência $R$ e a solicitação $S$ como sendo duas variáveis aleatórias com médias iguais a $\mu_{R}$ e $\mu_{S}$, respectivamente, calcula-se o chamado coeficiente de segurança central, $\lambda_{0}$, através da Equação (4).

$$
\lambda_{0}=\frac{\mu_{R}}{\mu_{S}}
$$

Como os valores da resistência e da solicitação na estrutura real podem ser maiores ou menores que as médias, não há certeza que um determinado coeficiente de segurança central seja suficiente para garantir a segurança de uma estrutura (BECK, 2009).

Nas modernas normas técnicas de projeto estrutural passaram a ser utilizados coeficientes parciais de segurança. Valores característicos de solicitações $\left(s_{k}\right)$ e de resistência $\left(r_{k}\right)$ são especificados e coeficientes parciais de segurança são aplicados às solicitações e resistências no intuito de garantir que a estrutura seja segura o suficiente (SORENSEN, 2004).

\subsection{VARIÁVEIS ALEATÓRIAS}

Uma variável aleatória real $X(\omega)$ é, por definição, uma função real que atribui a cada ponto amostral $\omega_{i}$ pertencente a um espaço amostral $\Omega$ um valor real $x\left(\omega_{i}\right)$ tal que o conjunto $\{X \leq x\}$ é um evento para qualquer número real $x$. A notação $\{X \leq x\}$ equivale a dizer que a variável aleatória $X$ assume qualquer valor menor ou igual a $x$. 
Variáveis aleatórias (VAs) são utilizadas para representar numericamente resultados de experimentos aleatórios. São representadas geralmente por uma letra maiúscula, enquanto que uma realização desta variável (ou um resultado do experimento) é representada por uma letra minúscula. Além disso, elas podem ser contínuas ou discretas, visto que o espaço amostral pode ser constituído por conjunto discretos ou contínuos de pontos (ANG \& TANG, 2007).

A probabilidade de ocorrência do evento $\{X \leq x\}$ é uma função de $x$. Esta função é denominada função de distribuição acumulada de probabilidades (Cumulative density function - CDF) da variável aleatória $X$, representada por $F_{X}$, definida para qualquer número $x$ tal que $-\infty \leq x \leq+\infty$ e dada pela Equação (5).

$$
F_{X}(x)=P[\{X \leq x\}]
$$

A partir daí, pode-se definir valores característicos e nível de confiança, dados pela Equação (6) em se tratando de variáveis aleatórias de resistência, ou pela Equação (7), no caso das variáveis aleatórias de solicitação. Os valores característicos $r_{k}$ e $s_{k}$ são, portanto, diretamente vinculados aos níveis de confiança.

$$
\begin{gathered}
P\left[\left\{R>r_{k}\right\}\right]=1-F_{R}\left(r_{k}\right) \\
P\left[\left\{S<s_{k}\right\}\right]=F_{S}\left(s_{k}\right)
\end{gathered}
$$

Derivando-se a função de distribuição acumulada de probabilidades em relação a $x$ obtém-se a chamada função de densidade de probabilidades (Probability density function PDF) de uma variável aleatória $X$, representada por $f_{X}$, dada pela Equação (8).

$$
f_{X}(x)=\frac{d F_{X}(x)}{d x}
$$

A FDP de uma variável aleatória representa a distribuição de probabilidades desta variável, ou seja, as probabilidades de ocorrência dos diversos eventos envolvendo a mesma. Trata-se de uma função muito utilizada no cálculo de diversas quantidades descritivas das variáveis aleatórias, incluindo o valor esperado e os momentos, abordados na próxima subseção. 


\subsubsection{Valor esperado, variância e momentos de uma VA}

Dada uma variável aleatória $X$, define-se como seu valor esperado ou média a integral apresentada na Equação (9).

$$
E[X]=\mu_{X}=\int_{-\infty}^{+\infty} x f_{X}(x) d x
$$

Para uma função $g(X)$, o valor esperado $E[g(X)]$ é dado pela Equação (10).

$$
E[g(X)]=\int_{-\infty}^{+\infty} g(x) f_{X}(x) d x
$$

A variância, $\operatorname{Var}(X)$ ou $E\left[\left(X-\mu_{X}\right)^{2}\right]$, uma medida da dispersão da variável aleatória em torno da média, e o desvio padrão $\left(\sigma_{X}\right)$, raiz quadrada da variância, são duas medidas muito importantes na descrição das VAs, calculadas pela Equação (11) (ANG \& TANG, 2007).

$$
E\left[\left(X-\mu_{X}\right)^{2}\right]=\operatorname{Var}(X)=\sigma_{X}^{2}=\int_{-\infty}^{+\infty}\left(x-\mu_{X}\right)^{2} f_{X}(x) d x
$$

Devido à dificuldade de comparar desvios padrão de VAs diferentes, uma medida adimensional da dispersão passa a ser mais significativa. Dividindo-se o desvio padrão pela média da variável aleatória tem-se o coeficiente de variação (c.v.).

$$
\text { c.v. }=\frac{\sigma_{X}}{\mu_{X}}
$$

O valor esperado de uma VA é, na verdade, um caso particular do chamado momento de ordem $k$ da variável, definido pela Equação (13), enquanto que variância é um caso particular de momento central de ordem $k$, definido pela Equação (14). Ambas as equações apresentam os momentos para $X$ contínua. 


$$
\begin{gathered}
E\left[X^{k}\right]=\mu_{X}^{k}=\int_{-\infty}^{+\infty} x^{k} f_{X}(x) d x \\
E\left[\left(X-\mu_{X}\right)^{k}\right]=\int_{-\infty}^{+\infty}\left(x-\mu_{X}\right)^{k} f_{X}(x) d x
\end{gathered}
$$

\subsection{ALGUMAS DISTRIBUIÇÕES USUAIS}

Apesar de existir uma infinidade de funções de distribuição de probabilidades, algumas delas são especialmente usuais, por representarem de maneira aceitável processos físicos, características de materiais, dentre outros objetos de estudo, ou por serem funções resultantes de processos limite, como, por exemplo, o somatório de infinitas outras distribuições.

Algumas das FDPs usuais e de particular interesse desse trabalho são apresentadas na tabela a seguir baseada em ANG \& TANG (2007).

\begin{tabular}{|c|c|c|c|}
\hline Distribuição & $f_{X}(x)$ & Média & Variância \\
\hline \multirow{2}{*}{ Uniforme } & 1 & $a+b$ & $(b-a)^{2}$ \\
\hline & $\overline{b-a}$ & 2 & 12 \\
\hline Normal & $\frac{1}{\sigma \sqrt{2 \pi}} \exp \left[-\frac{1}{2}\left(\frac{x-\mu}{\sigma}\right)^{2}\right]$ & $\mu$ & $\sigma^{2}$ \\
\hline Gama & $\frac{\alpha}{\Gamma(r)}(\alpha x)^{r-1} e^{-\alpha x}$ & $\frac{r}{\alpha}$ & $\frac{r}{\alpha^{2}}$ \\
\hline Lognormal & $\frac{1}{\xi x \sqrt{2 \pi}} \exp \left[-\frac{1}{2}\left(\frac{\ln (x)-\lambda}{\xi}\right)^{2}\right.$ & $\exp \left(\lambda+0,5 \xi^{2}\right)$ & $\mu^{2}\left[\exp \left(\xi^{2}\right)-1\right]$ \\
\hline $\begin{array}{c}\text { Exponencial } \\
\text { deslocada }\end{array}$ & $v \exp (-v(x-\varepsilon))$ & $\frac{1}{v}+\varepsilon$ & $\frac{1}{v^{2}}$ \\
\hline
\end{tabular}

Tabela 1 - Algumas distribuições de probabilidade contínuas.

OBS.: $\Gamma($.$) é a função Gama.$

A próxima seção apresenta um pouco sobre a escolha das distribuições adequadas às diferentes variáveis aleatórias que se encontram usualmente em projetos de engenharia. 


\subsection{INCERTEZA NA ENGENHARIA ESTRUTURAL}

Dentre as incertezas presentes na engenharia estrutural, as mais comuns são as denominadas incertezas intrínsecas e as incertezas epistêmicas. Intrínsecas são aquelas que não podem ser eliminadas, pois fazem parte da natureza dos processos envolvidos. Epistêmicas são aquelas que, em tese, podem ser reduzidas ou eliminadas, através da coleta de mais dados ou de melhor conhecimento do problema (BECK, 2009).

Enquanto que o efeito da incerteza intrínseca leva à probabilidade de falha calculada, o efeito do tipo epistêmico leva à incerteza da probabilidade ou risco estimado. A incerteza epistêmica pode ser reduzida através, por exemplo, da aplicação de melhores modelos estruturais (ANG \& TANG, 2007), e, portanto, está fora do escopo deste trabalho.

Com relação às incertezas intrínsecas, muitos estudos têm sido feitos no sentido de determinar quais funções de distribuição de probabilidade melhor representam as mesmas. A Tabela 2 apresenta algumas variáveis aleatórias de particular interesse para este trabalho e as distribuições usuais para representá-las, de acordo com Ellingwood \& Galambos (1982). O intervalo de variação do coeficiente de variação para as VAs de resistência decorre do fato de que o autor aborda as propriedades de acordo com a função estrutural do elemento em estudo. Outras abordagens podem ser vistas em Melchers (1999) e Probabilistic Model Code (2001).

Tabela 2 - Distribuições de probabilidade comumente utilizadas na descrição de variáveis aleatórias da engenharia estrutural.

\begin{tabular}{cccc}
\hline Variável aleatória & Tipo & Distribuição & c.v. \\
\hline \multirow{2}{*}{ de resistência } & Propriedades do Aço estrutural & Lognormal & 0,11 a 0,17 \\
& Propriedades do Concreto & Lognormal & 0,09 a 0,20 \\
\hline \multirow{2}{*}{ de solicitação } & Peso próprio & Normal & 0,10 \\
& Carga Acidental & Gama & 0,55 \\
\hline
\end{tabular}

Dadas as distribuições usuais, convém formular o problema de confiabilidade estrutural e definir o que é a probabilidade de falha dentro deste escopo. 


\subsection{FORMULAÇÃO DO PROBLEMA DE CONFIABILIDADE ESTRUTURAL INDEPENDENTE DO TEMPO}

O problema fundamental de confiabilidade pode ser resolvido através da variável denominada margem de segurança $(M)$. Para um problema envolvendo apenas duas variáveis aleatórias, resistência $R$ e solicitação $S, M$ é definida pela Equação (15), tratando-se também de uma variável aleatória.

$$
M=R-S
$$

A probabilidade de falha da estrutura passa a ser calculada a partir de $M$ :

$$
P_{f}=P[\{R-S \leq 0\}]=P[\{M \leq 0\}]=\int_{-\infty}^{0} f_{M}(m) d m=F_{M}(0)
$$

Caso $R$ e $S$ sejam variáveis aleatórias normais independentes, isto é, caso as distribuições de probabilidades das variáveis não influenciem umas às outras, pode-se calcular a média e o desvio padrão da variável $M$ pelas Equações (17) e (18) (BECK, 2009).

$$
\begin{gathered}
\mu_{M}=\mu_{R}-\mu_{S} \\
\sigma_{M}=\sqrt{\sigma_{R}^{2}+\sigma_{S}^{2}}
\end{gathered}
$$

Transformando a variável $M$ em uma variável normal padrão $Y$, com média nula e desvio padrão unitário, através da Equação (19), é possível avaliar probabilidades associadas a esta variável utilizando-se da função de distribuição acumulada normal padrão, $\Phi()$. Dessa forma, a probabilidade de falha pode ser calculada pela Equação (20).

$$
\begin{gathered}
Y=\frac{M-\mu_{M}}{\sigma_{M}} \\
P[\{M \leq 0\}]=P\left[\left\{Y \leq-\frac{\mu_{M}}{\sigma_{M}}\right\}\right]=\Phi\left[-\frac{\mu_{M}}{\sigma_{M}}\right]
\end{gathered}
$$


Constata-se que $\frac{\mu_{M}}{\sigma_{M}}$ é a distância entre o ponto correspondente a $m=0$ e a origem da distribuição de $Y$, esta distância é chamada de índice de confiabilidade, representada por $\beta$ e utilizada freqüentemente como uma medida da confiabilidade.

Para um problema estrutural envolvendo apenas variáveis aleatórias, ou seja, desprezando a variação das variáveis aleatórias no tempo, o vetor de variáveis aleatórias que caracteriza o problema é simplesmente chamado de $\mathbf{X}$. Trata-se de uma generalização de $M$ para um número qualquer de variáveis aleatórias, sendo que, em geral, estas variáveis aleatórias são de resistência ou de solicitação.

A probabilidade de falha é obtida então integrando-se a função conjunta de densidade de probabilidades $f_{\mathbf{X}}(\mathbf{x})$ sobre o domínio de falha, conforme a Equação a seguir.

$$
P_{f}=\int_{D_{f}} f_{\mathbf{X}}(\mathbf{x}) d x
$$

A solução da integral apresentada é feita por meio de vários métodos. No presente trabalho foi utilizado o Método de Confiabilidade de Primeira Ordem, ou FORM (First Order Reliability Method), descrito na próxima seção.

\subsection{MÉTODO DE CONFIABILIDADE DE PRIMEIRA ORDEM (FORM)}

O Método de Confiabilidade de Primeira Ordem ou FORM (First Order Reliability Method) é um dos métodos para cálculos de confiabilidade estrutural disponíveis no programa StRAnD (Structural Risk Analysis and Design, BECK, 2007) e foi o método adotado neste trabalho. O FORM é um método que permite estimar eficientemente a confiabilidade, mesmo em processos que exigem muitas repetições, tais como o processo de otimização estrutural (ENEVOLDSEN \& SORENSEN, 1994).

Conforme apresentado em Beck (2009), este método parte da construção de uma função conjunta de distribuição de probabilidades $f_{\mathbf{X}}(\mathbf{x})$, utilizando as distribuições de probabilidades marginais (distribuições de probabilidades de cada uma das variáveis aleatórias do problema) e uma matriz de correlação formada pelos coeficientes de correlação entre pares de variáveis. Nesta construção, as distribuições marginais originais são transformadas em distribuições normais equivalentes (conjunto de variáveis aleatórias correlacionadas), são determinados os coeficientes de correlação equivalentes para as 
distribuições marginais normais e em seguida a correlação é eliminada, ou seja, incorporada às distribuições marginais. Dessa forma, a função $f_{\mathbf{X}}(x)$ é transformada em uma distribuição normal padrão multivariada $f_{\mathbf{Y}}(\mathbf{y})$.

Este processo envolve a transformação do vetor de variáveis aleatórias $\mathbf{X}$, com média e desvios-padrão qualquer, em um conjunto $\mathbf{Y}$ de variáveis aleatórias normais com média nula e desvio-padrão unitário, operação feita por meio da chamada transformação de Hassofer e Lind (Equação (22)).

$$
Y_{i}=\frac{X_{i}-\mu_{X_{i}}}{\sigma_{X_{i}}}
$$

Aplicando-se a transformação às variáveis aleatórias $R$ e $S$ do problema de confiabilidade fundamental (Equação (16)), obtém-se as variáveis transformadas $Y_{1}$ e $Y_{2}$. A expressão da margem de segurança passa a ser:

$$
m\left(y_{1}, y_{2}\right)=r-s=y_{1} \sigma_{R}+\mu_{R}-y_{2} \sigma_{S}-\mu_{S}
$$

Para $m\left(y_{1}, y_{2}\right)=0$ obtém-se $y_{2}$ em função de $y_{1}$, das médias e desvios-padrão.

$$
y_{2}=\frac{y_{1} \sigma_{R}+\mu_{R}-\mu_{S}}{\sigma_{S}}
$$

O quadrado da distância entre um ponto qualquer $\left(y_{1}, y_{2}\right)$ e a origem é dado por $d^{2}=y_{1}^{2}+y_{2}^{2}$. Derivando em relação a $y_{1}$ e igualando a zero (condição de mínimo), obtém-se a coordenada $y_{1}^{*}$ do ponto sobre a equação $m\left(y_{1}, y_{2}\right)=0$ mais próximo da origem.

$$
y_{1}^{*}=-\frac{\sigma_{R}\left(\mu_{R}-\mu_{S}\right)}{\sigma_{R}^{2}+\sigma_{S}^{2}}
$$

Derivando o quadrado da distância em relação a $y_{2}$ e igualando a zero, obtém-se a respectiva coordenada $y_{2}^{*}$. 


$$
y_{2}^{*}=-\frac{\sigma_{S}\left(\mu_{R}-\mu_{S}\right)}{\sigma_{R}^{2}+\sigma_{S}^{2}}
$$

Substituindo o chamado ponto de projeto $\left(y_{1}^{*}, y_{2}^{*}\right)$ na expressão $d^{2}=y_{1}^{2}+y_{2}^{2}$, encontra-se a expressão para a mínima distância entre a equação $m\left(y_{1}, y_{2}\right)=0$ e a origem.

$$
d_{\min }=\frac{\mu_{R}-\mu_{S}}{\sigma_{R}^{2}+\sigma_{S}^{2}}
$$

Observa-se que o índice de confiabilidade $\beta$ é igual a $d_{\min }$, ou seja, corresponde à mínima distância entre a equação de estado limite e a origem do espaço normal padrão.

A solução do problema de confiabilidade via FORM envolve a solução de um problema de otimização para busca do ponto de projeto. A seguir é descrito superficialmente um método que foi desenvolvido especificamente para solução do problema de otimização em confiabilidade estrutural, denominado HLRF (Hassofer, Lind, Rackwitz e Fiessler), bem como uma modificação do mesmo que garante convergência. Este método modificado é o método utilizado pelo programa StRAnD.

\subsubsection{Algoritmo de Hassofer, Lind, Rackwitz e Fiessler}

A fórmula recursiva do algoritmo HLRF baseia-se na aproximação de um ponto qualquer $\mathbf{y}$ à superfície $g(\mathbf{y})=0$ e na perpendicularização entre o vetor $\mathbf{y}$ e a tangente à superfície no ponto (BECK, 2009).

Sendo $\mathbf{y}_{k}$ um ponto inicial qualquer que pode estar fora da superfície de falha, aproxima-se a equação de estado limite com os termos de primeira ordem de sua expansão em série de Taylor neste ponto:

$$
\tilde{g}\left(\mathbf{y}_{k+1}\right)=g\left(\mathbf{y}_{k}\right)+\nabla g\left(\mathbf{y}_{k}\right)^{T} \cdot\left(\mathbf{y}_{k+1}-\mathbf{y}_{k}\right)
$$

$\nabla g\left(\mathbf{y}_{k}\right)$ é o gradiente da equação de estado limite (no espaço normal padrão) avaliado no ponto $\mathbf{y}_{k}$. Nos exemplos numéricos deste trabalho, o gradiente é calculado utilizando-se o método das diferenças finitas no programa StRAnD. 
Para a equação linearizada procura-se um novo ponto $\mathbf{y}_{k+1}$, de forma que $\tilde{g}\left(\mathbf{y}_{k+1}\right)=0$. O valor inicial do índice de confiabilidade é dado por $\beta_{k}=\sqrt{\mathbf{y}_{k}{ }^{T} \cdot \mathbf{y}_{k}}$ e o vetor de cossenos diretores da equação de estado limite $\left(\boldsymbol{\alpha}_{k}\right)$ é definido por:

$$
\boldsymbol{\alpha}_{k}=\frac{\nabla g\left(\mathbf{y}_{k}\right)}{\left\|\nabla g\left(\mathbf{y}_{k}\right)\right\|}
$$

Dessa forma, chega-se à seguinte expressão para determinação do novo ponto:

$$
\mathbf{y}_{k+1}=-\boldsymbol{\alpha}_{k}\left[\beta_{k}+\frac{g\left(\mathbf{y}_{k}\right)}{\left\|\nabla g\left(\mathbf{y}_{k}\right)\right\|}\right]
$$

O termo entre colchetes representa a nova aproximação do índice de confiabilidade. A expressão é utilizada iterativamente até que se atinja convergência em $\mathbf{y}$ ou $\beta$.

Apesar de ser o algoritmo mais utilizado para encontrar o ponto de projeto em problemas de confiabilidade estrutural, algumas modificações são necessárias para que a convergência seja garantida.

A direção de busca inicial passa a ser determinada pela Equação (31).

$$
\mathbf{d}_{k}=\mathbf{y}_{k+1}-\mathbf{y}_{k}=\frac{\nabla g\left(\mathbf{y}_{k}\right)^{T} \cdot \mathbf{y}_{k}-g\left(\mathbf{y}_{k}\right)}{\left\|\nabla g\left(\mathbf{y}_{k}\right)\right\|^{2}} \cdot \nabla g\left(\mathbf{y}_{k}\right)-\mathbf{y}_{k}
$$

No algoritmo HLRF original, o passo $\lambda_{k}$ era unitário:

$$
\mathbf{y}_{k+1}=\mathbf{y}_{k}+\lambda_{k} \mathbf{d}_{k}
$$

Introduz-se uma função mérito $m(\mathbf{y})$ com o objetivo de determinar um passo ótimo. A cada iteração, após determinar a direção de busca, seria realizada uma busca linear para encontrar o passo $\lambda_{k}$ que minimiza a função mérito. Devido à dificuldade em resolver este problema, admite-se um passo que apenas reduza a função mérito suficientemente. Para tal propósito a regra de Armijo (LUENBERGER, 1984) pode ser utilizada. 


$$
\lambda=\max _{p \in \mathbb{N}}\left[b^{p} \mid m\left(\mathbf{y}_{k}+b^{p} \mathbf{d}_{k}\right)-m\left(\mathbf{y}_{k}\right) \leq-a b^{p}\left\|\nabla g\left(\mathbf{y}_{k}\right)\right\|^{2}\right], \quad a, b \in(0,1)
$$

Zhang e Kiureghian (1997) propõem a seguinte função mérito, que apresenta propriedades suficientes para assegurar convergência incondicional do algoritmo HLRF.

$$
m(\mathbf{y})=\frac{1}{2}\|\mathbf{y}\|^{2}+c|g(\mathbf{y})|
$$

Uma vez determinado o ponto de projeto, calcula-se (aproximadamente) a probabilidade de falha desejada por meio da Equação (35).

$$
P_{f}=\int_{D_{f}} f_{\mathbf{Y}}(\mathbf{y}) d y \cong \Phi(-\beta)
$$




\section{MÉTODOS DE OTIMIZAÇÃO}

Existem inúmeros métodos de otimização disponíveis na literatura. A opção por determinado método na solução de determinado problema envolve questões como eficiência, confiabilidade e precisão.

Neste trabalho foram implementados inicialmente dois métodos heurísticos de otimização, ou seja, métodos que não apresentam fundamentação matemática: o algoritmo de otimização por enxame de partículas, ou PSO (Particle Swarm Optimization), e o algoritmo genético SCE (Shuffled Complex Evolution). A seguir foram implementados dois métodos de otimização com fundamentação matemática: o método de Powell Modificado e o Método de Polak-Ribiere.

Por realizarem buscas simultâneas em diversas regiões do espaço de busca, os algoritmos heurísticos supracitados são razoavelmente eficientes para a identificação da região na qual se encontra a solução ótima global, porém lentos para convergir para tal solução. Os algoritmos matemáticos apresentam convergência rápida, mão são susceptíveis a problemas com mínimos locais. São capazes de chegar ao mínimo global desde que o ponto de partida esteja próximo ou inserido na região na qual se encontra a solução ótima global. Buscando aproveitar o melhor de cada algoritmo, os algoritmos matemáticos e heurísticos foram acoplados, formando quatro algoritmos híbridos.

No processo de acoplamento foram verificadas possibilidades de melhorias no algoritmo PSO com foco em sua utilização em algoritmos híbridos. Tais melhorias foram efetuadas, englobando, dentre outras coisas, a otimização dos parâmetros do algoritmo PSO por meio do método Simplex. O algoritmo PSO modificado foi denominado PSS (Particle Swarm - Simplex) e foi aplicado apenas como constituinte de algoritmos híbridos, não como um método heurístico à parte.

Neste capítulo, primeiramente é apresentado o problema geral de otimização. Em seguida são abordados alguns detalhes e referências sobre os algoritmos heurísticos, passando por uma breve descrição do Método Simplex, dos métodos matemáticos implementados, e, finalmente, da busca unidirecional. Para efeito de organização, o Método Simplex e a busca unidirecional são incluídos na seção 3.3. Por último, são descritas as estratégias híbridas desenvolvidas. 


\subsection{FORMULAÇÃO DO PROBLEMA DE OTIMIZAÇÃO}

O problema de otimização, também conhecido como problema de programação nãolinear (PNL), de acordo com Vanderplaats (1984), consiste basicamente em:

Minimizar $f(\mathbf{z})$

sujeita a

$$
\begin{gathered}
g_{j}(\mathbf{z}) \leq 0, \quad j=1, \ldots, m \\
h_{k}(\mathbf{z})=0, \quad k=1, \ldots, l \\
z_{i}^{\min } \leq z_{i} \leq z_{i}^{\max }, \quad i=1, \ldots, n
\end{gathered}
$$

O problema consiste em minimizar a chamada função objetivo $(f(\mathbf{z}))$ sujeita a restrições de igualdade $h_{k}(\mathbf{z})$, a restrições de desigualdade $g_{j}(\mathbf{z})$ e a limites impostos a cada variável $z_{i}$. O vetor $\mathbf{z}$ contém as variáveis de projeto, ou seja, aquelas variáveis cujo valor se deseja determinar de forma a obter o menor valor possível da função objetivo e sem desobedecer às restrições ou limites.

No presente trabalho os limites das variáveis, declarados pelo usuário, são substituídos por restrições $l_{i}(\mathbf{z})$, através da Equação (40), caso $z_{i}$ seja menor que o limite inferior $\left(z_{i}^{\min }\right)$ ou através da Equação (41), caso $z_{i}$ seja maior que o limite superior $\left(z_{i}^{\max }\right)$. A restrição $l_{i}(\mathbf{z})$ é nula caso $z_{i}^{\min } \leq z_{i} \leq z_{i}^{\max }$.

O fator de multiplicação 1000 foi introduzido para evitar, por exemplo, que nos passos iniciais as variáveis de projeto assumam valores muito menores que zero, ou seja, para assegurar que as variáveis não saiam dos limites estabelecidos.

$$
\begin{aligned}
& l_{i}(\mathbf{z})=1000 \cdot\left(z_{i}^{\min }-z_{i}\right)^{2} \\
& l_{i}(\mathbf{z})=1000 \cdot\left(z_{i}^{\max }-z_{i}\right)^{2}
\end{aligned}
$$


Para resolver o problema de otimização, o Método do Lagrangiano Aumentado foi adotado, de acordo com Vanderplaats (1984). Neste método as restrições são incluídas na função objetivo, obtendo-se o Lagrangiano Aumentado ( $A$ ), dado pela Equação (42), onde $\rho$ é um número real maior que zero, denominado parâmetro de penalidade. O problema assim transformado tem soluções iguais ou parecidas às do problema original (MARTÍNEZ, 2009).

$$
A(\mathbf{z}, \lambda, \rho)=f(\mathbf{z})+\sum_{j=1}^{m}\left[\lambda_{j} \psi_{j}+\rho \psi_{j}^{2}\right]+\sum_{k=1}^{l}\left\{\lambda_{k+m} h_{k}(\mathbf{z})+\rho\left[h_{k}(\mathbf{z})\right]^{2}\right\}+\sum_{i=1}^{N}\left[\lambda_{m+l+i} \psi_{m+i}+\rho \psi_{m+i}^{2}\right]
$$

O parâmetro de penalidade é inicializado com um valor pequeno e é multiplicado diversas vezes por um valor maior que 1 , à medida que o problema de otimização vai sendo resolvido. Maiores detalhes sobre o mesmo podem ser encontrados em Vanderplaats (1984), no capítulo que aborda o método da penalidade.

$\mathrm{Na}$ Equação (42) tem-se que:

$$
\begin{gathered}
\psi_{j}=\max \left[g_{j}(\mathbf{z}),-\frac{\lambda_{j}}{2 \rho}\right] \\
\psi_{m+i}=\max \left[l_{i}(\mathbf{z}),-\frac{\lambda_{m+l+i}}{2 \rho}\right]
\end{gathered}
$$

Além disso, os multiplicadores de Lagrange $(\lambda)$ são atualizados utilizando as Equações (45), (46) e (47), para cada nova iteração ite +1.

$$
\begin{gathered}
\lambda_{j}^{i t e+1}=\lambda_{j}^{i t e}+2 \rho\left\{\max \left[g_{j}\left(\mathbf{z}^{i t e}\right), \frac{-\lambda_{j}^{i t e}}{2 \rho}\right]\right\}, \quad j=1, \ldots, m \\
\lambda_{k+m}^{i t e+1}=\lambda_{k+m}^{i t e}+2 \rho h_{k}\left(\mathbf{z}^{i t e}\right), \quad k=1, \ldots, l \\
\lambda_{m+l+i}^{i t e+1}=\lambda_{m+l+i}^{i t e}+2 \rho\left\{\max \left[l_{i}\left(\mathbf{z}^{i t e}\right), \frac{-\lambda_{m+l+i}^{i t e}}{2 \rho}\right]\right\}, \quad i=1, \ldots, n
\end{gathered}
$$

Dentre as características atrativas do Lagrangiano Aumentado apresentadas em Vanderplaats (1984), algumas são de particular interesse deste trabalho: o ponto inicial pode ser factível ou não, sendo que um ponto é considerado factível (ou admissível) caso satisfaça 
a todas as restrições; o método é relativamente insensível ao valor do parâmetro de penalização, de forma a não ser necessário fazer $\rho$ tender ao infinito para chegar ao ponto ótimo; no ponto ótimo, os valores de $\lambda_{j} \neq 0$ identificarão automaticamente o conjunto de restrições ativas. Outras importantes características do método podem ser vistas em Martínez (2009).

Um fluxograma do método do Lagrangiano Aumentado é apresentado a seguir. Os multiplicadores de Lagrange iniciais $\left(\lambda^{0}\right)$ são nulos, o valor inicial do parâmetro de penalidade $(\rho)$ e de seu coeficiente de multiplicação $\left(\rho_{\text {coef }}\right)$ são definidos pelo usuário. $\mathrm{O}$ ponto inicial $\left(\mathbf{z}^{0}\right)$ é definido pelo usuário para os métodos de Powell e de Polak-Ribiere, determinado automaticamente nos métodos híbridos e não utilizado nos métodos heurísticos.

São adotados critérios de parada para avaliação de convergência ou não convergência. Considera-se que a solução convergiu se a Inequação (48) é satisfeita, onde tol é a tolerância definida pelo usuário. Admite-se que não houve convergência se ite > nitemax, sendo nitemax o máximo número de iterações, também definido pelo usuário. O objetivo da adição de um número muito pequeno $\left(1 \times 10^{-25}\right)$ na Inequação (48) é evitar divisões por zero.

$$
\left[\frac{\left|A\left(\mathbf{z}^{i t e}, \lambda, \rho\right)-A\left(\mathbf{z}^{i t e-1}, \lambda, \rho\right)\right|}{A\left(\mathbf{z}^{i t e-1}, \lambda, \rho\right)+1 \times 10^{-25}}+\sqrt{\left(\mathbf{z}^{i t e}-\mathbf{z}^{i t e-1}\right)^{T} \cdot\left(\mathbf{z}^{i t e}-\mathbf{z}^{i t e-1}\right)}\right] \leq t o l
$$

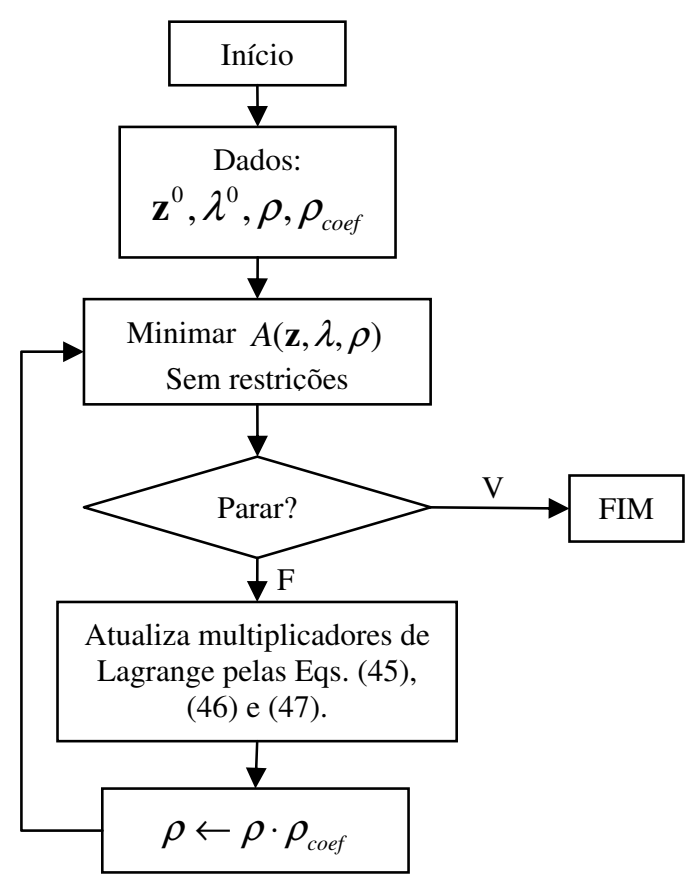

Figura 3 - Fluxograma do Método do Lagrangiano Aumentado. 


\subsection{MÉTODOS HEURÍSTICOS}

\subsubsection{PSO}

O método Particle Swarm Optimization (Otimização por Enxame de Partículas) foi inspirado no comportamento social de organismos biológicos, especificamente na capacidade que algumas espécies animais apresentam de trocar informações entre si durante a busca por pontos desejados numa determinada área. Isto ocorre, por exemplo, quando pássaros sobrevoam um local a procura de comida (BRATTON \& KENNEDY, 2007).

Partindo desta inspiração, o método foi modificado de forma a formulá-lo matematicamente. Muitos pesquisadores expandiram a ideia original, inserindo novas ideias e criando diversas versões do PSO. Neste trabalho uma versão semelhante à do PSO original com inércia, apresentada em Bratton \& Kennedy (2007), foi implementada e é descrita a seguir.

Seja $N$ o número de variáveis de otimização. Cada partícula $i$ é composta por três vetores: sua posição no espaço de busca $N$-dimensional $\mathbf{z}_{i}=\left(z_{i 1}, z_{i 2}, \ldots, z_{i N}\right)$, a melhor posição pela qual a partícula passou até então $\mathbf{p}_{i}=\left(p_{i 1}, p_{i 2}, \ldots, p_{i N}\right)$ e sua velocidade $\mathbf{v}_{i}=\left(v_{i 1}, v_{i 2}, \ldots, v_{i N}\right)$. As partículas são inicializadas aleatoriamente, procurando distribuí-las por todo o espaço de busca, através de uma distância mínima entre partículas. Essa distância é definida calculando-se primeiramente o volume $N$-dimensional da região de busca. Dividindo esse volume pelo número de partículas, obtém-se um volume de referência. Tomando-se uma esfera $N$-dimensional de diâmetro $d_{\text {esfera }}$ e volume igual ao volume de referência, tem-se que a distância mínima é igual a 90\% deste diâmetro. As velocidades das partículas também são inicializadas aleatoriamente, devendo obedecer às velocidades limite definidas pelas Equações (49) e (50), ou seja, $v_{j}^{\min } \leq v_{i j} \leq v_{j}^{\max }$, para $j=1, \ldots, N$.

$$
\begin{gathered}
v_{j}^{\max }=\frac{\left(z_{j}^{\max }-z_{j}^{\min }\right)}{H} \\
v_{j}^{\min }=-1 \cdot v_{j}^{\max }
\end{gathered}
$$

O parâmetro $H$ e os valores limite de cada uma das variáveis de otimização $z_{j}$ são definidos pelo usuário. 
Tomando-se o vetor $\vec{p}_{g}=\left(p_{g 1}, p_{g 2}, \ldots, p_{g N}\right)$ como sendo a melhor posição encontrada dentre todas as partículas (melhor posição global), em cada nova iteração (ite +1 ) a velocidade e a posição de cada partícula $i$ são atualizadas pelas Equações (51) e (52), respectivamente. Nestas Equações, $c_{1}$ e $c_{2}$ são constantes definidas pelo usuário, que refletem a autoconfiança e a confiança no melhor indivíduo do enxame (aquele que passou pela melhor posição global), respectivamente; $a l_{1}$ e $a l_{2}$ são números aleatórios entre zero e um.

$$
\begin{gathered}
v_{i j}^{i t e+1}=w \cdot v_{i j}^{i t e}+c_{1} \cdot a l_{1} \cdot\left(p_{i j}^{i t e}-z_{i j}^{i t e}\right)+c_{2} \cdot a l_{2} \cdot\left(p_{g j}^{i t e}-z_{i j}^{i t e}\right), \quad j=1, \ldots, N \\
z_{i j}^{i t e+1}=z_{i j}^{i t e}+v_{i j}^{i t e+1}, \quad j=1, \ldots, N
\end{gathered}
$$

As velocidades e posições das partículas devem estar sempre de acordo com seus limites, de forma que valores maiores que os máximos são substituídos pelos máximos e valores menores que os mínimos pelos mínimos estabelecidos.

A chamada inércia da partícula, w, é um número cujo valor inicial é definido pelo usuário e decai a cada iteração de acordo com a Equação (53), onde ite +1é o número da próxima iteração.

$$
w=w \cdot\left(0,99^{i t e+1}\right)
$$

$\mathrm{Na}$ solução de problemas utilizando o Lagrangiano Aumentado e o PSO, os multiplicadores de Lagrange foram definidos como nulos e o parâmetro de penalidade como uma constante $\rho=1 \times 10^{8}$. Os critérios de parada adotados foram: número máximo de iterações ( nitemax, definido pelo usuário) e a média das três últimas variações relativas dos valores do Lagrangiano Aumentado. A variação relativa é dada pela Equação (54), onde $A_{a n t}$ é o melhor valor da iteração passada e $A_{\text {novo }}$ é o melhor valor da presente iteração.

$$
\text { variação }=\frac{\left(A_{\text {novo }}-A_{\text {ant }}\right)}{\left(A_{\text {ant }}+1 \times 10^{-25}\right)}
$$

O resultado final obtido é a melhor posição global juntamente com o valor correspondente da função objetivo. Detalhes sobre o algoritmo PSO podem ser encontrados em Poli, Kennedy \& Blackwell (2007) ou Carrillo (2007). Um fluxograma do algoritmo básico implementado neste trabalho é apresentado na Figura 4. 


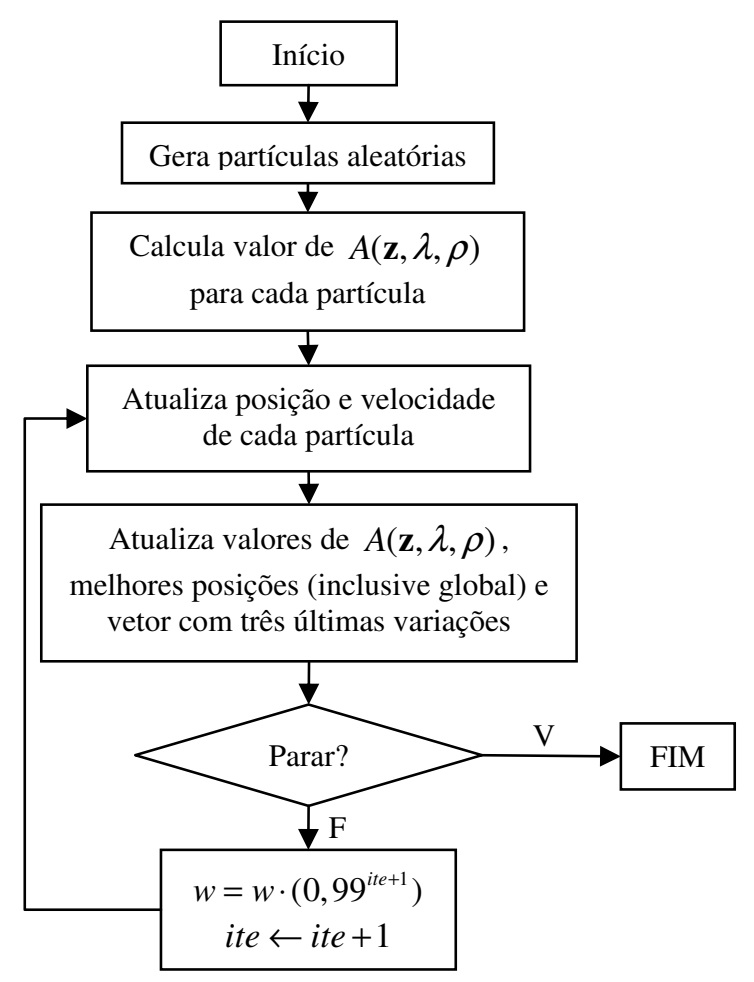

Figura 4 - Fluxograma do Algortimo PSO básico.

\subsubsection{Algoritmo Genético SCE}

Os Algoritmos Genéticos (AGs) foram inspirados nos mecanismos de evolução de populações de seres vivos. Eles seguem o princípio da seleção natural e sobrevivência do mais apto, declarado por Charles Darwin, em 1859, em seu livro “A origem das espécies" (CARVALHO \& LACERDA, 1999).

Neste método são criados vários indivíduos no espaço de busca, ou seja, vários pontos iniciais $\mathbf{z}$ no espaço $N$-dimensional. Os indivíduos são inicializados aleatoriamente, procurando distribuí-los ao longo de todo o espaço de busca, por meio de uma distância mínima entre partículas, da mesma forma que no algoritmo PSO.

Os indivíduos são selecionados de acordo com seu valor de Lagrangiano Aumentado. Aplica-se o chamado cruzamento (ou crossover) sobre os mesmos, gerando (sempre que possível) melhores indivíduos e eliminando os piores. Entende-se por melhor indivíduo aquele que apresenta menor valor da função Lagrangiano Aumentado.

Outras operações ou conceitos podem ser aplicados à população, tais como a mutação e o elitismo. As diferentes formas de cruzamento, mutação e outras operações, bem 
como a utilização ou não de elitismo e outros conceitos, levam aos diferentes tipos de algoritmos genéticos.

No presente trabalho foi implementado o algoritmo genético SCE (Shuffled Complex Evolution), desenvolvido por Duan, Sorooshian \& Gupta (1992), conforme apresentado em Diniz (1999). Neste método a população é dividida em subcomplexos, ou comunidades, e é aplicado o esquema de procura Simplex (NELDER \& MEAD, 1965) para evolução de cada subcomplexo (SANTOS, SUZUKI \& WATANABE, 2003). Trata-se, pois, de um algoritmo genético no qual o cruzamento é feito utilizando o método Simplex (abordado na próxima seção deste capítulo).

Optou-se por trabalhar sempre com subcomplexos de três indivíduos. Desta forma, caso o número de indivíduos não seja múltiplo de três, alguns indivíduos não participam dos cruzamentos. A escolha aleatória dos indivíduos que compõem cada subcomplexo faz com que diferentes indivíduos sejam deixados de lado em cada iteração.

Além do cruzamento Simplex, aplicado em cada subcomplexo, a operação mutação é aplicada em cada indivíduo. Uma probabilidade de mutação $\left(P_{m u t}\right)$ é definida pelo usuário, e pode gerar perturbações de até $0,75 \cdot P_{m u t}$ em cada característica do indivíduo. A perturbação é dada por $0,75 \cdot P_{m u t} \cdot n$, onde $n$ é um número aleatório entre zero e um.

A população sofre cruzamentos e mutações até que pelo menos um dos critérios de parada seja atingido. Os critérios de parada adotados são os mesmos do algoritmo PSO. O resultado final obtido é o melhor indivíduo, juntamente com o respectivo valor da função objetivo.

$\mathrm{Na}$ solução de problemas usando AG's e Lagrangiano Aumentado, os multiplicadores foram definidos como nulos e o parâmetro de penalidade como uma constante $\rho=1 \times 10^{8}$, como no algoritmo PSO. O fluxograma resultante é mostrado na Figura 5. 


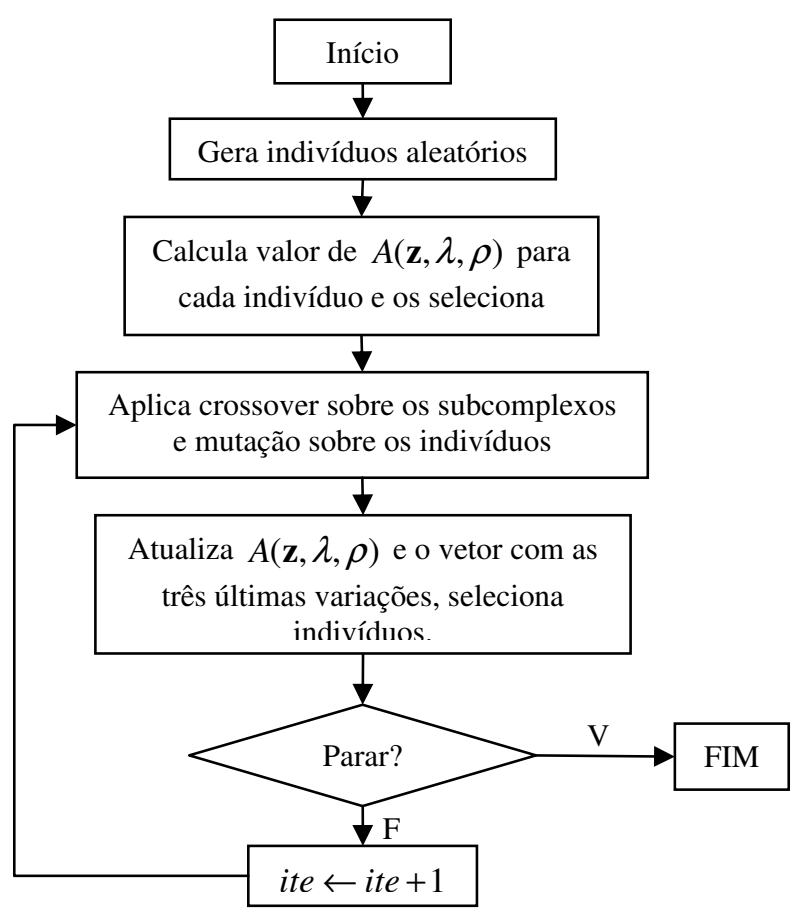

Figura 5 - Fluxograma do algoritmo genético SCE.

\subsection{MÉTODOS COM FUNDAMENTAÇÃO MATEMÁTICA}

\subsubsection{Método SIMPLEX}

O método simplex não-linear, ou NSM (Nonlinear Simplex Method), desenvolvido por Nelder \& Mead (1965), é um método de minimização de funções que não utiliza derivadas, apenas valores da função objetivo. O método se utiliza de uma figura geométrica constituída de $N+1$ vértices e todos os segmentos, poligonais e faces que os interconectam, denominada $N$-dimensional simplex, ou simplesmente simplex.

O simplex é submetido a uma série de passos nos quais se procura substituir o vértice com mais alto valor da função objetivo (da função Lagrangiano Aumentado, no presente trabalho) por um ponto com menor valor. De acordo com Parsopoulos \& Vrahatis (2002), existem quatro possíveis movimentos de um simplex: reflexão, reflexão e expansão, contração e contração múltipla. A experiência deste autor mostra que, com os passos de contração múltipla e de reflexão e expansão, os benefícios não justificaram os custos computacionais. Desta forma, tais passos foram ignorados, restando apenas os passos de reflexão e contração. 
Considere o caso bidimensional como exemplo, no qual o simplex é formado por três vetores $\mathbf{z}_{1}, \mathbf{z}_{2}$ e $\mathbf{z}_{3}$. Adotando $\mathbf{z}_{3}$ como o ponto com maior valor da função objetivo, define-se os passos aqui utilizados. O passo de reflexão, que corresponde à reflexão do pior ponto sobre a face oposta ao mesmo, é dado pela Equação (55). O passo de contração, que corresponde a uma contração do pior ponto em direção ao centróide, é dado pela Equação (56). Esses passos são mostrados na Figura 6.

$$
\begin{gathered}
z_{i}=z_{1 i}+z_{2 i}-z_{3 i}, \quad i=1,2 \\
z_{i}=\left(z_{1 i}+z_{2 i}+2 \cdot z_{3 i}\right) / 4, \quad i=1,2
\end{gathered}
$$

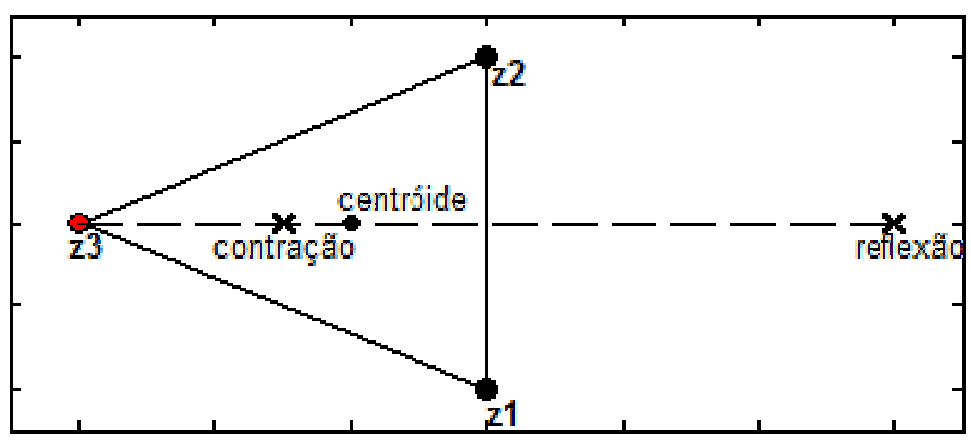

Figura 6 - Passos de contração e reflexão do NSM.

A adoção de subcomplexos de três indivíduos no algoritmo genético SCE leva à aplicação direta dos passos mostrados acima nos cruzamentos. A aplicação do método Simplex ao algoritmo PSO, na geração do algoritmo PSS, é descrita na subseção "Utilizando o algoritmo PSO (PSS)", presente na seção 3.4.

\subsubsection{Método de Powell Modificado}

O Método de Powell é uma variação do Método de Busca por Movimento Baseado em Amostragem e tem por idéias básicas:

a) Minimizar a função uma vez em cada direção coordenada $\left(\mathbf{d}_{i}, i=1, \ldots, n\right)$;

b) Minimizar a função em direção obtida por amostragem $\left(\mathbf{d}_{q}\right)$;

c) Substituir ciclicamente as direções coordenadas, ou seja, a primeira das direções coordenadas é substituída pela segunda, a segunda pela terceira, e assim sucessivamente até a penúltima direção;

d) Substituir a última direção coordenada pela direção obtida por amostragem. 
Tomando um ponto inicial $\mathbf{z}_{0}$ e um ponto final $\mathbf{z}_{N}$, com $\mathbf{z}_{0}, \mathbf{z}_{N} \in \mathfrak{R}^{\mathrm{N}}$, após efetuados $N$ passos nas direções coordenadas, tem-se a direção $\mathbf{d}_{q}$ obtida por amostragem:

$$
\mathbf{d}_{q}=\mathbf{z}_{0}-\mathbf{z}_{N}
$$

O algoritmo original de Powell, acima descrito, é aplicado nos problemas com cinco ou menos variáveis de projeto. Powell constatou que, em especial para funções com mais de cinco variáveis, seu algoritmo poderia levar a direções de busca linearmente dependentes, e desenvolveu um método modificado.

No método de Powell modificado, conforme apresentado em Cordeiro (2007), a direção de busca obtida por amostragem só é englobada nas direções de busca se algumas condições são satisfeitas. Definindo para a iteração ite ${ }^{*}: f_{1}=A\left(\mathbf{z}_{0}^{i t e^{*}}, \lambda, \rho\right), f_{2}=A\left(\mathbf{z}_{N}^{i t t^{*}}, \lambda, \rho\right)$ e $f_{3}=A\left(\mathbf{z}_{N+1}^{i t t^{*}}, \lambda, \rho\right)$, onde $\mathbf{z}_{N+1}^{i t e^{*}}$ é o ponto obtido pela busca na direção obtida por amostragem. Definindo ainda $\Delta^{i t e^{*}}=\max _{i=1, \ldots, N}\left[A\left(\mathbf{z}_{i-1}^{i t t^{*}}, \lambda, \rho\right)-A\left(\mathbf{z}_{i}^{i t e^{*}}, \lambda, \rho\right)\right]$. As condições para substituir uma das direções de busca pela direção obtida por amostragem são apresentadas nas Inequações (58) e (59), bastando que uma das duas condições seja satisfeita. A direção de busca a ser substituída é aquela que apresentou maior variação na iteração ite*, designada por $\mathbf{d}_{q \max }$.

$$
\begin{gathered}
f_{3}<f_{1} \\
\left(f_{1}-2 \cdot f_{2}+f_{3}\right) \cdot\left(f_{1}-f_{2}-\Delta^{i t t^{*}}\right)^{2}<\frac{1}{2} \cdot \Delta^{i t e^{*}} \cdot\left(f_{1}-f_{3}\right)^{2}
\end{gathered}
$$

Para verificar a convergência do algoritmo três critérios de parada foram adotados. Os dois primeiros levam em conta a tolerância definida pelo usuário e consideram que o algoritmo convergiu se o erro definido pela Equação (60) e/ou a soma definida pela Equação (61) são menores que a tolerância.

$$
\operatorname{erro}^{i t e^{*}}=\left(\frac{\left(f_{3}-f_{1}\right)}{f_{1}+1 \times 10^{-20}}\right)+\sqrt{\left(\mathbf{z}^{i t t^{*}}-\mathbf{z}^{i t e^{*}-1}\right)^{T} \cdot\left(\mathbf{z}^{i t e^{*}}-\mathbf{z}^{i t t^{*}-1}\right)}
$$




$$
\operatorname{soma}_{\mathbf{d} q}=\sum_{i=1}^{N}\left|\mathbf{d} q_{i}\right|
$$

O terceiro critério de parada é baseado em um número máximo de iterações do método de Powell (ite*), sendo este máximo o valor mínimo entre 3 e ite +1 , onde ite refere-se ao número da iteração do método do Lagrangiano Aumentado. Como, em geral, são efetuadas várias iterações com valores cada vez maiores do parâmetro de penalidade, não é necessário um resultado preciso para cada iteração ite, por isso a adoção de um número máximo de iterações relativamente pequeno.

A Figura 7 apresenta um fluxograma do Método de Powell Modificado. 


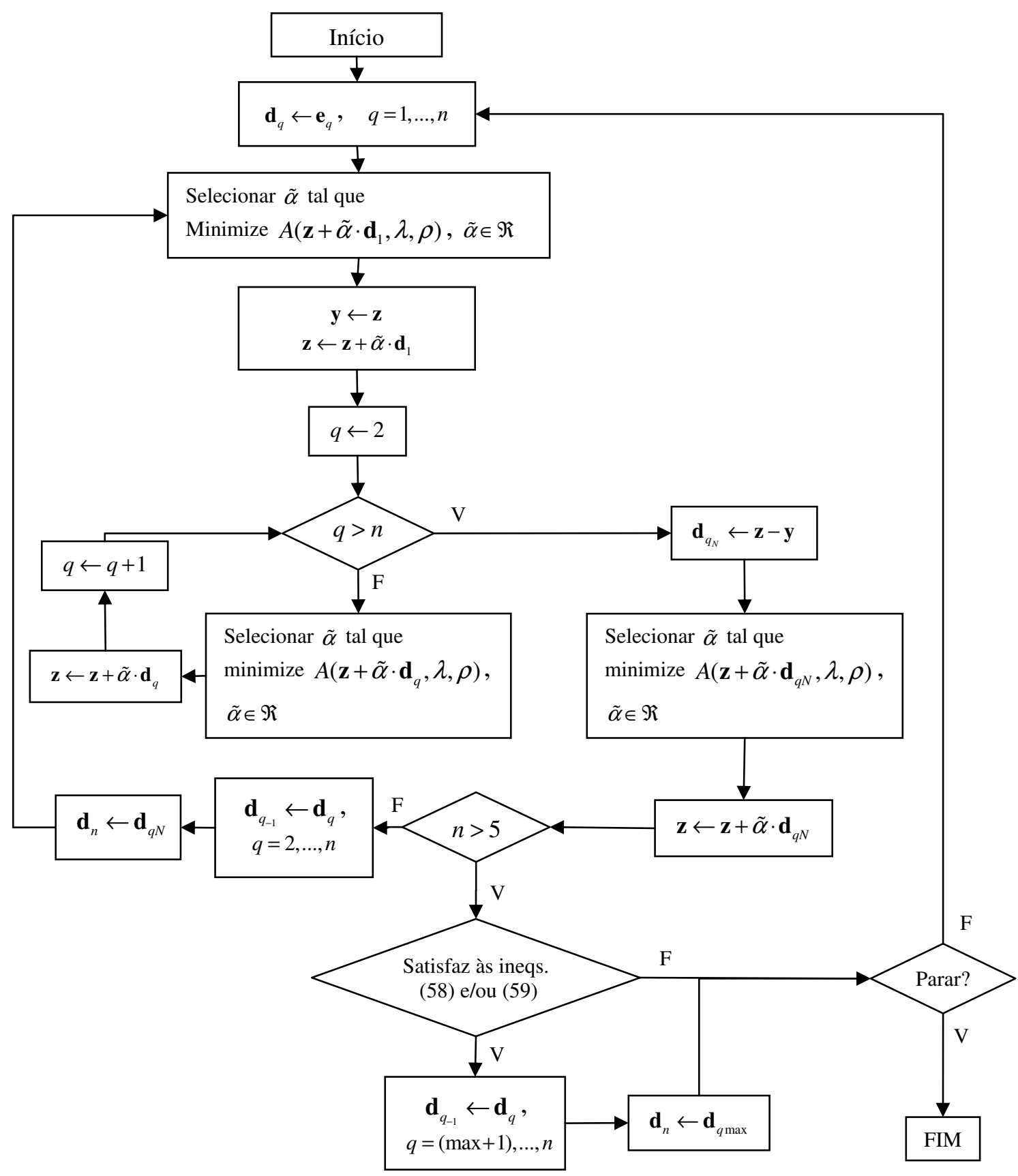

Figura 7 - Fluxograma do Método de Powell Modificado.

\subsubsection{Método de Polak-Ribiere}

O método de Polak-Ribiere é dito um método primeira ordem por utilizar o gradiente da função a ser minimizada, ou seja, a primeira derivada da mesma, mas não derivadas de maior ordem. 
Os métodos de primeira ordem são considerados neste trabalho por sua eficiência e por requererem bem menos memória computacional que outros métodos existentes, características essas importantes na resolução de problemas de muitas variáveis.

Dentre os métodos de primeira ordem mais conhecidos estão o de Fletcher-Reeves (FR) e o de Polak-Ribiere (PR). Na prática o método de PR é preferido em relação ao de FR (GRIPPO \& LUCIDI, 1995), tendo sido, portanto, adotado neste trabalho.

Conforme Vanderplaats (1984), na primeira iteração do Método de Polak-Ribiere a direção de busca é tomada como o negativo do gradiente do Lagrangiano Aumentado (Equação (62), onde ite =1).

$$
\mathbf{d}^{\text {ite }}=-\nabla A\left(\mathbf{z}^{i t e}, \lambda, \rho\right)
$$

Nas outras iterações a direção de busca é conjugada de acordo com a Equação (63).

$$
\mathbf{d}^{i t e}=-\nabla A\left(\mathbf{z}^{i t e}, \lambda, \rho\right)+\beta_{i t e} \mathbf{d}^{i t e-1}
$$

Na Equação (63) $\beta_{i t e}$ é um escalar, definido pela Equação (64).

$$
\beta_{\text {ite }}=\frac{\left(\nabla A\left(\mathbf{z}^{i t e}, \lambda, \rho\right)-\nabla A\left(\mathbf{z}^{i t e-1}, \lambda, \rho\right)\right)^{T} \cdot \nabla A\left(\mathbf{z}^{i t e}, \lambda, \rho\right)}{\nabla A\left(\mathbf{z}^{i t e}, \lambda, \rho\right)^{T} \cdot \nabla A\left(\mathbf{z}^{i t e}, \lambda, \rho\right)}
$$

Devido à natureza do problema a ser resolvido, ou a imprecisões numéricas nas buscas unidimensionais, pode ser necessário reiniciar o processo (VANDERPLAATS, 1984). Isso é feito calculando a direção de busca novamente pela Equação (62) e voltando a utilizar a Equação (63) nas iterações seguintes. A reinicialização ocorre após, no máximo, $m$ iterações, onde $m$ é o menor valor entre o número de variáveis de projeto e 3 , podendo ocorrer menos iterações caso o comprimento do vetor direção de busca se aproxime de zero.

A quantidade de reinicializações no método de PR depende de um critério de parada, no qual se considera que o algoritmo convergiu se o erro definido pela Equação (65) (para cada iteração ite ) é menor que a tolerância determinada pelo usuário.

$$
\text { erro }^{i t e}=\sqrt{\left(\mathbf{z}^{i t e}-\mathbf{z}^{i t e-1}\right)^{T} \cdot\left(\mathbf{z}^{i t e}-\mathbf{z}^{i t e-1}\right)}
$$


Para cada iteração do Método do Lagrangiano Aumentado, no máximo duas iterações do Método de Polak-Ribiere são efetuadas. No entanto, o número de iterações máximas pode ser modificado a depender da complexidade do problema.

Um fluxograma do Método de Polak-Ribiere é apresentado na Figura 8.

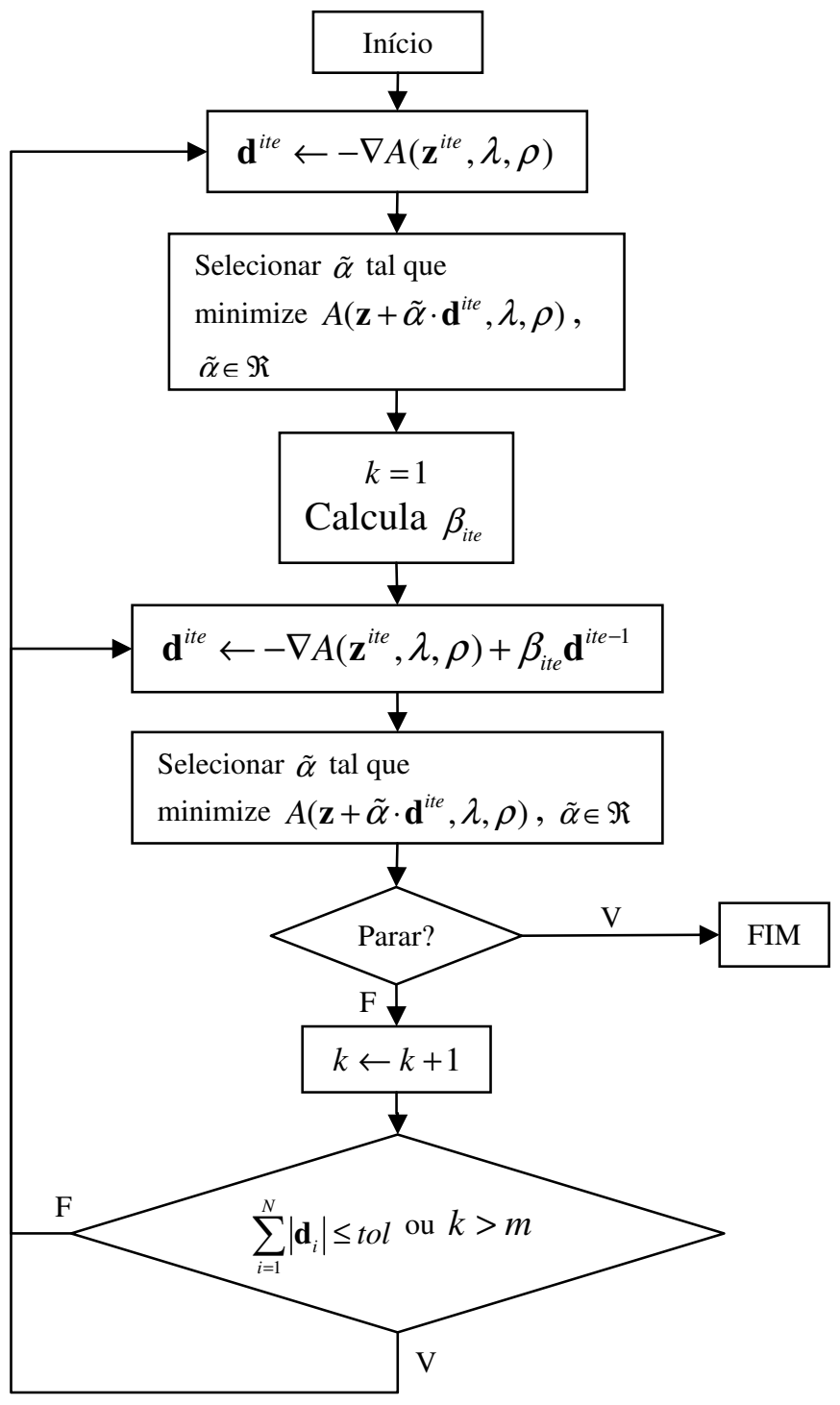

Figura 8 - Fluxograma do Método de Polak-Ribiere. 


\subsubsection{Busca Unidirecional}

Nos métodos com fundamentação matemática aplicados neste trabalho (Powell Modificado e Polak-Ribiere), a otimização é feita determinando primeiramente uma direção de busca (d) e, em seguida, realizando a chamada busca unidirecional naquela direção. Esta busca consiste em determinar $\tilde{\alpha} \in \mathfrak{R}$ que leve a um menor valor de $A(\mathbf{z}+\tilde{\alpha} \cdot \mathbf{d}, \lambda, \rho)$ e substituir o vetor $\mathbf{z}$ por $\mathbf{z}+\tilde{\alpha} \cdot \mathbf{d}$. O processo (determinação de $\mathbf{d}$, determinação de $\tilde{\alpha}$ e atualização de $\mathbf{z}$ ) se repete até que o critério de parada seja satisfeito.

Existem vários métodos de busca unidirecional. A opção por um destes métodos em particular depende das características do mesmo, bem como das características do método que define as direções de busca. A eficiência do algoritmo é definida então pelo conjunto formado pelos dois tipos de método.

Várias tentativas foram feitas na procura por métodos que apresentassem bons resultados em conjunto com os algoritmos de Powell e de Polak-Ribiere. Foram implementados o algoritmo da seção áurea, a interpolação quadrática, a interpolação cúbica (VANDERPLAATS, 1984), a regra de Armijo (RIGO, 1999) e o algoritmo de Davies, Swann e Campey (DSC), entre outros. Ao final, foi adotado um algoritmo semelhante ao DSC, cuja descrição é dada por Cordeiro (2007). Na primeira iteração de otimização, ou quando $\tilde{\alpha}$ da iteração anterior é muito pequeno, determina-se um valor inicial para $\tilde{\alpha}$. Este valor inicial ( $\tilde{\alpha}_{0}$ ) é uma fração da variação máxima possível de $\tilde{\alpha}$, de acordo com o ponto $\mathbf{z}$, a direção de busca atual e os limites das variáveis de projeto. A partir de $\tilde{\alpha}$ inicial é feita uma busca imprecisa, tentando encontrar $\tilde{\alpha}$ tal que $A(\mathbf{z}+\tilde{\alpha} \cdot \mathbf{d}, \lambda, \rho)$ seja maior que $A(\mathbf{z}, \lambda, \rho)$, dividindo este $\tilde{\alpha}$ por dois e efetuando uma interpolação quadrática (ver Cordeiro, 2007). O valor de $\tilde{\alpha}$ será o que conduz ao menor valor de $A(\mathbf{z}+\tilde{\alpha} \cdot \mathbf{d}, \lambda, \rho)$, dentre os cinco seguintes valores: os quatro últimos da busca imprecisa e o obtido pela interpolação quadrática. Durante a execução do algoritmo, os $\tilde{\alpha}$ e seus respectivos valores de Lagrangiano Aumentado são armazenados numa matriz denominada $[Q]$. A Figura 9 e a Figura 10 apresentam fluxogramas do método de busca para os métodos de Polak-Ribiere e Powell, respectivamente, partindo do valor inicial $\tilde{\alpha}_{0}$.

Constata-se a existência de três detalhes que foram implementados no sentido de melhorar (na prática) a eficiência dos algoritmos. O primeiro detalhe é a diminuição do $\tilde{\alpha}$ caso $A(\mathbf{z}+\tilde{\alpha} \cdot \mathbf{d}, \lambda, \rho)$ encontrado seja muito maior que $A(\mathbf{z}, \lambda, \rho)$, tratando-se de uma 
tentativa de obter uma melhor aproximação na interpolação quadrática. Os demais detalhes referem-se exclusivamente ao método de Powell. Trata-se da mudança do sentido da busca e da verificação do valor do Lagrangiano no sentido contrário ao definido para a busca.

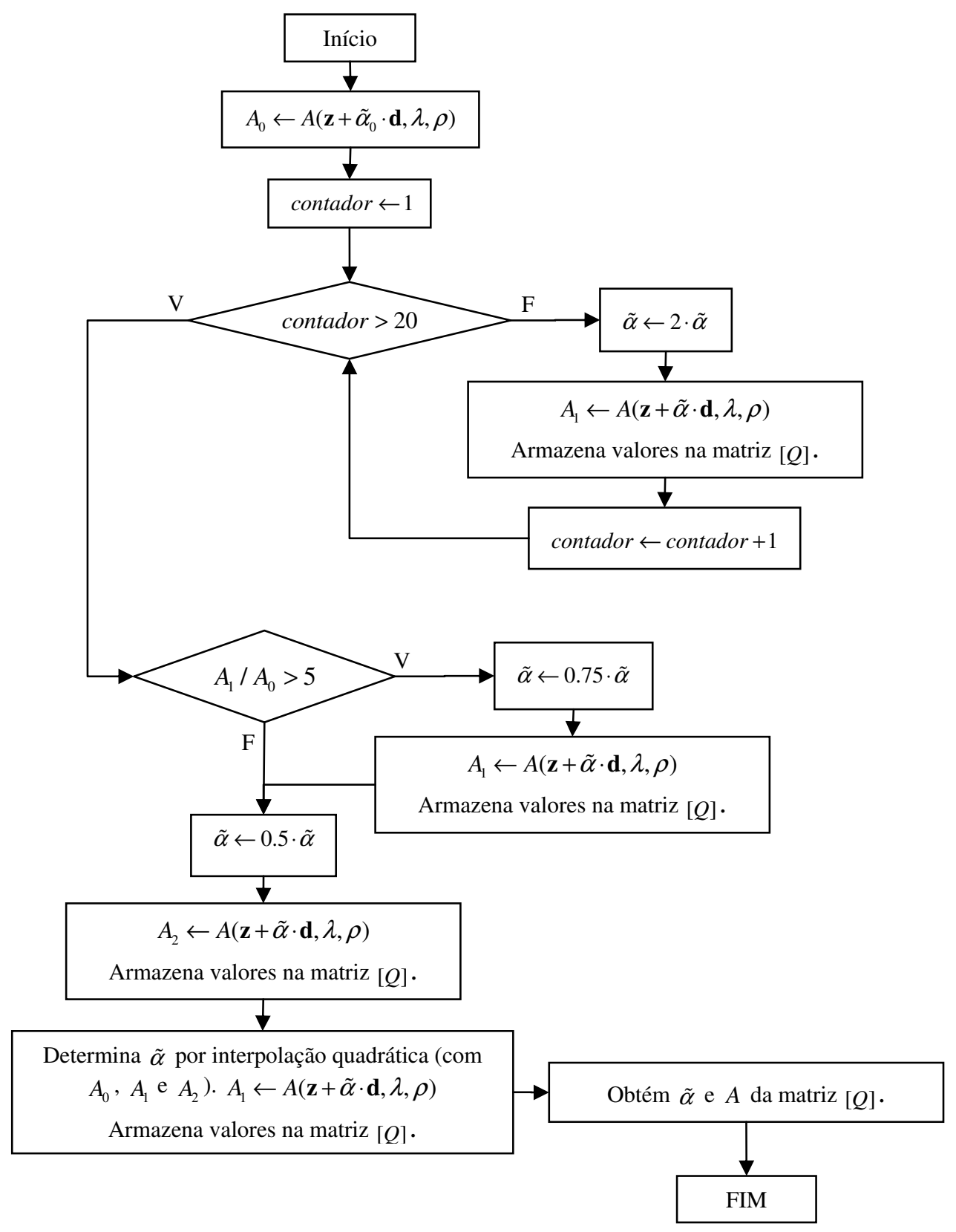

Figura 9 - Fluxograma do método de busca unidirecional para o método de Polak-Ribiere. 


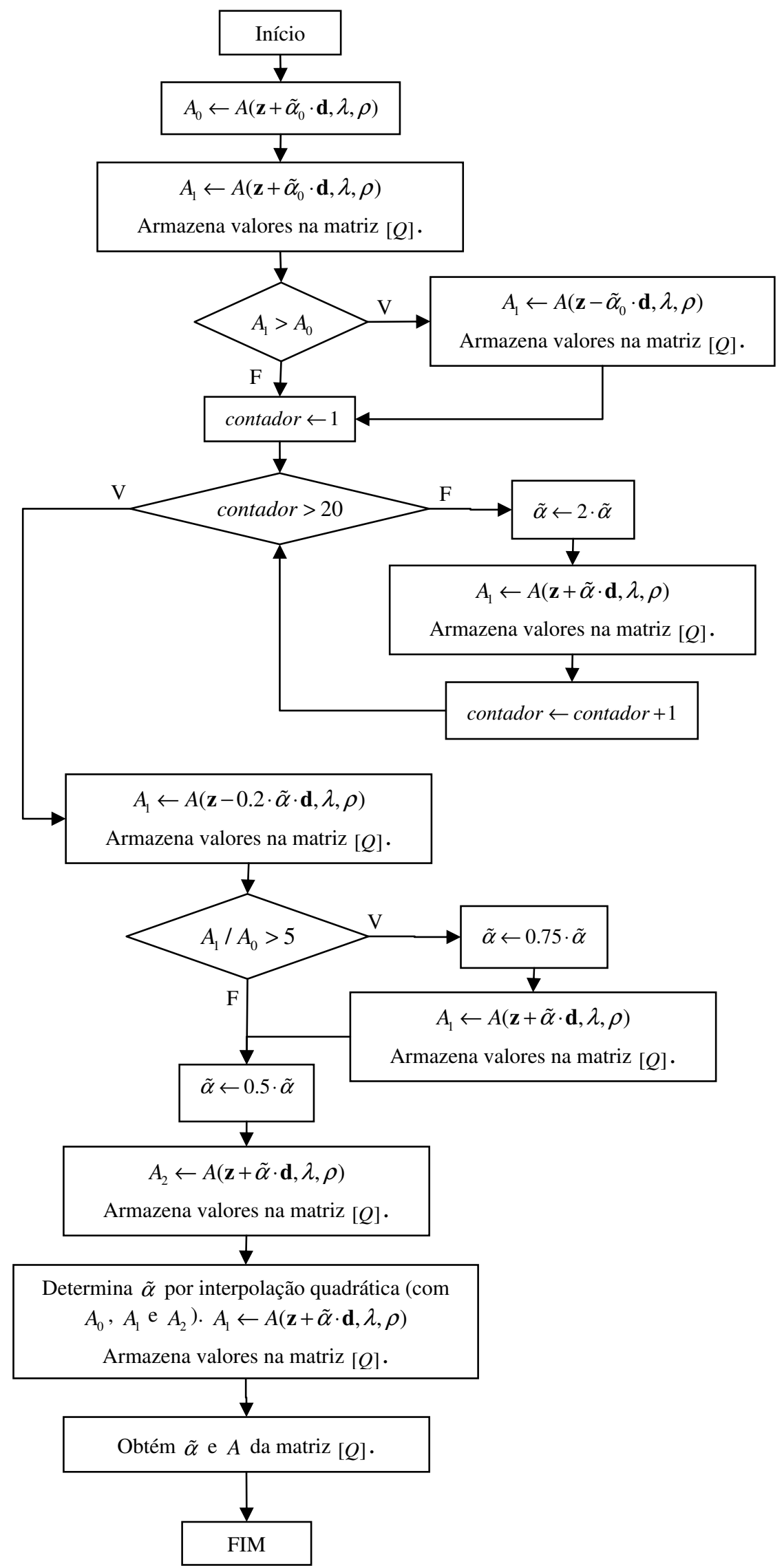

Figura 10 - Fluxograma do método de busca unidirecional para o método de Powell. 


\subsection{ESTRATÉGIAS HÍBRIDAS}

Estratégias híbridas são obtidas por meio do acoplamento de um algoritmo heurístico a um algoritmo matemático. O algoritmo heurístico é utilizado para cobrir todo o domínio, identificando a região do mínimo global. O algoritmo matemático, partindo de um ponto nesta região, chega rapidamente ao mínimo. Esta estratégia aumenta a confiabilidade em relação aos métodos matemáticos, pois há maior confiança de se chegar ao mínimo global, e aumenta a eficiência em comparação com o algoritmo heurístico puro. A seguir são descritas as estratégias desenvolvidas neste trabalho, de acordo com o algoritmo heurístico empregado.

\subsubsection{Utilizando o Algoritmo Genético}

O algoritmo genético SCE sem modificações foi aplicado para geração de um ponto inicial para os algoritmos de Powell e de Polak-Ribiere, gerando dois algoritmos híbridos, respectivamente.

A resolução de alguns problemas de otimização simples levou ao estabelecimento do número de indivíduos e da taxa de mutação como sendo iguais a $21 \cdot N$ (onde $N$ é o número de variáveis de otimização) e $20 \%$, respectivamente. A quantidade de indivíduos também é limitada por questões de memória computacional, sendo definido um máximo de 150 indivíduos.

\subsubsection{Utilizando o algoritmo PSO (PSS)}

Procurando-se um algoritmo de maior eficiência para geração do ponto inicial, várias modificações foram feitas no algoritmo PSO, dando origem ao aqui denominado PSS (Particle Swarm - Simplex).

A primeira alteração foi feita na forma como são geradas as partículas iniciais. Calcula-se a quantidade de partículas iniciais ( $N p)$ através da Equação (66). Caso o número de variáveis de projeto seja menor que um máximo denominado $\operatorname{Nmax}_{\text {hip }}$, definido de acordo com a memória computacional disponível, as primeiras $\left(2^{N}+1\right)$ amostras são geradas por um hipercubo $N$-dimensional com um ponto no centro, enquanto que as outras amostras iniciais são geradas aleatoriamente, respeitando uma distância mínima, da mesma forma que no 
método PSO. Caso o número de variáveis de projeto seja maior ou igual a $\operatorname{Nmax}_{\text {hip }}$, se houverem amostras suficientes para geração do hipercubo, o mesmo é gerado, sendo as outras amostras geradas aleatoriamente, caso contrário, todas as amostras são geradas aleatoriamente, aplicando-se a restrição de distâncias mínimas em ambos os casos.

$$
N p=\min \left[\left(2^{\text {Nmax }_{h i p}}+1\right) ;\left(2^{N}+1\right)\right]+\min [45 ; 13 \cdot N]
$$

A Figura 11 mostra o hipercubo juntamente com o ponto central para o caso tridimensional.

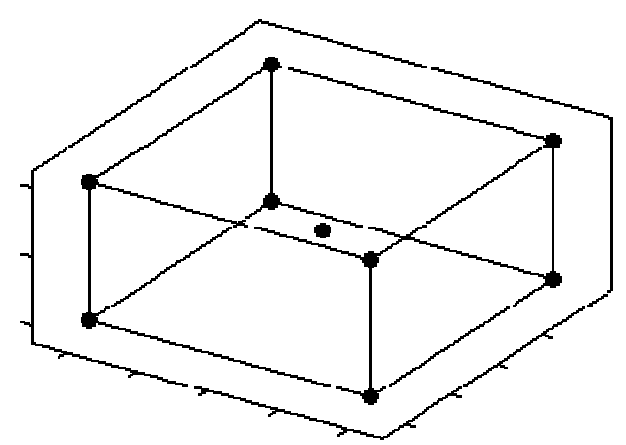

Figura 11 - Hipercubo mais o ponto central para o caso 3D.

Para garantir uma melhor distribuição das amostras geradas aleatoriamente, os limites das variáveis são transformados de forma que todas as variáveis passam a aceitar valores entre -1 e 1 , as amostras são geradas no espaço transformado e em seguida se aplica a transformação inversa nas amostras e nos limites das variáveis.

Para as $N p$ partículas da amostra inicial, calcula-se os valores do Lagrangiano Aumentado. Para levar em conta a irregularidade da função objetivo, define-se uma quantidade de amostras adicionais $\left(N p_{a d}\right)$ por meio de uma análise envolvendo o erro obtido pelo ajuste de um hiperplano a estes dados. Tanto o erro quanto o hiperplano são definidos conforme encontrado em Beck (2009). O hiperplano $(h p(\mathbf{z}))$ é definido pela Equação (67), onde $\mathbf{A}=\left\{a_{0}, \ldots, a_{N}\right\}$ são coeficientes determinados através do método dos mínimos quadrados, minimizando o erro dado pela Equação (68) em relação ao valor dos coeficientes. 


$$
\begin{gathered}
h p(\mathbf{z})=a_{0}+\sum_{i=1}^{N} a_{i} z_{i} \\
\operatorname{Erro}(\mathbf{A})=\sum_{k=1}^{N p}\left(A\left(\mathbf{z}^{k}, \lambda, \rho\right)-h p\left(\mathbf{z}^{k}\right)\right)^{2}
\end{gathered}
$$

Definindo os vetores $\mathbf{V}^{k}=\left\{1, z_{1}^{k}, \ldots, z_{N}^{k}\right\}, k=1, \ldots, N p$, obtém-se os coeficientes através da Equação (69) (FARAVELLI, 1989).

$$
\mathbf{A}=\left(\mathbf{Q}^{T} \cdot \mathbf{Q}\right)^{-1} \cdot \mathbf{Q}^{T} \cdot \mathbf{B}
$$

onde $\mathbf{Q}$ é a matriz cujas colunas são formadas pelos vetores $\mathbf{V}^{k}$ e $\mathbf{B}=\left\{A\left(\mathbf{z}^{k}, \lambda, \rho\right)\right\}_{k=1, \ldots, N p}$.

O número de amostras adicionais é igual $5 \cdot \operatorname{Erro}(\mathbf{A})$, tendo por mínimo e máximo valores 5 e 50 , respectivamente. Essas amostras são geradas aleatoriamente também levando em conta distâncias mínimas. Esta quantidade de partículas reflete um pouco a complexidade do problema.

O enxame é divido então em três grupos, com N/3-2, N/3 e N/3+2 partículas. A cada grupo são atribuídos diferentes valores dos parâmetros $c_{1}, c_{2}, w$ e $H$ do método PSO. Para um dos grupos estes valores correspondem aos definidos pelo usuário. Para os outros dois grupos os valores sofrem um desvio de $15 \%$ para mais ou para menos, respectivamente. Define-se também a média normalizada dos valores do Lagrangiano Aumentado de cada grupo ( $A_{g k}^{i t e}, k=1,2,3$ ) e a variação desta média para cada iteração ( $A_{g \text { vark }}^{\text {ite }}, k=1,2,3$ ), calculada pela Equação (70).

$$
A_{g \operatorname{var} k}^{i t e}=\frac{A_{g k}^{i t e}-A_{g k}^{i t e-1}}{A_{g k}^{i t e-1}}
$$

O passo de reflexão do método Simplex é aplicado aos grupos no sentido de encontrar os valores dos parâmetros do PSO que levem à maior variação da média normalizada, ou seja, procura-se o conjunto de parâmetros que possibilite às partículas explorarem o espaço de busca o mais rápido possível.

Como se trata da aplicação do Simplex com apenas um passo e sem verificação do ponto gerado por este passo, optou-se por incluir informações das variações médias de cada grupo, o que, na prática, levou a melhoras na eficiência do algoritmo. No lugar do passo de 
reflexão descrito pela Equação (55), tomando-se os parâmetros dos grupos em cada iteração $\left(P_{g k}^{i t e}\right)$ e supondo que o terceiro grupo é o que apresentou menor variação, o novo passo de reflexão seria definido pelas Equações (71) e (72).

$$
\begin{gathered}
\text { Centroide }=\frac{\left(P a r_{g 1}^{i t e} \cdot A_{g \text { var1 }}^{\text {ite }}+P a r_{g 2}^{i t e} \cdot A_{g \text { var } 2}^{i t e}\right)}{\left(A_{g \text { var1 } 1}^{\text {ite }}+A_{g \text { var } 2}^{i t e}\right)} \\
\operatorname{Par}_{g 3}^{i t e+1}=2 \cdot \text { centroide }-P a r_{g 3}^{i t e}
\end{gathered}
$$

Em resumo, o método PSS apresenta diferenças em relação ao PSO durante a geração do enxame de partículas e na procura pelos parâmetros do PSO que aceleram a exploração da região de busca. Por último, para fazer com que as partículas continuem a busca pela região onde se situa o ponto ótimo por mais tempo foi definido um valor mínimo para a inércia $w=0,4$, sendo este valor aplicado ao três grupos, quando necessário.

Este método (PSS) foi utilizado para obter um ponto inicial, a partir do qual é realizada a busca do ponto ótimo via métodos de Powell ou Polak-Ribiere. Estas soluções são indicadas por PSS_POWELL e PSS_PR nos exemplos do capítulo 5. 


\section{FORMULAÇÕES DE OTIMIZAÇÃO ESTRUTURAL}

Para estudar o efeito de incertezas, soluções obtidas através de três formulações distintas são utilizadas: a otimização determinística, a otimização baseada em confiabilidade e a otimização de risco baseada em confiabilidade. Neste capítulo mostra-se como as incertezas são incluídas e/ou negligenciadas nestas formulações, os efeitos resultantes desta inclusão e/ou negligência são estudados no capítulo 5.

Antes de apresentar cada uma das formulações, convém definir as funções objetivo utilizadas, a saber: custo esperado total e custo de manufatura (englobando custos de material e mão-de-obra).

O custo esperado total depende da definição do custo esperado de falha, que, por sua vez, é o produto de um custo de falha pela respectiva probabilidade de falha. Portanto, o custo esperado de falha é uma conseqüência da existência de incertezas.

Considere $\mathbf{X}$ e $\mathbf{z}$ como dois vetores de parâmetros de um sistema estrutural. O vetor $\mathbf{X}$ inclui características geométricas, propriedades de resistência de materiais e de membros estruturais, e solicitações. Alguns destes parâmetros são variáveis aleatórias por natureza; outros não podem ser definidos deterministicamente devido a diversas fontes de incerteza. Tipicamente, variáveis de resistência são representadas como variáveis aleatórias, enquanto que as ações são representadas como variáveis aleatórias ou processos estocásticos. O vetor $\mathbf{z}$ contém as variáveis do problema de otimização.

Uma consequiência das incertezas é a probabilidade de falha. Para um vetor de variáveis aleatórias $\mathbf{X}$, esta pode ser determinada pelas Equações (21) ou (35), conforme apresentado.

O custo total esperado de um sistema estrutural que apresenta risco de falha pode ser decomposto em: custo inicial ou de construção da estrutura; custo de operação; custo de inspeções e de manutenção e custo esperado de falha.

O custo esperado de falha, ou risco de falha, é o produto do custo de falha pela probabilidade de falha para cada modo de falha distinto. Isto significa um custo potencial que pode (ou não) ocorrer ao longo da vida útil da estrutura. 
Custo esperado de falha $(\mathbf{z}, \mathbf{X})=$ custo de falha $(\mathbf{z}) \times P_{f}(\mathbf{z}, \mathbf{X})$

O custo de falha inclui custos de reparo ou de substituição dos componentes danificados, custo de reconstrução completa do sistema, custo de indenizações pagas a funcionários e à terceiros em decorrência da falha, e outros. Para determinar o custo esperado de falha, é necessário quantificar o custo de falha em termos monetários, bem como determinar a probabilidade de falha. A probabilidade de falha é avaliada utilizando-se a teoria de confiabilidade estrutural.

Para cada modo de falha do sistema ou de componentes do mesmo haverá um componente de custo esperado de falha. O custo esperado total do sistema é dado pela soma de todos os termos parciais de custo, incluindo os custos esperados de falha:

$$
\begin{aligned}
\text { Custo esperado total }(\mathbf{z}, \mathbf{X}) & =\text { custo inicial }(\mathbf{z}) \\
& + \text { custo operação }(\mathbf{z}) \\
& + \text { custo inspeção e manutenção }(\mathbf{z}) \\
& +\sum_{\text {\# modos de falha }} \text { custo de falha }{ }_{i}(\mathbf{z}) \cdot P_{f}(\mathbf{z}, \mathbf{X})
\end{aligned}
$$

O custo inicial e o custo de operação aumentam diretamente com o nível de controle ou de segurança utilizados. O custo inicial ou de construção depende diretamente dos coeficientes de segurança adotados em projeto. O custo de operação aumenta com o nível de controle porque o aumento da segurança exige mais equipamentos de segurança, maior redundância de equipamentos críticos, maior conservadorismo na utilização do sistema e maiores gastos em manutenção.

O custo esperado de falha, obviamente, diminui com o aumento da segurança e do nível de controle do sistema, pois a probabilidade de falha diminui. Esta redução no custo esperado de falha com o aumento da segurança não acontece de maneira proporcional, pois a partir de determinado nível de controle ou segurança o custo esperado de falha não se reduz de maneira significativa.

\subsection{OTIMIZAÇÃO ESTRUTURAL DETERMÍNISTICA}

A otimização estrutural determinística (DDO - Deterministic Design Optimization) aborda o problema da busca por um projeto ótimo do ponto de vista econômico, visando 
redução no uso de materiais, mas não verifica diretamente o aspecto de segurança, ou seja, a estrutura é otimizada sem que sejam calculadas probabilidades de falha.

O problema de otimização consiste em:

encontrar: $\mathbf{z}^{*}$

que minimize: custo $(\mathbf{z}), \operatorname{peso}(\mathbf{z})$

sujeito a: critério de falha determinístico $\left(\sigma(\mathbf{z})<\sigma_{\text {escoamento/ruptura }} / \lambda\right)$

Na Equação (75), $\lambda$ é o coeficiente de segurança, que não é uma variável de otimização, mas sim um parâmetro do problema. A função custo inclui apenas custo (ou volume) dos materiais estruturais, podendo incluir também alguns custos de manufatura e/ou de manutenção ou reparo da estrutura.

A otimização topológica se encaixa nesta categoria, e permite encontrar a forma ótima de uma estrutura para suportar determinado carregamento. No entanto, a otimização topológica resulta em uma estrutura na qual todos os pontos estão "projetados contra o limite", ou seja, não existe capacidade de reserva ou caminhos alternativos para a solicitação caso algum ponto da estrutura falhe. A estrutura ótima resultante pode apresentar segurança comprometida, quando comparada com a estrutura original (não otimizada).

A otimização determinística baseada em método semi-probabilístico, relacionada às normas de projeto modernas de concreto e aço, leva em conta de uma forma primitiva a aleatoriedade da variável, e é a DDO adotada neste trabalho.

\subsection{OTIMIZAÇÃO BASEADA EM CONFIABILIDADE}

A otimização baseada em confiabilidade (RBDO - Reliability-Based Design Optimization), também conhecida como RBO (Reliability-Based Optimization (FRANGOPOL, 1985)) permite endereçar a questão da segurança ao impor restrições em termos de probabilidades de falha admissíveis, mas não leva em conta os custos esperados de falha. O problema de otimização consiste em:

encontrar: $\mathbf{z}^{*}$

que minimize: custo $(\mathbf{z}), \operatorname{peso}(\mathbf{z})$

sujeito a: $P_{f}(\mathbf{z}, \mathbf{X})<P_{f_{\text {admisivel }}}$ 
Em geral, o termo de custo nesta formulação é o mesmo da formulação DDO, e não inclui custos esperados de falha. A formulação RBDO permite encontrar uma estrutura que é ótima do ponto de vista mecânico e que não compromete a segurança. Entretanto, os resultados dependem da probabilidade de falha admissível usada como restrição. O balanço entre segurança e economia não é endereçado, pois a probabilidade de falha não é uma variável de otimização.

\subsection{OTIMIZAÇÃO DE RISCO ESTRUTURAL}

Ao incluir os custos esperados de falha no balanço econômico, a otimização de risco estrutural (RBRO - Reliability Based Risk Optimization) permite encontrar o ponto ótimo no balanço entre economia e segurança (BECK \& VERZENHASSI, 2008a). Esta formulação (RBRO) é complementar às formulações DDO e RBDO, no sentido de que o projeto mais econômico é também o mais eficiente do ponto de vista mecânico e consiste em:

$$
\text { encontrar: } \mathbf{z}^{*}, P_{f}^{*}\left(\mathbf{z}^{*}, \mathbf{X}\right)
$$

que minimize: custo esperado total $(\mathbf{z}, \mathbf{X})$

Trata-se de um problema de otimização sem restrições, visto que todas as "restrições" relacionadas a critérios de falha ou probabilidades de falha são incluídas na função custo esperado total.

Se a falha do sistema em questão envolve conseqüências sem mensuração monetária, como a morte de pessoas ou danos irreparáveis ao meio ambiente, então um limite inferior aceitável para a probabilidade de falha pode ser incluído no problema:

encontrar: $\mathbf{z}^{*}, P_{f}^{*}\left(\mathbf{z}^{*}, \mathbf{X}\right)$

que minimize: custo esperado $\operatorname{total}(\mathbf{z}, \mathbf{X})$

sujeito a: $P_{f}(\mathbf{z}, \mathbf{X})<P_{f_{\text {admissivel }}}$

\subsection{SOBRE AS TRÊS FORMULAÇÕES APRESENTADAS}

A Figura 12 ilustra o escopo das três formulações apresentadas. Está claro que as formulações não são equivalentes, mas complementares, cada uma endereçando uma diferente 
parte do problema. A formulação RBRO é complementar às formulações DDO e RBDO, pois a estrutura mais econômica também precisa ser a mais eficiente mecanicamente. De fato, a formulação RBRO aumenta o escopo do problema, através da consideração dos custos de falha.

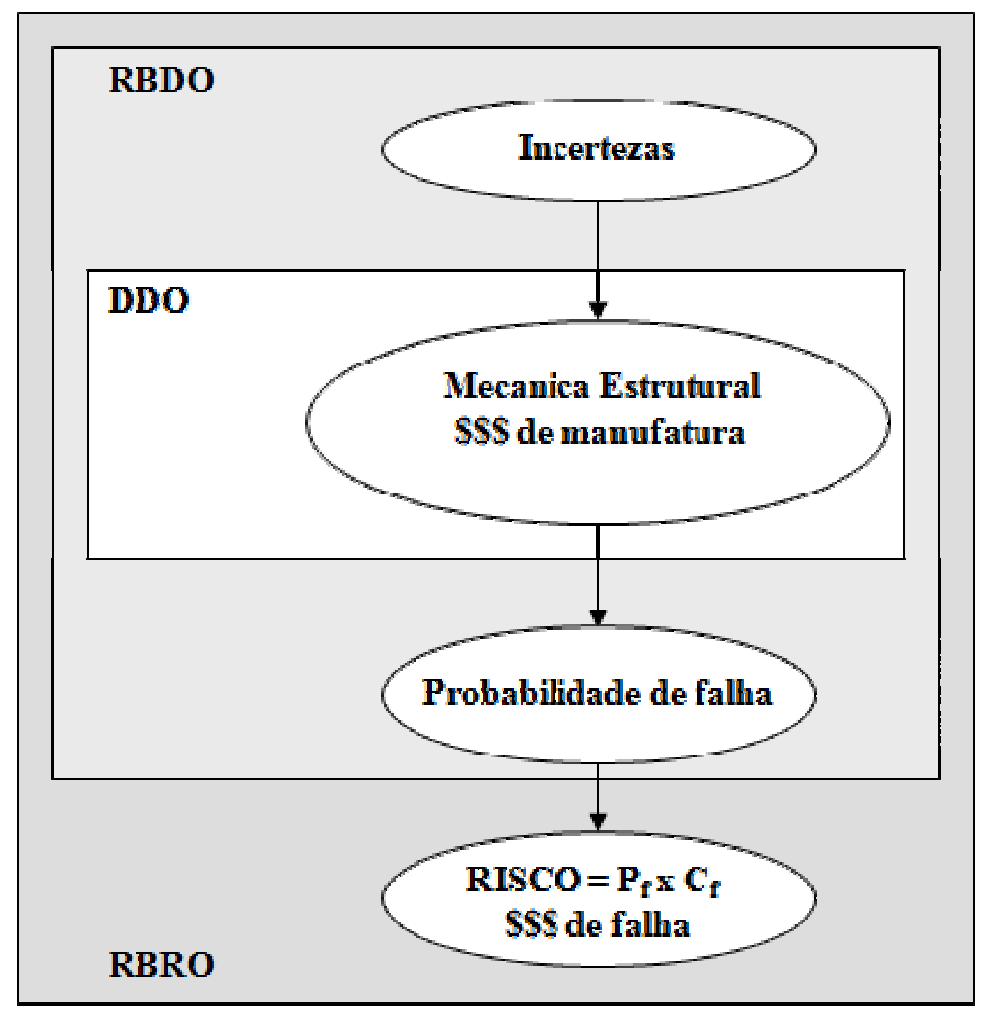

Figura 12 - Escopo das formulações de otimização estrutural.

Constata-se que, em comparação com a RBRO, a formulação DDO trata a questão da incerteza indiretamente via valores de cálculo das variáveis aleatórias. A RBDO considera a incerteza diretamente, mas negligencia uma de suas principais conseqüências: os custos de falha esperados. É importante notar que a nomenclatura usada neste trabalho não está necessariamente de acordo com a literatura: em muitos casos o nome RBDO é usado para problemas onde o custo esperado total é considerado. O presente trabalho se refere à RBDO e à RBRO como duas formulações diferentes por causa do interesse nas diferenças resultantes nas estruturas ótimas obtidas pela utilização de cada uma dessas formulações.

O objetivo deste trabalho, conforme já foi visto, é estudar os efeitos das incertezas através das diferenças entre as estruturas ótimas encontradas com essas três formulações em problemas diversos de otimização estrutural. 


\subsection{ANÁLISES COMPARATIVAS DE OTIMIZAÇÃO}

As três formulações apresentadas foram utilizadas de diferentes maneiras, no sentido de levar a uma melhor percepção dos efeitos das incertezas. Nesta seção explica-se como as formulações são aplicadas nos exemplos do capítulo 5.

É óbvio que as formulações DDO e RBDO dependem das restrições utilizadas, ou seja, da probabilidade de falha e dos coeficientes de segurança ótimos aplicados. No entanto, considera-se o procedimento descrito a seguir.

A solução RBRO é encontrada primeiro. Tendo em vista que o escopo da RBRO é mais abrangente e que inclui os escopos da DDO e RBDO, a solução geral da RBRO é usada como referência. Espera-se primeiramente que, utilizando a probabilidade de falha ótima $\left(P_{f}^{*}\right)$ como uma restrição na formulação RBDO, seja obtida a mesma estrutura ótima encontrada pela RBRO. Similarmente, espera-se que, encontrando os coeficientes de segurança ótimos pela formulação RBRO e usando-os como restrições da DDO, seja obtida, novamente, a mesma estrutura ótima. Conforme será mostrado no próximo capítulo, isto não ocorre sempre.

Com o intuito comparativo, os custos esperados totais são calculados para as estruturas ótimas encontradas em cada análise. Daí, após a análise DDO, probabilidades de falha e custos de falha são computados. Similarmente, depois da análise RBDO, custos de falha também são computados. No sentido de entender as diferenças entre os resultados, é interessante também computar e comparar a função objetivo (custo) usada nas formulações DDO e RBDO, que não incluem os custos esperados de falha.

Em aplicações reais, não se conhece a priori a probabilidade de falha ótima $\left(P_{f}^{*}\right)$ ou os coeficientes de segurança ótimos do problema. Daí, a ordem "natural" de solução para problemas reais seria a análise DDO (ou RBDO), seguida (ou não) pela otimização de risco (RBRO). Neste trabalho, verifica-se também as implicações de efetuar primeiro uma análise DDO, seguida de uma análise RBRO. Neste caso, a configuração estrutural ótima é encontrada pela análise DDO. A otimização de risco que segue mantém as proporções entre as variáveis de projeto, "aumentando" ou "diminuindo" a estrutura para determinar sua probabilidade de falha ótima (ou os coeficientes de segurança ótimos).

A Tabela 3 traz um resumo das diferentes otimizações consideradas neste trabalho e apresenta as palavras-chave que identificam cada solução. 
Tabela 3 - Resumo das otimizações comparativas.

\begin{tabular}{|c|c|c|}
\hline Palavra-chave & Descrição & Resultados \\
\hline RBRO_ref & RBRO completa, usada como referência para as outras análises. & $\begin{array}{c}\text { Configuração ótima }\left(\mathbf{z}^{*}\right), \\
\text { ótima } P_{f}^{*} \text { e coeficientes de } \\
\text { segurança ótimos } \lambda *\end{array}$ \\
\hline RBDO & RBDO, com $P_{f}^{*}$ usada como restrição. & Configuração ótima $\left(\mathbf{z}^{*}\right)$. \\
\hline DDO1 & DDO, com um único coeficiente de segurança ótimo $\lambda^{*}$ usado & Configuração ótima $\left(\mathbf{z}^{*}\right)$. \\
\hline DDOn & DDO, com $n$ coeficicientes de segurança ótimos $\lambda_{i}^{*}, i=1, \ldots, n$ & Configuração ótima $\left(\mathbf{z}^{*}\right)$. \\
\hline RBRO_esc & usados como restrições, para $n$ equações de estado limite. & \\
\hline & DDO, seguida por uma RBRO escalonada, que mantém \\
& proporções, mas busca a ótima $P_{f}^{*} \cdot$ & $\begin{array}{l}\text { Configuração ótima }\left(\mathbf{z}^{*}\right) \text { pela } \\
\text { DDO e } P_{f}^{*} \text { ótima pela RBRO. }\end{array}$ \\
\hline
\end{tabular}




\section{EXEMPLOS NUMÉRICOS}

Para que as comparações sejam válidas, é necessário que o ótimo global seja encontrado em cada problema. Com este intuito, os vários métodos de otimização implementados são aplicados com diferentes sementes para geração aleatória de pontos iniciais, até que se tenha certeza do ótimo global.

A seguir são apresentados cinco exemplos numéricos nos quais se aplicam todas as análises comparativas de otimização descritas anteriormente. Os resultados obtidos são expostos em tabelas e gráficos. Algumas conclusões e discussões são levantadas baseando-se nas estruturas ótimas (globais) encontradas.

\subsection{SISTEMA ESTRUTURAL: TRÊS BARRAS EM PARALELO}

Este problema envolve um sistema estrutural em paralelo composto por três barras, conforme pode ser visto na Figura 13, constituídas de diferentes materiais e submetidas a um carregamento $P$.

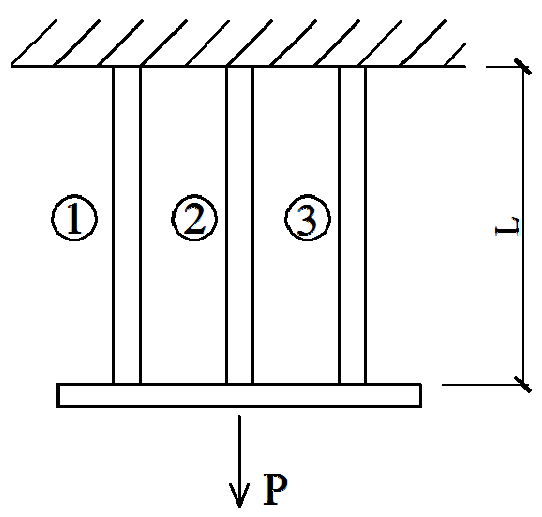

Figura 13 - Sistema estrutural composto por três barras em paralelo.

A resistência média é a mesma para os materiais das três barras, mas um coeficiente de variação (c.v. ) é adotado para cada material, refletindo diferentes controles de qualidade. O custo de material também é diferente, conforme mostrado na Tabela 4. 
Tabela 4 - Resumo dos dados das VAs do problema de três barras em paralelo.

\begin{tabular}{|c|c|c|c|c|c|}
\hline Variável Aleatória & Variações & Distribuição & Média & C.v. & Custo \\
\hline Carregamento $(P)$ & - & normal & $75 \mathrm{kN}$ & $15 \%$ & - \\
\hline $\begin{array}{c}\text { Módulo de } \\
\text { elasticidade }(E)\end{array}$ & - & normal & $200 \mathrm{GPa}$ & $3 \%$ & - \\
\hline \multirow{2}{*}{$\begin{array}{c}\text { Resistência do } \\
\text { material }\left(f_{y}\right)\end{array}$} & material 1 & lognormal & $250 \mathrm{MPa}$ & $15 \%$ & 1 (referência) \\
\cline { 2 - 6 } & material 2 & lognormal & $250 \mathrm{MPa}$ & $10 \%$ & 1,05 \\
\cline { 2 - 6 } & material 3 & lognormal & $250 \mathrm{MPa}$ & $5 \%$ & 1,10 \\
\hline
\end{tabular}

As variáveis de otimização deste problema são a área da seção transversal de cada barra ( $\left.A_{i}, i=1,2,3\right)$ e o número de barras (máximo três barras). Se o algoritmo de otimização reduz a área de alguma barra para menos que $0,1 \mathrm{~cm}^{2}$, a barra é considerada não necessária, e eliminada. Daí, tem-se que $\mathbf{z}=\left\{A_{1}, A_{2}, A_{3}\right\}$.

A única restrição determinística de projeto é dada pela Equação (79), na qual $\lambda$ é o coeficiente de segurança e $f_{y i}$ é a resistência do i-ésimo material. Para análises de confiabilidade, $\lambda=1$.

$$
\sum_{i}\left(f_{y i} \cdot A_{i}\right) \geq P \cdot \lambda
$$

O comportamento dos materiais depende do coeficiente de resistência residual $(\eta)$, podendo apresentar comportamento elástico (frágil), com $\eta=0$, perfeitamente elasto-plástico, com $\eta=1$, ou algum comportamento entre estes dois, para $0<\eta<1$, de acordo com a formulação de Hendawi \& Frangopol (1994) e conforme pode ser visto na Figura 14.

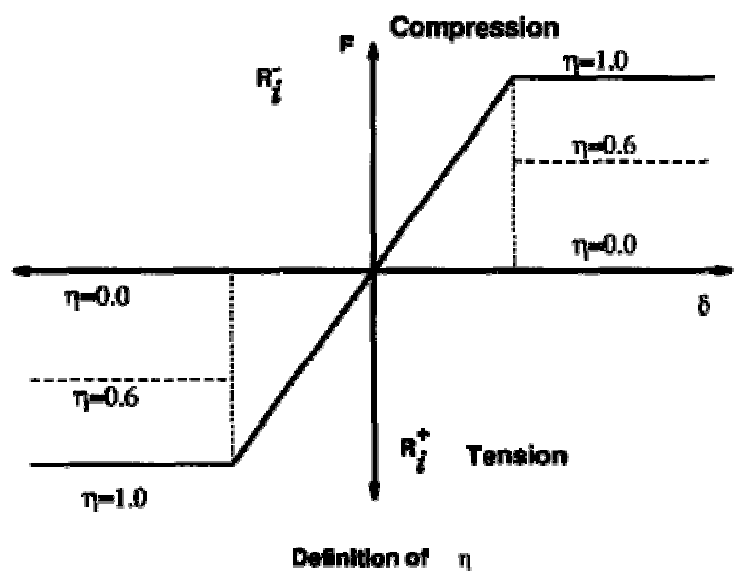

Figura 14 - Definição de $\eta$ (FONTE: Hendawi \& Frangopol (1994)). 
A rigidez da i-ésima barra é dada por $K_{i}=E A_{i} / L$, onde $L$ é o comprimento da barra, tido como unitário. O fator de carregamento ( $R S F$ - Resistance Sharing Factor) para a barra 1, dado que nenhuma barra foi eliminada ou falhou, é dado por $R S F_{1}=K_{1} / K_{S}$, onde $K_{S}$ é a rigidez total do sistema, dada por $K_{S}=K_{1}+K_{2}+K_{3}$. Dessa forma, a equação de estado limite utilizada para calcular a probabilidade de que a barra 1 falhe, dado que nenhuma outra barra falhou, é a seguinte:

$$
g_{1}\left(A_{1}\right)=f_{y 1} \cdot A_{1}-R S F_{1} \cdot P
$$

A falha da primeira barra, seja ela a barra 1, 2 ou 3, é considerada uma falha de serviço, visto que as barras remanescentes continuarão suportando o carregamento.

A partir da falha da barra 1, o fator de carregamento para a segunda barra é dado por $R S F_{2}=K_{2} / K_{S}$, onde $K_{S}$ passa a ser calculado por $K_{S}=K_{2}+K_{3}$. A equação de estado limite para a falha da segunda barra, dado que a primeira barra falhou, é dada por:

$$
g_{2}\left(A_{1}, A_{2}\right)=f_{y 2} \cdot A_{2}-R S F_{2} \cdot\left(P-\eta \cdot f_{y 1} \cdot A_{1}\right)
$$

Esta falha também é considerada falha de serviço, pois a terceira barra continuará suportando o carregamento. $\mathrm{O}$ termo $\eta \cdot f_{y 1} \cdot A_{1}$ dá a resistência residual da barra 1 , que é nula quando o material é frágil.

A probabilidade da falha última para esta sequiência de falha é dada pela probabilidade que a barra 3 falhe, dado que as outras duas barras já falharam. A equação de estado limite para este caso é:

$$
g_{3}\left(A_{1}, A_{2}, A_{3}\right)=f_{y 3} \cdot A_{3}-\left(P-\eta \cdot\left(f_{y 1} \cdot A_{1}+f_{y 2} \cdot A_{2}\right)\right)
$$

De forma similar, todas as seqüências de falha possíveis são consideradas. As Equações (80) a (82) são utilizadas para calcular as correspondentes probabilidades, com a devida mudança nos índices. Se a j-ésima seqüência de falha é denotada por $S_{j}$, a probabilidade de colapso do sistema é dada pela Equação (83). 


$$
\left.P_{f}\right|_{\text {sistema }}=P\left[\bigcup_{j} S_{j}\right]
$$

A função objetivo para as formulações DDO e RBDO é a função custo de "manufatura", que inclui custos de materiais e mão-de-obra. O custo de materiais $\left(C_{\text {mat }}\right)$ é dado pela Equação (84), onde $\$_{\text {mat }}$ é o custo do material 1 (por unidade de peso), $\rho$ é a densidade do material, 1,05 e 1,10 são os fatores relativos de custo para os materiais 2 e 3, respectivamente.

$$
C_{\text {mat }}\left(A_{1}, A_{2}, A_{3}\right)=\$_{\text {mat }} \cdot \rho \cdot L \cdot\left(A_{1}+1,05 \cdot A_{2}+1,10 \cdot A_{3}\right)
$$

Um custo fixo de referência, $C_{r e f}$, é calculado a partir de uma otimização determinística inicial com coeficiente de segurança central $\lambda=2,0$. Este custo é obtido como sendo $C_{r e f}=5,5 \cdot \$_{m a t}$. O custo de mão-de-obra $\left(C_{\text {work }}\right)$ passa a ser dado pela Equação (85), na qual $N_{b a r s}$ é o número de barras presentes (descontando as que apresentam área menor ou igual a $\left.0,1 \mathrm{~cm}^{2}\right)$.

$$
C_{\text {work }}\left(A_{1}, A_{2}, A_{3}\right)=C_{\text {ref }}+0,2 \cdot C_{\text {mat }}\left(A_{1}, A_{2}, A_{3}\right)+\left(N_{\text {bars }}\left(A_{1}, A_{2}, A_{3}\right)-1\right) \cdot 0,05 \cdot C_{\text {ref }}
$$

O primeiro termo na Equação (85) é um custo fixo de mão-de-obra, o segundo termo uma fração do custo de materiais (parcela de mão-de-obra proporcional à quantidade de materiais) e o último termo é uma penalidade pela complexidade, isto é, considerando que um sistema com três barras em paralelo é mais difícil de ser executado que um sistema com uma única barra, por exemplo.

A função custo de manufatura é dada então pela Equação (86).

$$
C M\left(A_{1}, A_{2}, A_{3}\right)=1,2 \cdot C_{\text {mat }}\left(A_{1}, A_{2}, A_{3}\right)+C_{r e f} \cdot\left[1+0,05 \cdot\left(N_{\text {bars }}\left(A_{1}, A_{2}, A_{3}\right)-1\right)\right]
$$

A função objetivo para a formulação RBRO é o custo esperado total, que é a soma dos custos de manufatura e dos custos esperados de falha. Assume-se que o custo de falha de serviço é igual ao $C_{r e f}$, e o custo da falha última da estrutura (ou colapso da mesma) é dado por $10 \cdot C_{r e f}$. Se $E_{i}$ denota o evento em que a i-ésima barra falhou, então o custo esperado total é dado pela Equação (87). 


$$
\operatorname{CET}\left(A_{1}, A_{2}, A_{3}, \mathbf{X}\right)=C M\left(A_{1}, A_{2}, A_{3}\right)+C_{r e f} \cdot \sum_{i=1}^{N_{\text {bars }}} P\left[E_{i}\right]+C_{r e f} \cdot \sum_{j=1, j \neq i}^{N_{\text {bars }}} \cdot P\left[E_{j} \mid E_{i}\right]+\left.10 \cdot C_{r e f} \cdot P_{f}\right|_{s y s t e m}
$$

Soluções são obtidas para três variações do problema, conforme a Tabela 5.

Tabela 5 - Variações do problema de três barras em paralelo.

\begin{tabular}{|c|c|c|}
\hline Variação & Material Frágil/dúctil $(\eta)$ & Custo de Falha de serviço \\
\hline$(1 \mathrm{~A})$ & 0 & $C_{r e f}$ \\
\hline$(1 \mathrm{~B})$ & 1 & $C_{r e f}$ \\
\hline$(1 \mathrm{C})$ & 1 & 0 \\
\hline
\end{tabular}

Os resultados para o problema (1A), com material frágil e incluindo custos de falha de serviço, são mostrados na Tabela 6.

Tabela 6 - Resultados para o problema (1A), áreas em $\mathrm{cm}^{2}$.

\begin{tabular}{|c|c|c|c|c|}
\hline Variação & Análise & A1 & A2 & A3 \\
\hline \multirow{4}{*}{ (1A) } & RBRO_ref & 0 & 0 & 4,35745 \\
\cline { 2 - 5 } & RBDO & 0 & 0,1 & 3,80354 \\
\cline { 2 - 5 } & DDO 1 & 0 & 0 & 4,35745 \\
\cline { 2 - 5 } & RBRO_esc & 0 & 0 & 4,357 \\
\hline
\end{tabular}

Para este problema, RBRO e DDO convergem para um sistema com uma única barra, constituída pelo material de melhor qualidade (material 3). Dessa forma, custos de manufatura e custos esperados totais são idênticos, incluindo para a solução com RBRO_esc (DDO seguida por RBRO). A solução pela formulação RBDO converge para duas barras, feitas dos materiais 2 e 3 , e tais que $A_{3}>A_{2}$. Na Figura 15 pode-se observar que a formulação RBDO conseguiu reduzir custos de manufatura, mas comprometeu os custos esperados totais. As razões para este comportamento serão esclarecidas mais à frente. 


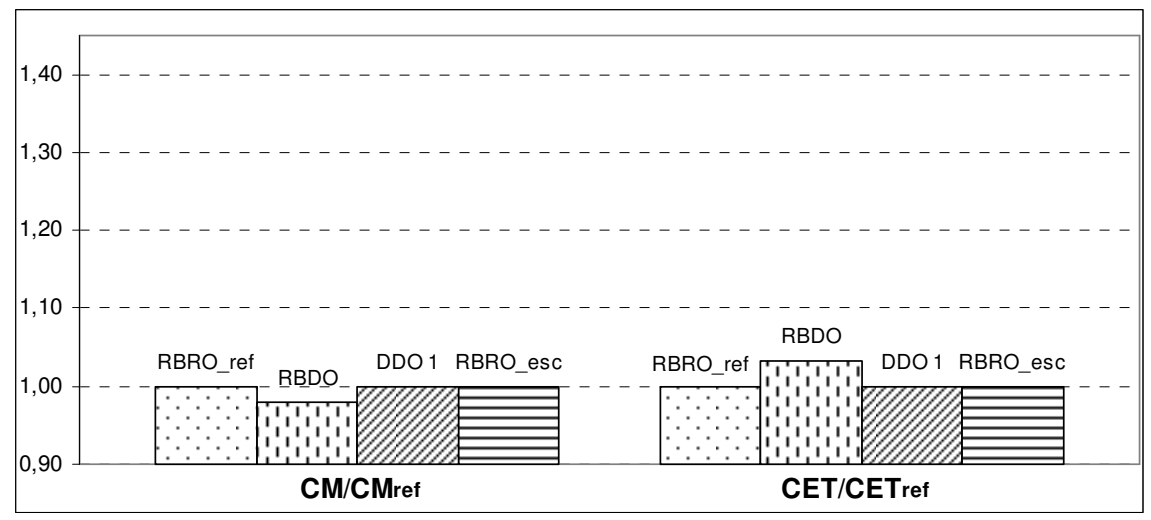

Figura 15 - Comparação de custos ótimos - Problema (1A).

A Tabela 7 mostra os resultados encontrados para o problema (1B), para materiais dúcteis.

Tabela 7 - Resultados para o problema (1B), áreas em $\mathrm{cm}^{2}$.

\begin{tabular}{|c|c|c|c|c|}
\hline Variação & Análise & A1 & A2 & A3 \\
\hline \multirow{4}{*}{ (1B) } & RBRO_ref & 0 & 4,0740 & 0,1075 \\
\cline { 2 - 5 } & RBDO & 0 & 2,5220 & 1,5728 \\
\cline { 2 - 5 } & DDO 1 & 0 & 0 & 3,8472 \\
\cline { 2 - 5 } & RBRO_esc & 0 & 0 & 4,3575 \\
\hline
\end{tabular}

Para este problema, a solução de referência (pela RBRO) é um sistema de duas barras, constituídas pelos materiais 2 e 3 , com $A_{2} \gg A_{3}$. A segunda barra tem aproximadamente a mínima área considerável e é feita com o melhor material, o que leva a um caminho de carga alternativo no caso de falha da primeira barra. Para materiais dúcteis, esta solução com duas barras é mais barata que a solução com uma única barra obtida no problema (1A). Nenhuma das formulações alternativas atingiu o ótimo obtido pela solução de referência. A formulação DDO, bem como a RBRO_esc, encontraram uma solução com uma barra apenas, feita do melhor material, tal como no problema (1A). Dessa forma, observa-se que a formulação determinística não leva em conta o comportamento pós-falha do material, nem seus efeitos na confiabilidade do sistema. A formulação RBDO neste problema levou a um sistema com duas barras, mas com $A_{2}>A_{3}$. Esta solução não é a mesma que a da RBRO_ref, pois as áreas das barras não são muito diferentes (não há uma barra com área mínima). Na Figura 16 se observa que a solução RBDO não afeta os custos de manufatura, mas aumenta os custos esperados totais. Esta diferença na solução ótima e também as 
diferenças observadas para o problema (1A) podem ser explicadas pelo custo de falha de serviço, tal explicação é apresentada no próximo parágrafo.

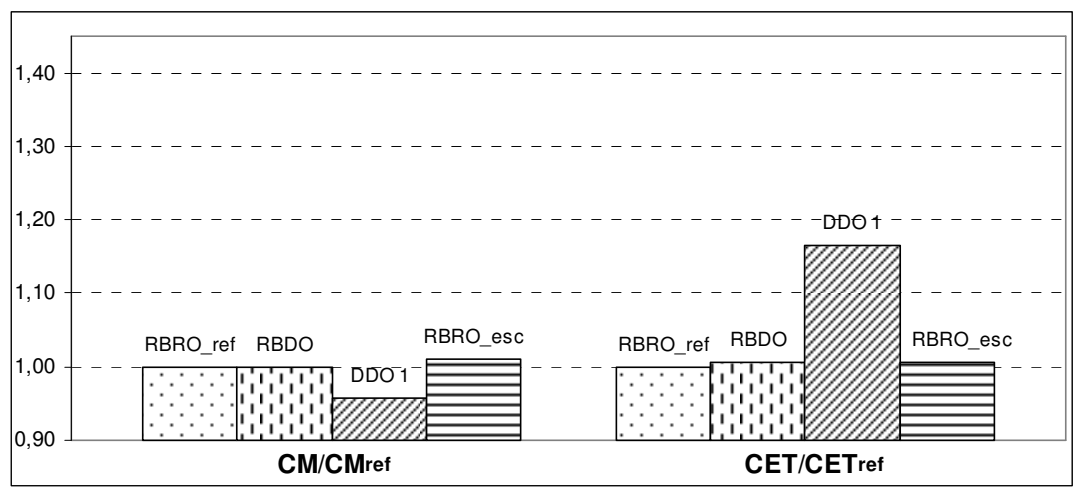

Figura 16 - Comparação de custos ótimos - Problema (1B).

O problema (1C) considera materiais dúcteis mas sem custos de falha de serviço. A Tabela 8 apresenta os resultados obtidos para este problema, enquanto que a Figura 17 mostra os custos relacionados.

Tabela 8 - Resultados para o problema (1C), áreas em $\mathrm{cm}^{2}$.

\begin{tabular}{|c|c|c|c|c|}
\hline Variação & Análise & A1 & A2 & A3 \\
\hline \multirow{4}{*}{ (1C) } & RBRO_ref & 0 & 3,0394 & 0,8887 \\
\cline { 2 - 5 } & RBDO & 0 & 3,0395 & 0,8885 \\
\cline { 2 - 5 } & DDO 1 & 0 & 0 & 3,6787 \\
\cline { 2 - 5 } & RBRO_esc & 0 & 0 & 4,3575 \\
\hline
\end{tabular}

Nesta figura se observa que a solução RBDO agora está de acordo com a solução de referência (RBRO), que é idêntica à solução de referência obtida para o problema (1B) - uma barra de material 2 e uma barra com área mínima de material 3. Assim, constata-se que a formulação RBDO respeita a restrição da probabilidade de falha do sistema, mas não leva em conta os custos associados à falha de serviço. Para que a formulações se tornassem equivalentes, seria necessário especificar uma restrição de probabilidade de falha ótima para cada modo de falha de serviço e para cada modo de falha último. 


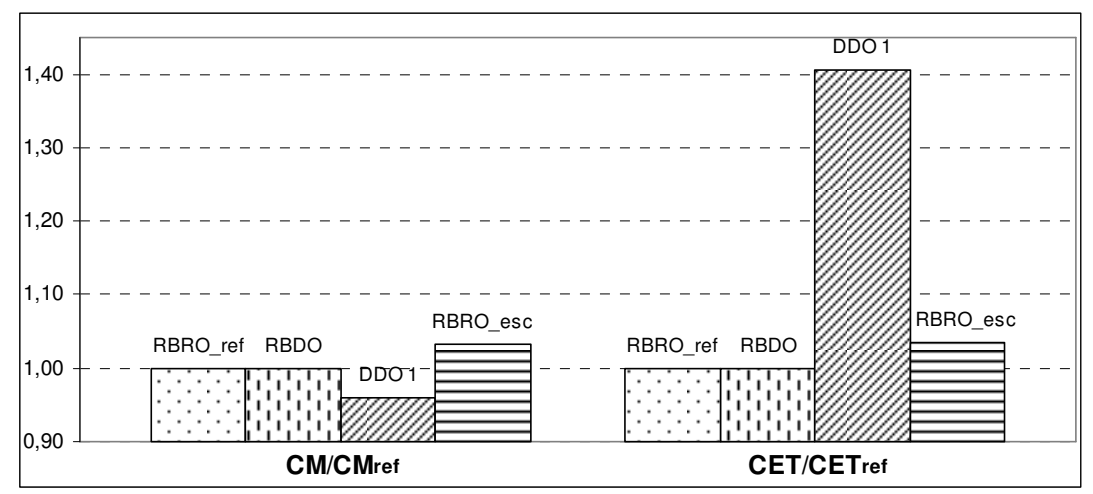

Figura 17 - Comparação de custos ótimos - Problema (1C).

Na Figura 17 também se constata que a solução ótima da formulação DDO (barra única de melhor material) leva a um custo esperado total muito alto. A formulação DDO é capaz de encontrar um ótimo que reduz os custos de manufatura, mas que resulta em um custo esperado total muito grande. A formulação RBRO_esc, que tenta melhorar a solução DDO encontrando o coeficiente de segurança ótimo, consegue reduzir os custos esperados totais, mas não atinge os resultados obtidos pela formulação RBRO mais geral.

\subsection{SISTEMA ESTRUTURAL: TRÊS BARRAS EM SÉRIE}

Este problema é baseado no sistema com três barras em paralelo (as mesmas barras feitas dos mesmos materiais), mas neste caso as barras estão conectadas em série (Figura 18).

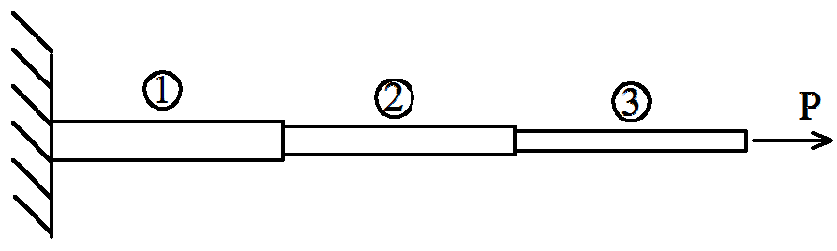

Figura 18 - Sistema estrutural composto por três barras em série.

Para este problema as quatro formulações levaram aos mesmos resultados quando da aplicação na formulação DDO com três diferentes coeficientes de segurança ótimos, ou seja, um coeficiente para a equação de estado limite de cada barra. Utilizando apenas um coeficiente (o maior entre os três valores ótimos), os resultados levaram a um pequeno aumento nos custos de manufatura da DDO.

O mesmo problema foi resolvido para três valores diferentes de correlação $(\rho)$ entre as resistências dos materiais, $\rho=0, \rho=0,5$ e $\rho=1$. O aumento da correlação levou a 
maiores probabilidades de falha, no entanto, as diferenças (da ordem de $1 \times 10^{-4}$ ) dessas probabilidades foram desprezíveis quando comparadas aos outros custos presentes. Valores mais elevados do custo de falha da estrutura fariam com que essas diferenças passassem a ser mais significativas, de forma que existem casos em que a correlação entre as variáveis de resistência pode ter grande impacto na escolha de um projeto ótimo por métodos probabilísticos.

\subsection{TRELIÇA PLANA}

Este problema é baseado em Fox (1973) e ilustrado na Figura 19.
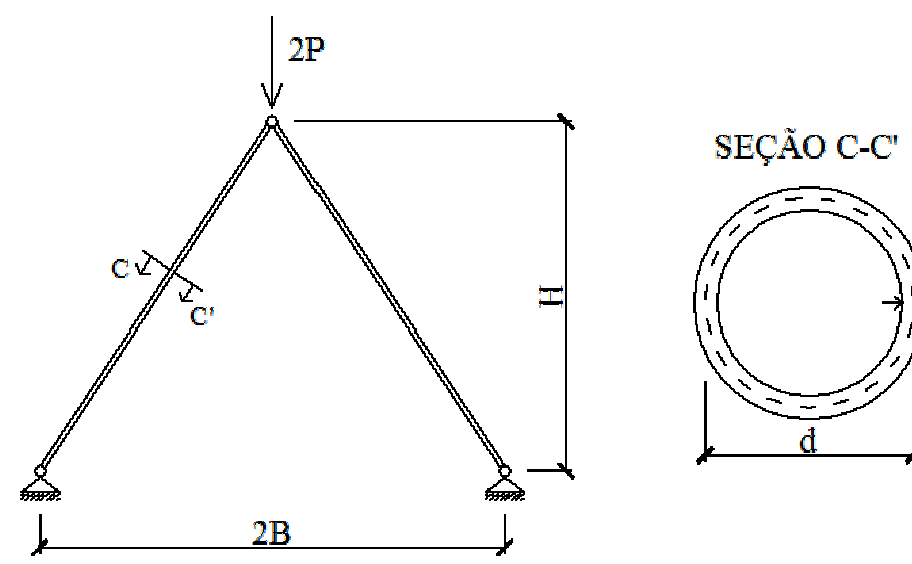

Figura 19 - Treliça Plana.

Trata-se de uma treliça plana composta por dois tubos. $\mathrm{O}$ vão $2 B$ tem seu valor fixado em $2 B=6 m$ e as variáveis de otimização são a altura $H$, o diâmetro médio $d$ e a espessura dos tubos $t$, daí, $\mathbf{z}=\{H, d, t\}$.

A seguinte restrição é imposta às variáveis $d$ e $t$ :

$$
D_{\min } \leq \frac{d}{t} \leq D_{\max }
$$

para que a espessura não possa ser maior que metade do diâmetro $\left(D_{\min }=2\right)$ e para evitar instabilidades locais das paredes dos tubos $\left(D_{\max }=10\right)$.

As variáveis aleatórias consideradas neste problema são apresentadas na Tabela 9. 
Tabela 9 - Resumo dos dados das VAs do problema da treliça plana.

\begin{tabular}{|c|c|c|c|}
\hline Variável Aleatória & Distribuição & Média & C.v. \\
\hline Carregamento $(P)$ & normal & $337 \mathrm{kN}$ & $10 \%$ \\
\hline Módulo de elasticidade $(E)$ & normal & $30 \mathrm{GPa}$ & $3 \%$ \\
\hline Resistência do material $\left(f_{y}\right)$ & lognormal & $105 \mathrm{MPa}$ & $7 \%$ \\
\hline
\end{tabular}

A tensão de compressão nos tubos ( $\sigma$ ) é dada pela Equação (89), e, aproximando a área da seção transversal dos mesmos por $A=\pi \cdot d \cdot t$, a tensão crítica de flambagem de Euler $\left(\sigma_{E}\right)$ é obtida através da Equação (90).

$$
\begin{gathered}
\sigma(H, d, t)=\frac{P}{\pi t} \frac{\left(B^{2}+H^{2}\right)^{1 / 2}}{H d} \\
\sigma_{E}(H, d, t)=\frac{\pi^{2} E}{8} \frac{\left(d^{2}+t^{2}\right)}{\left(B^{2}+H^{2}\right)}
\end{gathered}
$$

Duas equações determinísticas de projeto são consideradas, Equações (91) e (92). A primeira delas representa plastificação da seção transversal, a segunda se relaciona à flambagem. Nestas Equações $\lambda_{i}, i=1,2$, são os coeficientes de segurança.

$$
\begin{gathered}
g_{1}\left(\lambda_{1}, H, d, t\right)=f_{y}-\lambda_{1} \cdot \sigma(H, d, t) \\
g_{2}\left(\lambda_{2}, H, d, t\right)=\sigma_{E}(H, d, t)-\lambda_{2} \cdot \sigma(H, d, t)
\end{gathered}
$$

Neste problema, por simplificação, valores médios das variáveis aleatórias são utilizados nas equações determinísticas de projeto. Estas equações são também as equações de estado limite do problema, para $\lambda_{1}=\lambda_{2}=1,0$.

O custo de manufatura é calculado seguindo o exemplo 5.1. Um custo unitário de material é considerado, e fixa-se um custo de referência a partir de uma otimização determinística inicial com $\lambda_{1}=\lambda_{2}=2,0$, resultando $C_{r e f}=10 \cdot \$_{\text {mat }}$. O custo de mão-de-obra é composto de uma parte fixa (igual ao $C_{r e f}$ ), mais um termo proporcional ao custo de material (igual a 20\% deste). O custo final de manufatura é calculado então através da Equação (93).

$$
C M(H, d, t)=\$_{\text {mat }} \cdot\left[1,2 \cdot \rho \cdot 2 \pi \cdot d \cdot t \cdot\left(B^{2}+H^{2}\right)^{1 / 2}+10\right]
$$


Neste problema, uma distinção é introduzida entre os estados limites últimos e de serviço. Escoamento da seção transversal é considerado falha de serviço, com custo de falha $C_{f 1}=5 \cdot C_{r e f}$. Flambagem é considerada falha última, com custo de falha igual a $C_{f 2}=20 \cdot C_{r e f}$. Assim, o custo esperado total é dado por:

$$
C E T(H, d, t, \mathbf{X})=C M(H, d, t)+C_{r e f} \cdot\left(C_{f 1} \cdot P\left[g_{1} \leq 0\right]+C_{f 2} \cdot P\left[g_{2} \leq 0\right]\right)
$$

A Tabela 10 mostra os resultados obtidos para este problema. A Figura 20 compara os resultados em termos de custos de manufatura e custos esperados totais.

Tabela 10 - Resultados (em metros) para o problema da treliça plana.

\begin{tabular}{|c|c|c|c|}
\hline Análise & d & H & t \\
\hline RBRO_ref & 0,1755 & 1,6313 & 0,0176 \\
\hline RBDO & 0,1746 & 1,6894 & 0,0175 \\
\hline DDO 1 & 0,1762 & 1,6145 & 0,0176 \\
\hline DDO 2 & 0,1755 & 1,6313 & 0,0176 \\
\hline RBRO_esc & 0,1739 & 1,8624 & 0,0174 \\
\hline
\end{tabular}

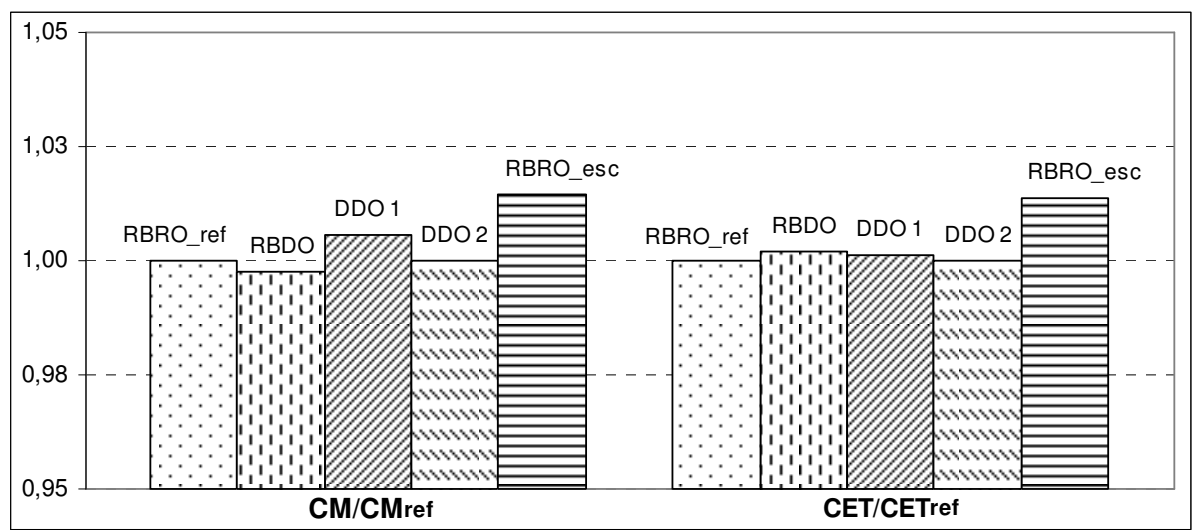

Figura 20 - Comparação de custos ótimos para o problema da treliça plana.

A configuração ótima encontrada pela solução de referência (RBRO) é $H=1,632 m$, $d=0,1755 m$ e $t=0,0176 m$. Utilizando os dois coeficientes de segurança ótimos na solução $\mathrm{DDO}_{2}$, a mesma configuração ótima é obtida. Entretanto, se a análise DDO é feita com apenas um coeficiente de segurança (o maior entre $\lambda_{1}$ e $\lambda_{2}$ ), então a configuração ótima não é atingida e há um aumento no custo de manufatura e no custo esperado total. Isto significa que a margem extra de segurança obtida em um dos estados limite não aumenta a segurança, 
enquanto penaliza custo de materiais. A otimização de risco mantendo proporções, obtida pela aplicação da formulação RBRO após uma análise DDO, também é incapaz de reproduzir a configuração estrutural ótima. A DDO aplicada sem coeficientes de segurança ótimos atingiu uma dada configuração e a tentativa de otimizar a probabilidade de falha desta configuração mantendo suas proporções não levou à melhor configuração possível.

A formulação RBDO também foi incapaz de reproduzir a configuração estrutural ótima para este problema. A probabilidade de falha ótima (do sistema), encontrada pela solução de referência é aplicada como restrição na análise RBDO, entretanto, esta formulação leva a uma outra configuração, que respeita a probabilidade de falha do sistema aceitável e reduz custos de manufatura, mas encontra outro balanceamento entre os dois modos de falha. Não levando em conta distinções de custo entre os dois modos de falha, a RBDO compromete o custo esperado de falha. Assim, para que a formulação RBDO atinja o mesmo resultado da RBRO, uma probabilidade de falha ótima para cada modo de falha deve ser especificada. Tal afirmação é confirmada, por exemplo, quando os custos de falha dos dois modos de falha são os mesmos, caso no qual a RBDO encontra o mesmo resultado da RBRO (referência).

\subsection{COLUNA DE AÇO EM PERFIS U CONTRAVENTADOS}

A Figura 21 apresenta um sistema estrutural constituído por dois elementos em perfil $U 200 \times 75 \times 2,65$ de comprimento total $L$, na vertical, contraventados por elementos de aço de perfil $L 30 \times 2,25$. O sistema estrutural é submetido a um carregamento $P$.

As variáveis de otimização são a distância entre os perfis $U$, designada por $b$ (distância entre os centróides) e o número de contraventamentos $(N=L / d)$. As variáveis aleatórias são o carregamento $P$, o módulo de elasticidade e a tensão de escoamento do material, tal como apresentado na Tabela 11. 


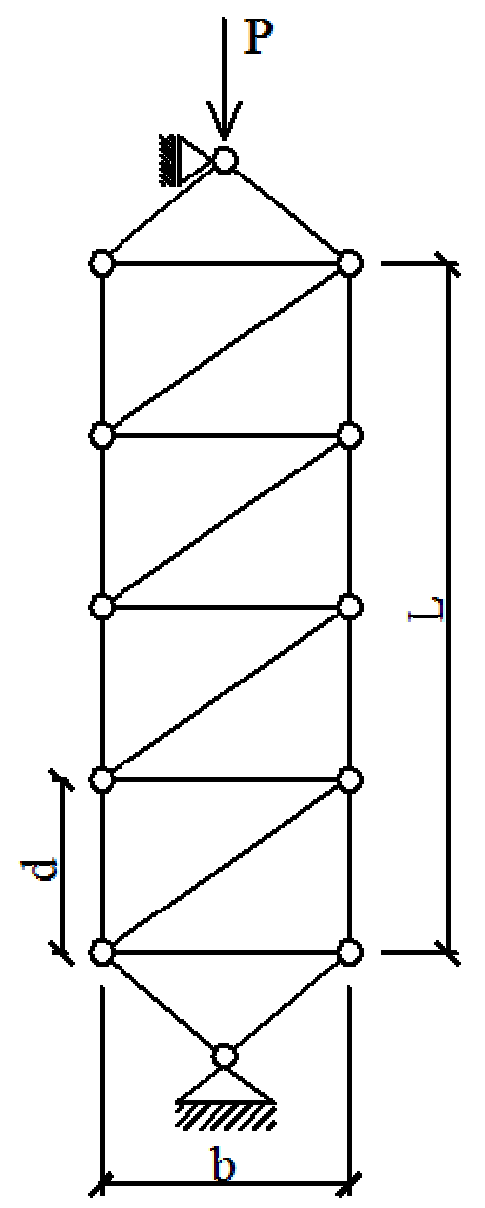

Figura 21 - Colunas de aço em perfil U contraventadas.

Tabela 11 - Resumo dos dados das VAs do problema da coluna de aço.

\begin{tabular}{|c|c|c|c|}
\hline Variável aleatória & Distribuição & Média & C.v. \\
\hline Carregamento $(P)$ & normal & $300 \mathrm{kN}$ & $15 \%$ \\
\hline Módulo de Elasticidade $(E)$ & normal & $210 \mathrm{GPa}$ & $3 \%$ \\
\hline Resistência do material $\left(f_{\mathrm{y}}\right)$ & lognormal & $250 \mathrm{MPa}$ & $10 \%$ \\
\hline
\end{tabular}

As restrições de projeto para este problema estão relacionadas à flambagem local e global. Para a flambagem local dos elementos em perfil $U$, tem-se a Equação (95), na qual $I_{U}$ é o momento de inércia da seção $U$.

$$
g_{L}\left(\lambda_{1}, N\right)=\frac{\pi^{2} \cdot E \cdot I_{U}}{d^{2}}-\lambda_{1} \cdot \frac{P}{2}
$$

A flambagem global do sistema estrutural é dada pela Equação (96), onde $I_{G}$ é o momento de inércia da seção transversal do sistema, calculado através da Equação (97). 


$$
\begin{gathered}
g_{G}\left(\lambda_{2}, N, b\right)=\frac{\pi^{2} \cdot E \cdot I_{G}(b)}{L^{2}}-\lambda_{2} \cdot P \\
I_{G}=2 \cdot\left(I_{U}+A_{U} \cdot(b / 2)^{2}\right)
\end{gathered}
$$

$A_{U}$ é a área da seção $U$, enquanto que $\lambda_{1}$ e $\lambda_{2}$ são os coeficientes de segurança.

As equações de estado limite são as mesmas, mas com coeficientes de segurança unitários.

Uma unidade de contraventamento é considerada como sendo um elemento horizontal mais um elemento diagonal, ambos com perfil $L 30 \times 2,25$. O comprimento total de unidade é dado então pela Equação (98).

$$
L_{b b}(N, b)=\sqrt{b^{2}+(L / N)^{2}}+b
$$

O custo básico de materiais é calculado por:

$$
C_{\text {mat }}(N, b)=\$_{\text {mat }} \cdot \rho \cdot\left(N \cdot L_{b b}(N, b) \cdot A_{L}+2 \cdot L \cdot A_{U}\right)
$$

O custo de referência é determinado conforme nos outros problemas e tem por valor $C_{r e f}=150 \cdot \$_{\text {mat }}$, de forma que o custo de mão-de-obra, que inclui este termo fixo, mais um termo proporcional ao custo de materiais e um termo para cada contraventamento adicional, é calculado pela Equação (100).

$$
C_{\text {work }}(N, b)=C_{r e f}+0.2 \cdot C_{m a t}(N, b)+(N-1) \cdot 0.025 \cdot C_{r e f}
$$

O custo total de manufatura é dado então por:

$$
C M(N, b)=1.2 \cdot C_{m a t}(N, b)+C_{r e f} \cdot[1+0.025 \cdot(N-1)]
$$

Adotando custo de falha igual a $10 \cdot C_{\text {ref }}$ para qualquer um dos possíveis modos de falha, obtém-se o custo total esperado a partir da Equação (102), na qual a probabilidade de falha do sistema (em série) é calculada por meio da Equação (103). 


$$
\begin{gathered}
\operatorname{CET}(N, b, \mathbf{X})=C M(N, b)+\left.10 \cdot C_{r e f} \cdot P_{f}\right|_{\text {sistema }} \\
\left.P_{f}\right|_{\text {sistema }}=P\left[\bigcap_{i}\left\{g_{i} \leq 0\right\}\right]
\end{gathered}
$$

O problema foi resolvido primeiramente para $L=7,5 m$, e os respectivos resultados são apresentados na Figura 22. A configuração estrutural ótima da análise RBRO de referência constitui-se de 4 contraventamentos e $b=16,77 \mathrm{~cm}$, e foi encontrada também pelas formulações RBDO e $\mathrm{DDO}_{2}$. Para um único coeficiente de segurança $\left(\mathrm{DDO}_{1}\right)$ o número ótimo de contraventamentos passa a ser 5, o que leva a custos bem maiores que os de referência. Fixando-se a quantidade de contraventamentos a RBRO_esc também não consegue atingir o ótimo de referência.

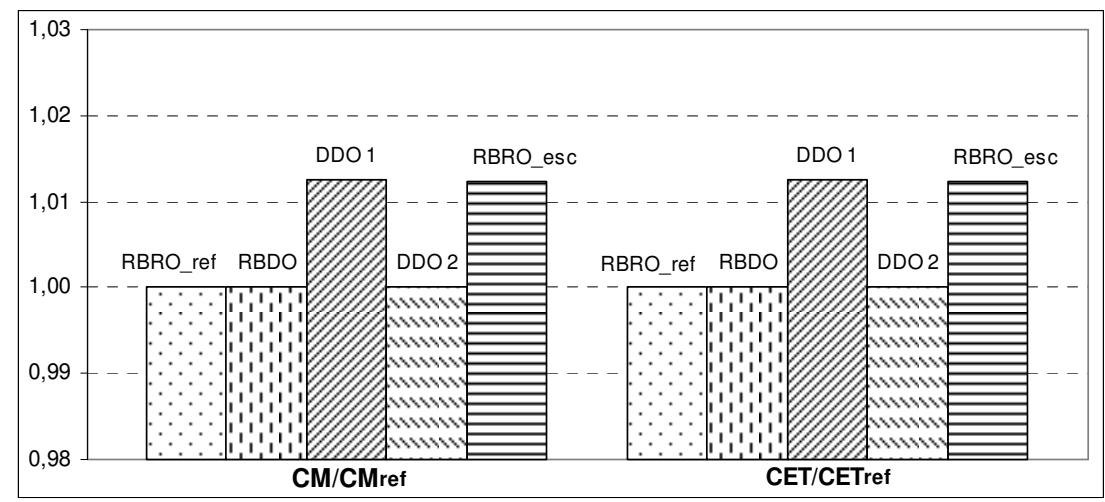

Figura 22 - Comparação entre custos ótimos para o problema da coluna formada por perfis U contraventados.

O problema foi resolvido outras vezes, variando-se a altura $L$ entre $7,5 \mathrm{~m}$ e $40 \mathrm{~m}$. Os resultados são apresentados na Tabela 12 . 
Tabela 12 - Quantidade de contraventamentos versus altura da estrutura.

\begin{tabular}{|c|c|c|c|c|c|}
\hline $\mathbf{L}$ & \multicolumn{2}{|c|}{ Número de contraventamentos } & \multirow{2}{L}{} & \multicolumn{2}{c|}{ Número de contraventamentos } \\
\cline { 2 - 3 } \cline { 5 - 6 }$(\mathbf{m})$ & RBRO & RBDO e RBRO_esc & $(\mathbf{m})$ & RBRO & RBDO e RBRO_esc \\
\hline 7,5 & 4 & 5 & 25 & 12 & 14 \\
\hline 9 & $\mathbf{5}$ & $\mathbf{5}$ & 27 & 13 & 15 \\
\hline 10 & 5 & 6 & 28 & 14 & 16 \\
\hline 11 & $\mathbf{6}$ & $\mathbf{6}$ & 29 & 14 & 16 \\
\hline 12 & 6 & 7 & 30 & 14 & 17 \\
\hline 13 & 7 & 8 & 31 & 15 & 17 \\
\hline 15 & 7 & 9 & 32 & 15 & 18 \\
\hline 17 & 8 & 10 & 33 & 16 & 18 \\
\hline 19 & 9 & 11 & 35 & 17 & 19 \\
\hline 20 & 10 & 11 & 37 & 18 & 20 \\
\hline 21 & 10 & 12 & 39 & 19 & 22 \\
\hline 22 & 11 & 12 & 40 & 19 & 22 \\
\hline 23 & 11 & 13 & \multicolumn{3}{|l}{} \\
\hline
\end{tabular}

Para cada solução, custos relativos são obtidos dividindo-se os custos encontrado pelas formulações RBDO e RBRO_esc pelo custo de referência (RBRO). Os custos esperados totais relativos são apresentados na Figura 23, enquanto que os custos de manufatura relativos são mostrados na Figura 24.

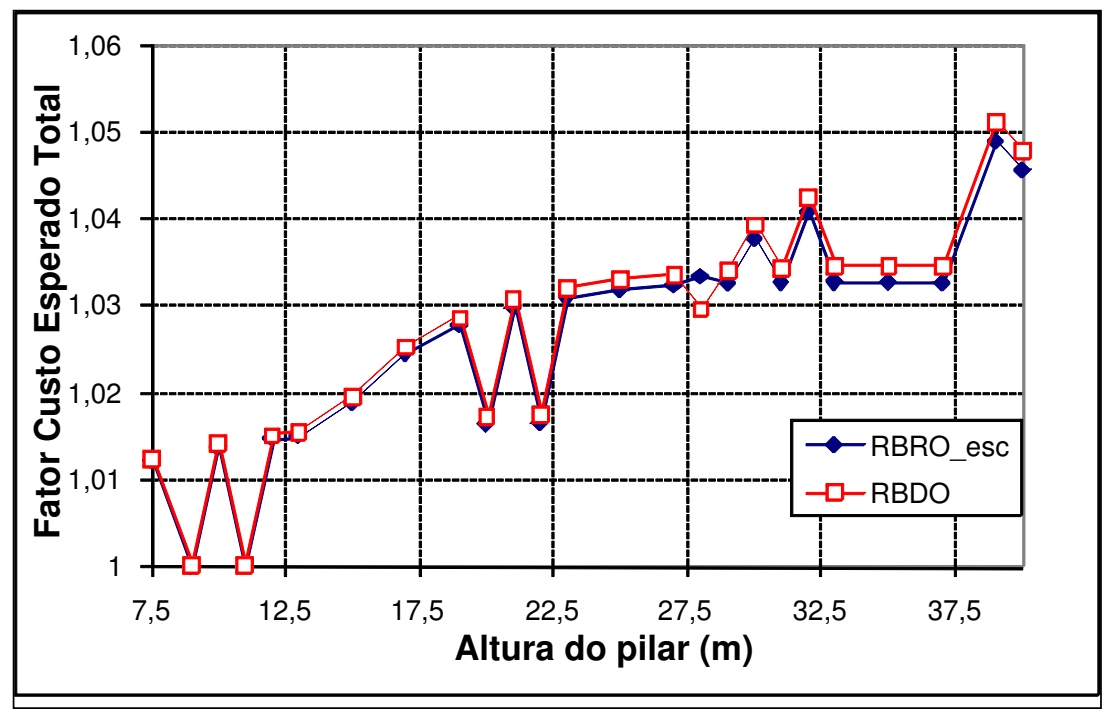

Figura 23 - Custos esperados totais obtidos pelas formulações RBDO e RBRO_esc, com relação ao custo de referência (RBRO). 


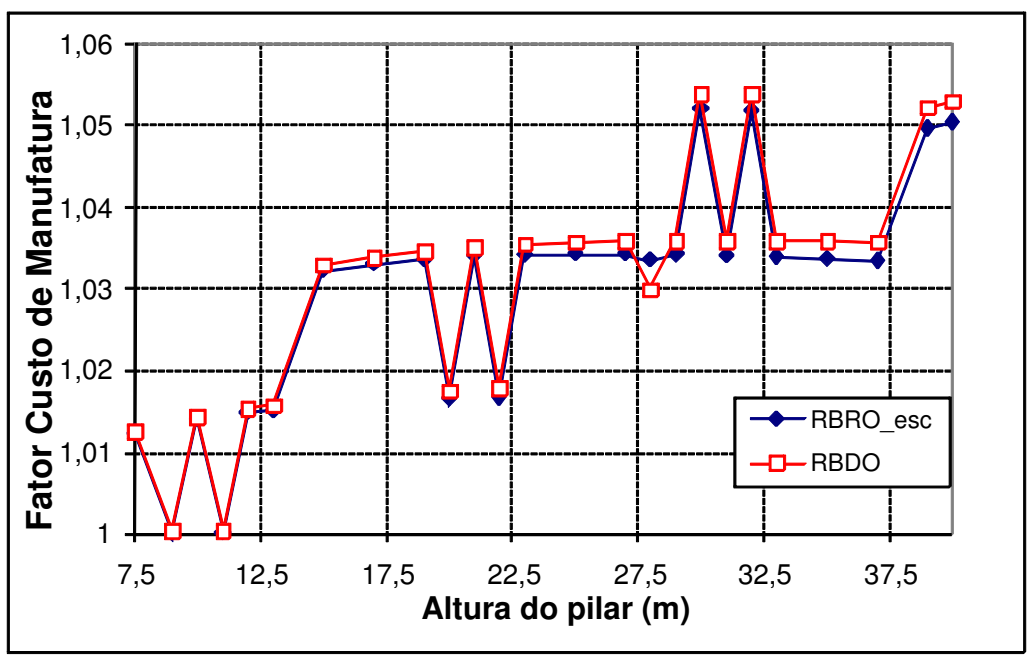

Figura 24 - Custos de manufatura obtidos pelas formulações RBDO e RBRO_esc, com relação ao custo de referência (RBRO).

Verificou-se que, para alguns intervalos de valores menores que 12,5 metros, as formulações investigadas conseguem atingir o ponto ótimo de referência, enquanto que nos outros casos, apesar das oscilações, os custos encontrados são sempre superiores aos custos mínimos. Essas oscilações ocorrem à medida que há mudanças da quantidade de contraventamentos, e as formulações investigadas só conseguem reproduzir o ponto ótimo de referência quando a DDO (caso inverso) encontra a quantidade de contraventamentos de referência, ou seja, a forma ótima. À medida que a altura aumenta, aumentam as diferenças entre essas quantidades, como pode ser visto na Tabela 12, e as formulações RBRO_esc e RBDO se afastam mais dos custos de referência. 


\section{DESEMPENHO DOS MÉTODOS DE OTIMIZAÇÃO}

Os oito métodos de otimização implementados (dois métodos heurísticos, dois métodos com fundamentação matemática e quatro métodos híbridos) foram aplicados aos quatro problemas apresentados no capítulo 5, utilizando-se apenas a formulação RBRO. O ponto inicial dos métodos de Polak-Ribiere e Powell foi gerado aleatoriamente de forma que todos os métodos passaram a depender da semente de um gerador de números aleatórios.

Cada um dos problemas foi resolvido um total de dez vezes, variando-se a semente para geração do número aleatório em cada uma das resoluções. Os resultados obtidos pela formulação híbrida PSS_POWELL foram adotados como referência, e foram determinados os seguintes valores (relativos aos resultados de referência) para cada um dos métodos de otimização: a média (relativa) da função objetivo, a média (relativa) do número de chamadas à função objetivo e o máximo valor (relativo) da função objetivo.

Os resultados mostrados nas figuras a seguir demonstram o desempenho (por meio da quantidade de chamadas à função objetivo) e da confiabilidade dos métodos (por meio dos valores médio e máximo da função objetivo), conforme discutido a seguir.

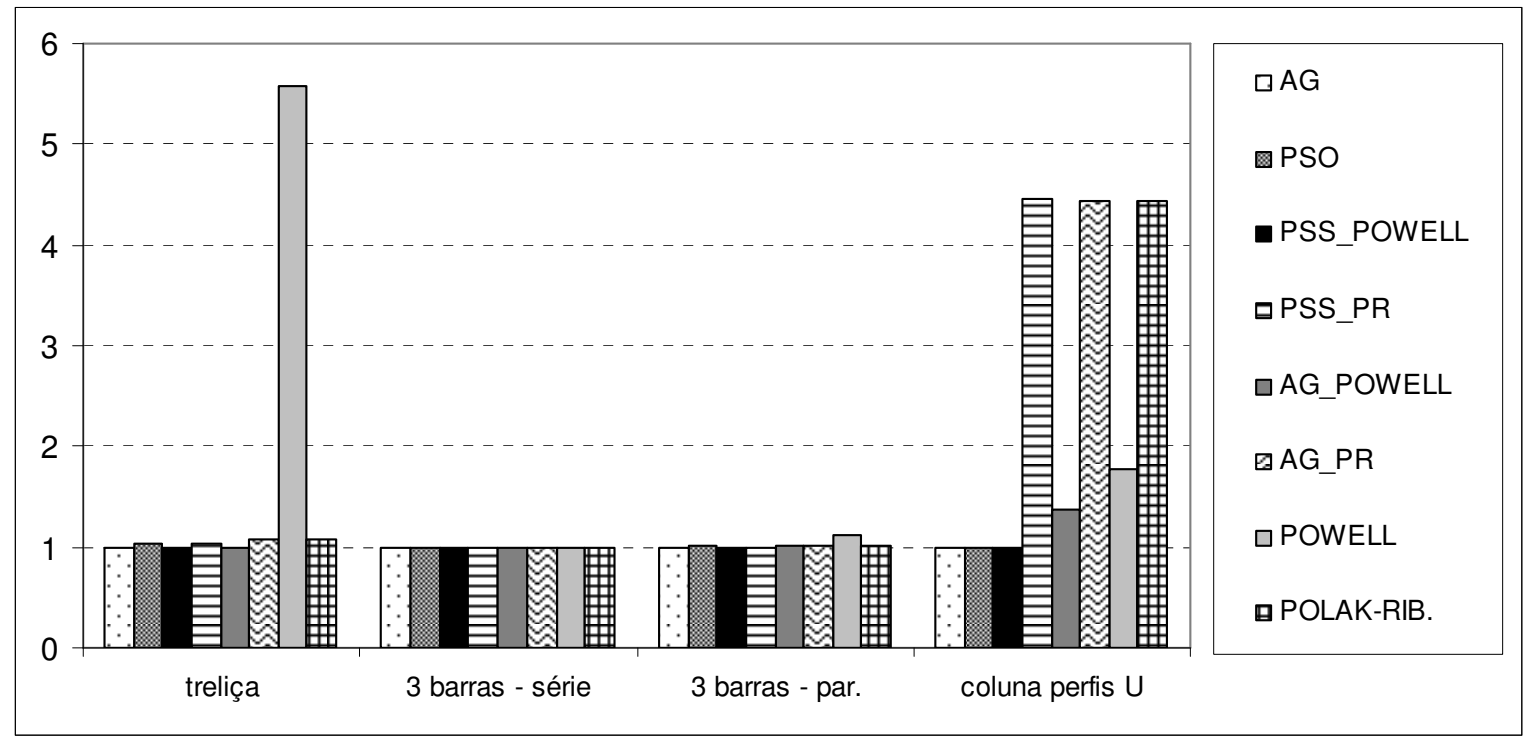

Figura 25 - Média da função objetivo (em relação ao PSS_POWELL). 


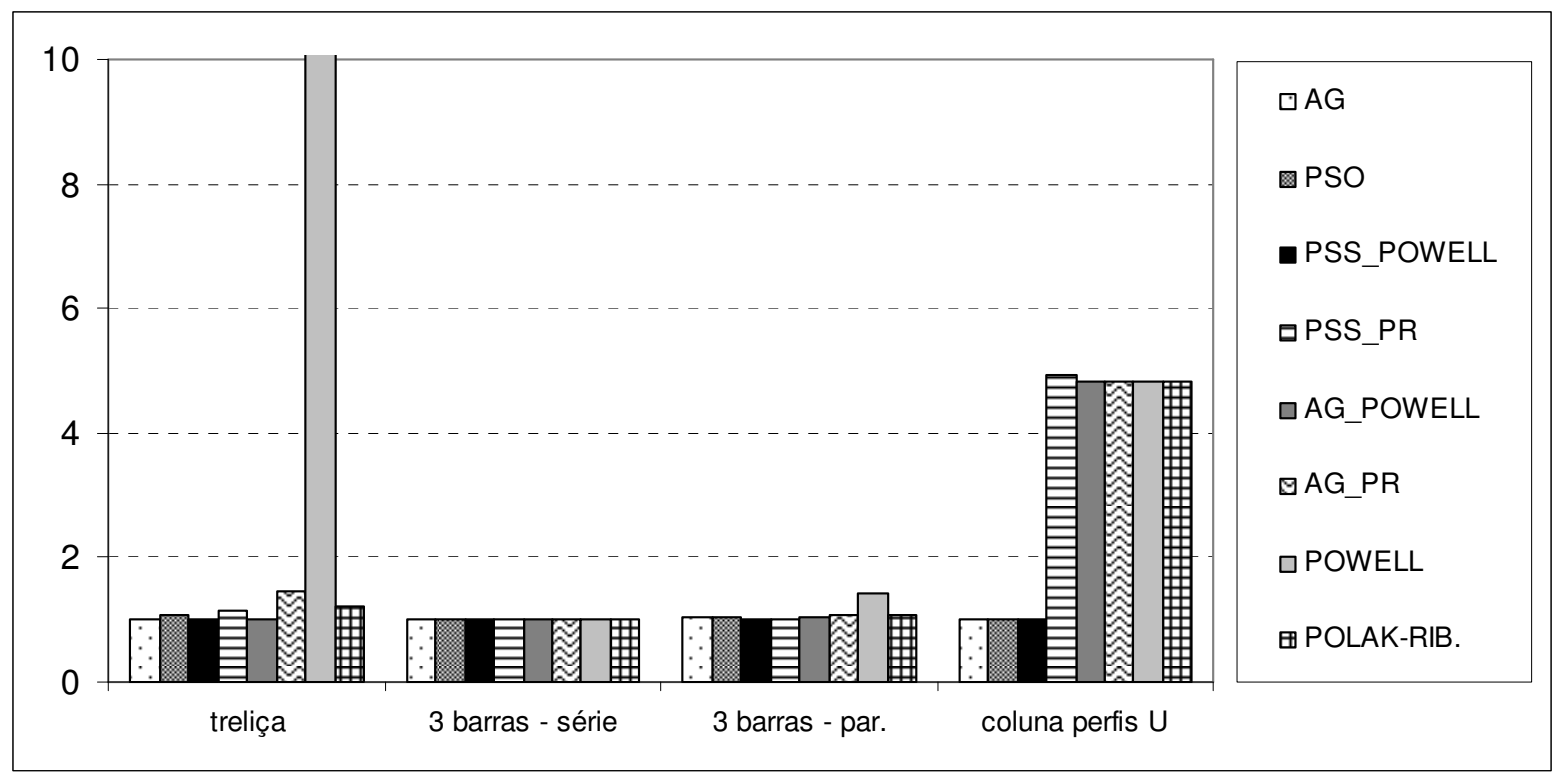

Figura 26 - Máximo da função objetivo (em relação ao PSS_POWELL).

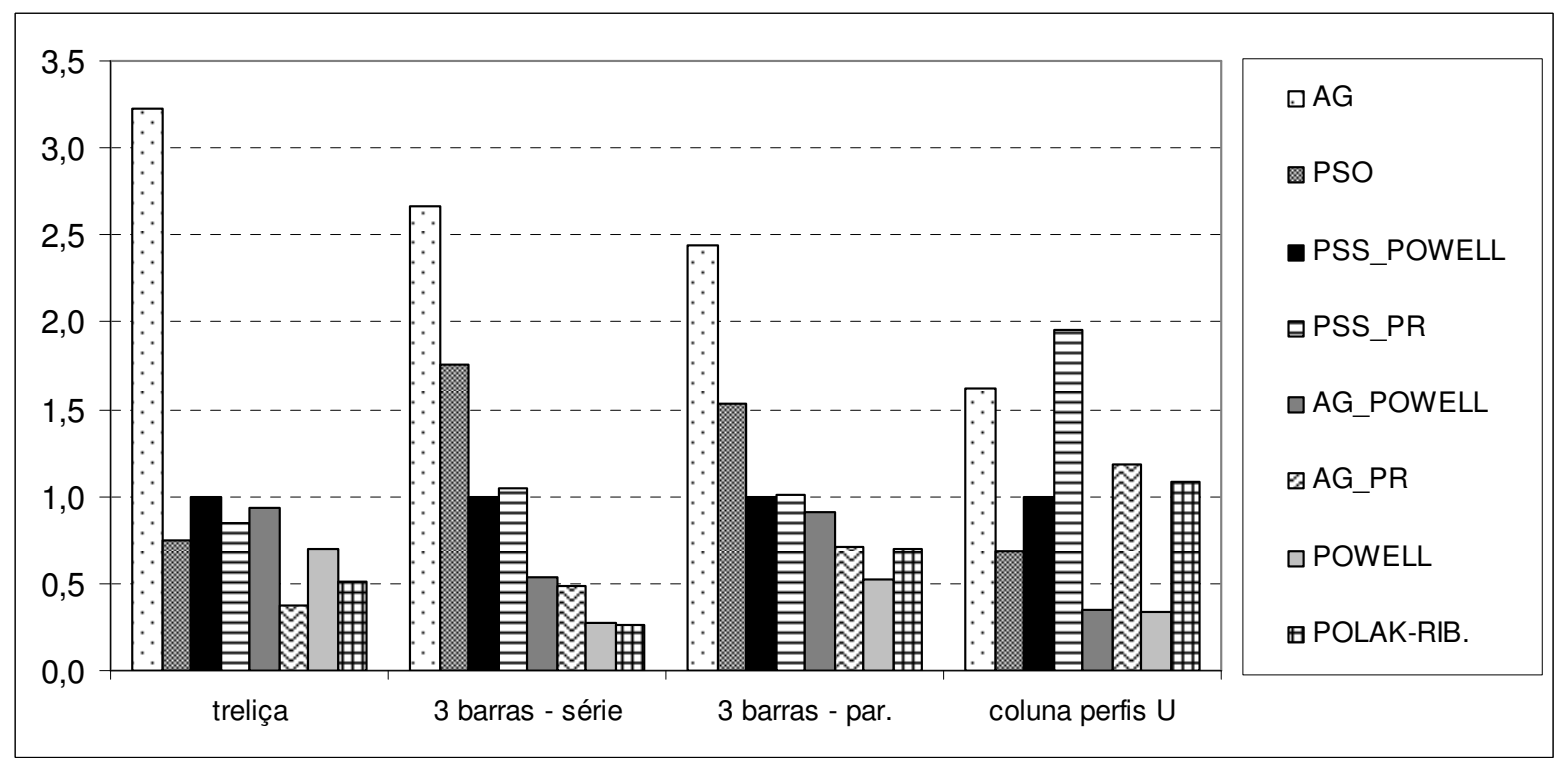

Figura 27 - Média de chamadas à função objetivo (em relação ao PSS_POWELL)

Os métodos heurísticos (AG e PSO) de uma forma geral conseguiram encontrar o valor mínimo da função objetivo, mas o AG apresentou alto custo computacional (muitas chamadas à função objetivo). Isso mostra que, como esperado, eles conseguem lidar com problemas diversos, até mesmo aqueles que apresentam variáveis de otimização descontínuas (caso do problema da coluna com perfis $U$ ). No entanto, desaconselhados para problemas com funções objetivo complexas e/ou para problemas com grande número de variáveis aleatórias, para os quais o custo computacional se torna proibitivo. 
Os métodos com fundamentação matemática (POWELL e POLAK-RIBIERE), se mostraram bastante dependentes do ponto inicial, ficando muitas vezes presos a mínimos locais. Este problema acentua-se para problemas mais complexos, o que se constata no exemplo da treliça plana (que apresenta diversos mínimos locais). Outro problema constatado decorre da existência de variáveis de otimização descontínuas, caso no qual os algoritmos apresentam dificuldade de convergência para o mínimo global, conforme pode ser visto nos resultados para a coluna com perfis $U$. Apesar destes problemas, os métodos de Powell e Polak-Ribiere apresentaram números de chamadas à função objetivo bem menores que os métodos heurísticos, e menores que o valor de referência para quase todos os casos. Concluise que estes métodos convergem mais rápido que os outros, mas nem sempre para o mínimo global.

Dentre os métodos híbridos, aqueles com geração do ponto inicial pelo método AG apresentaram os melhores resultados em alguns dos problemas, mas não conseguiram encontrar o ótimo global para outros casos. Por outro lado, entre os algoritmos com geração do ponto inicial pelo PSS, o híbrido PSS_POLAK-RIBIERE ficou muitas vezes preso a pontos de mínimo locais (devido às informações do gradiente da função objetivo, utilizadas no método de Polak-Ribiere). O algoritmo PSS_POWELL apresentou os melhores resultados, levando-se em conta desempenho e confiabilidade.

O método PSS, uma variação do algoritmo PSO feita com foco na geração de pontos iniciais, consegue determinar razoavelmente bem e de maneira rápida as regiões nas quais se encontra o ótimo global. Nos casos em que o PSS falha em sua busca por essa região, existe grande probabilidade do método de Powell ainda assim conseguir encontrar o ótimo procurado. Isto decorre do fato de que este método não utiliza informações de gradiente da função objetivo e que, portanto, é capaz de passar por regiões de "influência" de mínimos locais sem ficar preso a estes, pelos menos em alguns casos. Isto explica o porquê dos melhores resultados terem sido obtidos pelo método PSS_POWELL. 


\section{CONCLUSÕES}

Neste trabalho foi apresentado um estudo dos efeitos de incertezas na otimização estrutural, através da comparação de soluções ótimas obtidas por diferentes formulações do problema de otimização. Além disso, foi feita uma análise de desempenho e confiabilidade dos algoritmos de otimização implementados.

Foram apresentados resultados para quatro exemplos numéricos: sistemas estruturais compostos por três barras, em paralelo e em série, treliça plana, e coluna de aço em perfis $U$ contraventados.

\subsection{ESTUDO DOS EFEITOS DAS INCERTEZAS}

Com relação ao estudo dos efeitos das incertezas, todos os resultados levaram às mesmas seguintes conclusões.

A otimização determinística (DDO) permite que seja encontrada uma estrutura que é ótima do ponto de vista mecânico. Entretanto, uma vez que a formulação não leva em conta explicitamente a incerteza de parâmetros e seus efeitos sobre a segurança do sistema, a segurança da estrutura ótima é comprometida, quando comparada à estrutura original. $\mathrm{O}$ comportamento pós-falha do material e seus efeitos na confiabilidade do sistema não são levados em conta. Se um único coeficiente de segurança "ótimo" é aplicado como uma restrição na análise DDO, a formulação leva a uma configuração ótima que respeita tal restrição de projeto, reduz custos de manufatura, mas aumenta o custo esperado total (incluindo custos esperados de falha). Se uma otimização de risco é realizada no sentido de encontrar o coeficiente de segurança ótimo após a DDO, mas respeitando as proporções da estrutura ótima encontrada pela DDO, o custo esperado total pode ser reduzido, mas não tanto quanto numa formulação mais geral, na qual a configuração estrutural e o risco são otimizados simultaneamente. Se for utilizado um coeficiente de segurança ótimo para cada equação de estado limite (e se o número de variáveis de otimização do problema assim permitir), então o ótimo encontrado na RBRO pode ser reproduzido através da DDO.

A otimização baseada em confiabilidade (RBDO) apresenta algumas melhoras em relação à formulação DDO, através da consideração de incerteza de parâmetros e de uma de 
suas principais conseqüências: a probabilidade de falha. A probabilidade de falha do sistema é usada como uma restrição de projeto, garantindo que a estrutura ótima não sacrificará a segurança. Os resultados, como esperado, dependem do valor da probabilidade de falha do sistema utilizada como restrição. No entanto, a formulação RBDO em geral não leva em conta as conseqüências monetárias de falha, ou custos esperados de falha. Em conseqüência disso, mesmo quando a probabilidade de falha ótima do sistema é usada como restrição, a análise RBDO pode levar a um ponto de ótimo diferente, que reduz os custos de manufatura mas aumenta o custo esperado total. Isto pode acontecer quando os custos associados aos diferentes modos de falha são distintos (exemplo, custo de falha de serviço).

Em consideração à incerteza e seus possíveis efeitos (consequiências monetárias de falha), a estrutura ótima somente pode ser encontrada pela otimização de risco baseada em confiabilidade (RBRO), que procura pela configuração estrutural ótima e pelas margens de segurança ótimas, simultaneamente. A estrutura encontrada pela RBRO é ótima tanto do ponto de vista mecânico quanto em termos do compromisso entre economia e segurança.

\subsection{ANÁLISE DE DESEMPENHO E CONFIABILIDADE DOS MÉTODOS DE OTIMIZAÇÃO}

A análise de desempenho e confiabilidade foi feita com o intuito de determinar qual dentre os métodos de otimização implementados é o mais eficiente e o que apresenta resultados mais confiáveis para os problemas de particular interesse deste trabalho. Ressaltase que nesta comparação apenas a formulação RBRO foi considerada.

O método híbrido PSS_POWELL, que consiste na geração do ponto inicial de busca através do método PSS e posterior busca pelo ponto ótimo utilizando o método de Powell modificado, foi o que apresentou melhores resultados para os quatro exemplos numéricos. Verificou-se que os bons resultados deste híbrido são devidos a uma boa interação entre os dois métodos que o constituem, de forma que o método PSS consegue determinar um ponto inicial bom o suficiente para que o método de Powell consiga chegar ao ponto de mínimo global na grande maioria dos casos. 


\subsection{SUGESTÕES PARA TRABALHOS FUTUROS}

a) Extensão para problemas dependentes do tempo, envolvendo políticas de inspeção e manutenção;

b) Nos algoritmos de otimização, após algumas iterações substituir a função objetivo por uma Rede Neural Artificial (RNA) devidamente treinada, para os casos em que o cálculo da função objetivo apresenta alto custo computacional. Minimizar a RNA durante algumas iterações e retornar à função objetivo original para efetuar as últimas iterações de otimização. 


\section{REFERÊNCIAS}

AMSTUTZ, S.; ANDRÄ, H. A new Algorithm for topology optimization using a level-set method. Elsevier Science, 2005.

ANG, A. H-S.; TANG, W. H. Probability concepts in engineering: emphasis on applications to civil and environmental engineering. 2nd. Edition. John Wiley \& Sons, 2007.

BECK, A. T. StRAnD: Manual do Usuário. São Carlos: EESC-USP, 2007.

BECK, A. T. Curso de confiabilidade estrutural: notas de aula. São Carlos: EESC-USP, 2009.

BECK, A. T.; VERZENHASSI, C. C. Reliability based risk optimization. In: International Conference on Engineering Optimization, Proceedings, Rio de Janeiro, 2008a.

BECK, A. T.; VERZENHASSI, C. C. Risk optimization of a steel frame communications tower subject to tornado winds. Latin American Journal of Solids and Structures, v. 5, p.187-203, 2008b.

BRATTON, D.; KENNEDY, J. Defining a standard for particle swarm optimization. In: Proceedings of the Swarm Intelligence Symposium, IEEE, 2007.

CARRILLO, O. J. B. Algoritmo híbrido para avaliação da integridade estrutural: uma abordagem heurística. 162 f. Tese (Doutorado) - Escola de Engenharia de São Carlos - USP, São Carlos, SP, 2007.

CARVALHO, A. C. P. L. F.; LACERDA, E. G. M. Introdução aos algoritmos genéticos. GALVÃO, C. O. \& VALENÇA, M. J. S. (Organizadores), Sistemas inteligentes: aplicações a recursos hídricos e ciências ambientais. p. 99-150, ABRH, Editora da Universidade UFRGS, 1999. 
CORDEIRO, A. S. Otimização e melhoramento exergoeconômico de sistemas térmicos modelados em um simulador de processos utilizando métodos de busca direta e estocástico. 161 f. Dissertação (Mestrado) - COPPE - Universidade Federal do Rio de Janeiro, RJ, 2007.

DINIZ, L. S. Calibragem de modelos hidrológicos. GALVÃO, C. O. \& VALENÇA, M. J. S. (Organizadores), Sistemas inteligentes: aplicações a recursos hídricos e ciências ambientais. p. 151-164, ABRH, Editora da Universidade - UFRGS, 1999.

DUAN, Q.; SOROOSHIAN, S.; GUPTA, V. K. Effective and efficient global optimization for conceptual rainfall-runoff models. Water Resources Research, v.28, n.4, p.1015-1031, 1992.

ELLINGWOOD, B.; GALAMBOS, T. V. Probability-based criteria for structural design. Structural Safety, v. 1, p. 15-26, 1982.

ENEVOLDSEN, I.; SORENSEN, J. D. Reliability-based optimization in structural engineering. Structural Safety 15, p. 169-196, 1994.

FARAVELLI, L. Response-surface approach for reliability analysis. Journal of the Engineering Mechanics Division, ASCE, 115(12), p. 2763-2781, 1989.

FOX, R. Optimization methods for engineering design. Addison-Wesley Publishing Co., Inc., 1973.

FRANGOPOL, D. M. Structural optimization using reliability concepts. Journal of Structural Engineering, ASCE, v.111,n.11, p.2288-2301, Nov., 1985.

GRIPPO, L.; LUCIDI, S. N. A globally convergent version of the Polak-Ribiere conjugate gradient method. Itália: Università degli Studi di Roma "La Sapienza”, 1995.

HENDAWI, S.; FRANGOPOL, D. M. System reliability and redundancy in structural design evaluation. Structural Safety 16, p. 47-71, 1994. 
JCSS - Joint Committee on Structural Safety. Probabilistic Model Code. Disponível em: http://www.jcss.ethz.ch/ , (acesso em 29 de setembro de 2009), 2001.

LUENBERGER, D. Linear and Nonlinear Programming. $2^{\text {nd }}$ Ed., Reading: AddisonWesley, 1984.

MARTÍNEZ, J. M. Otimização prática usando o Lagrangiano Aumentado. Unicamp, 2009.

MELCHERS, R. E. Structural reliability analysis and prediction. 2nd. Ed., John Wiley \& Sons, NY, 1999.

NELDER, J. A.; MEAD, R. A simplex method for functional minimization. Computer Journal, v.4, n.7, p. 308-313, 1965.

PARSOPOULOS, K. E.; VRAHATIS, M. N. Initializing the particle swarm optimizer using the nonlinear simplex method. GRMELA, A. \& MASTORAKIS, N.E. (eds.), Advances in Intelligent Systems, Fuzzy Systems, Evolutionary Computation, p. 216-221, WSEAS Press, 2002.

POLI, R.; KENNEDY, J.; BLACKWELL, T. Particle swam optimization: an overview. Swarm Intell 1, p. 33-57, 2007.

RIGO, E. Métodos de otimização aplicados à análise de estruturas. $123 \mathrm{f}$. Dissertação (Mestrado) - Escola de Engenharia de São Carlos - USP, São Carlos, SP, 1999.

SANTOS, C. A. G.; SUZUKI, K.; WATANABE, M. Modificação no algoritmo genético SCE-UA e sua aplicação a um modelo hidrossedimentológico. Revista Brasileira de Recursos Hídricos, v.8, n.1, p. 137-146, 2003.

SORENSEN, J. D. Notes in structural reliability theory and risk analysis. Aalborg University, 2004. 
VANDERPLAATS, G. N. Numerical optimization techniques for engineering design: with applications. New York: McGraw-Hill, 1984.

ZHANG, Y. \& KIUREGHIAN, A. D. Finite Element Reliability Methods for Inelastic Structures. Report UCB/SEMM-97/05, Department of Civil and Environmental Engineering, University of California, Berkeley, 1997. 